\title{
Dayside nitrogen and carbon escape on Titan: the role of exothermic chemistry
}

\author{
H. Gu${ }^{1}$, J. Cui ${ }^{2,3,4}$, P. P. Lavvas ${ }^{5}$, D.-D. Niu ${ }^{1}$, X.-S. Wu ${ }^{3,4}$, J.-H. Guo ${ }^{6}, \mathrm{~F}^{-\mathrm{He}^{7}}$, and Y. Wei ${ }^{7}$ \\ ${ }^{1}$ Space Science Institute, Macau University of Science and Technology, Macau, PR China \\ e-mail: cuijun7@mail.sysu.edu.cn \\ ${ }^{2}$ School of Atmospheric Sciences, Sun Yat-Sen University, Zhuhai, Guangdong, PR China \\ ${ }^{3}$ National Astronomical Observatories, Chinese Academy of Sciences, Beijing, PR China \\ ${ }^{4}$ Chinese Academy of Sciences Center for Excellence in Comparative Planetology, Hefei, Anhui, PR China \\ ${ }^{5}$ Université de Reims Champagne Ardenne, CNRS, GSMA UMR 7331, 51097 Reims, France \\ ${ }^{6}$ Yunnan Astronomical Observatory, Chinese Academy of Sciences, Kunming, Yunnan, PR China \\ ${ }^{7}$ Institute of Geology and Geophysics, Chinese Academy of Sciences, Beijing, PR China
}

Received 2 October 2019 / Accepted 16 November 2019

\begin{abstract}
Context. Atmospheric escape has an appreciable impact on the long-term climate evolution on terrestrial planets. Exothermic chemistry serves as an important mechanism driving atmospheric escape and the role of such a mechanism is of great interest for Titan due to its extremely complicated atmospheric and ionospheric composition.

Aims. This study is devoted to a detailed investigation of neutral $\mathrm{N}$ and $\mathrm{C}$ escape on the dayside of Titan, which is driven by exothermic neutral-neutral, ion-neutral, and dissociative recombination (DR) reactions. It was carried out based on the extensive measurements of Titan's upper atmospheric structure by a number of instruments on board Cassini, along with an improved understanding of the chemical network involved.

Methods. A total number of $14 \mathrm{C}$ - and N-containing species are investigated based on 146 exothermic chemical reactions that release hot neutrals with nascent energies above their respective local escape energies. For each species and each chemical channel, the hot neutral production rate profile is calculated, which provides an estimate of the corresponding escape rate when combined with the appropriate escape probability profile obtained from a test particle Monte Carlo model.

Results. Our calculations suggest a total $\mathrm{N}$ escape rate of $9.0 \times 10^{23} \mathrm{~s}^{-1}$ and a total C escape rate of $4.2 \times 10^{23} \mathrm{~s}^{-1}$, driven by exothermic chemistry and appropriate for the dayside of Titan. The former is primarily contributed by neutral-neutral reactions, whereas the latter is dominated by ion-neutral reactions; however, contributions from neutral-neutral and DR reactions to the latter cannot be ignored either. Our calculations further reveal that the bulk of $\mathrm{N}$ escape is driven by hot $\mathrm{N}\left({ }^{4} \mathrm{~S}\right)$ production from the collisional quenching of $\mathrm{N}\left({ }^{2} \mathrm{D}\right)$ by ambient $\mathrm{N}_{2}$, while $\mathrm{C}$ escape is mainly driven by hot $\mathrm{CH}_{3}$ and $\mathrm{CH}_{4}$ production via a number of important ion-neutral and neutral-neutral reactions.

Conclusions. Considered in the context of prior investigations of other known escape mechanisms, we suggest that exothermic chemistry is likely to contribute appreciably to non-thermal $\mathrm{C}$ escape on the dayside of Titan, although it plays an insignificant role in $\mathrm{N}$ escape.
\end{abstract}

Key words. planets and satellites: atmospheres - planets and satellites: individual: Titan

\section{Introduction}

Solar Extreme Ultraviolet (EUV) and X-ray photons deposit a substantial amount of energy in a dayside planetary upper atmosphere, causing the dissociation and ionization of ambient neutrals and initializing a complicated chemical network, including neutral-neutral, ion-neutral, and dissociative recombination (DR) reactions (e.g. Fox et al. 2008). The chemical products from these reactions may gain sufficient energy and escape to the interplanetary space (e.g. Johnson et al. 2008).

Titan, the largest satellite of Saturn, has a thick and permanent atmosphere composed of $\mathrm{N}_{2}, \mathrm{CH}_{4}$, and $\mathrm{H}_{2}$, along with various hydrocarbons, nitriles, and oxides as trace species (e.g. Waite et al. 2005; Niemann et al. 2005). Considerable neutral escape is thought to occur on Titan (e.g. Strobel \& Cui 2014). For neutral escape driven by exothermic chemistry, Cravens et al. (1997) predicted pre-Cassini escape rates of $2.5 \times 10^{25} \mathrm{~s}^{-1}$ for total $\mathrm{N}$ and $4 \times 10^{25} \mathrm{~s}^{-1}$ for total $\mathrm{C}$, whereas De La Haye et al. (2007) estimated the post-Cassini escape rates to be
$8.3 \times 10^{24}$ and $7.2 \times 10^{24} \mathrm{~s}^{-1}$, respectively. In both studies, the ideal exobase approximation (e.g. Levine et al. 1978; Wallis 1978) was adopted to calculate the escape rates.

Other non-thermal or thermal escape mechanisms have also been explored on Titan (e.g. Johnson et al. 2008; Jiang et al. 2017). Shematovich et al. (2003) obtained a total N escape rate of $9.2 \times 10^{24} \mathrm{~s}^{-1}$ due to $\mathrm{N}_{2}$ dissociation by solar EUV and $\mathrm{X}$-ray photons, as well as photoelectrons. Atmospheric sputtering was estimated to cause a total $\mathrm{N}$ escape rate of $10^{24}-10^{25} \mathrm{~s}^{-1}$ (Lammer \& Bauer 1993; Shematovich et al. 2001, 2003; Michael et al. 2005) and a total C escape rate an order of magnitude lower (Gu et al. 2019). While the thermal evaporation of $\mathrm{N}$-containing species is negligible on Titan, the same process is likely to drive strong $\mathrm{C}$ escape at a rate of $\sim 10^{27} \mathrm{~s}^{-1}$ in the form of slow hydrodynamic escape of $\mathrm{CH}_{4}$ (e.g. Yelle et al. 2008; Strobel 2009, 2012a,b; Cui et al. 2012), despite the ongoing debate over such a conclusion (e.g. Tucker \& Johnson 2009; Bell et al. 2010, 2011; Schaufelberger et al. 2012). 
With the accumulation of extensive measurements for Titan's atmospheric neutral and ion densities (e.g. Cui et al. 2009b,a; Magee et al. 2009; Mandt et al. 2012), along with the improved understanding of Titan's atmospheric and ionospheric chemistry (e.g. Wilson \& Atreya 2004; Vuitton et al. 2006a,b, 2007, 2008, 2019; Lavvas et al. 2008a,b; Krasnopolsky 2014), it is now timely to perform a state-of-the-art evaluation of neutral escape on this interesting body as driven by exothermic chemistry. We calculate in Sects. 2 and 3 the production rates of relevant hot neutrals and their escape probabilities. The escape rates are then determined in Sect. 4, where we also discuss the relative contributions of various chemical channels. Finally, we discuss our results and end with concluding remarks in Sect. 5. If not stated explicitly, hot neutral species mentioned throughout the remaining of the paper always refer to those with nascent kinetic energies above the respective local escape energies.

\section{Hot neutral production rates}

Due to the relatively low gravity on Titan compared to other terrestrial planets, a large number of neutral species could gain sufficient kinetic energy from exothermic chemistry and escape. Here we consider $14 \mathrm{~N}$ - and $\mathrm{C}$-containing species including $\mathrm{N}\left({ }^{4} \mathrm{~S}\right), \mathrm{N}\left({ }^{2} \mathrm{D}\right),{ }^{3} \mathrm{CH}_{2}, \mathrm{CH}_{3}, \mathrm{NH}, \mathrm{CH}_{4}, \mathrm{NH}_{3}, \mathrm{C}_{2} \mathrm{H}_{2}, \mathrm{C}_{2} \mathrm{H}_{3}, \mathrm{HCN}$, $\mathrm{C}_{2} \mathrm{H}_{4}, \mathrm{~N}_{2}, \mathrm{C}_{2} \mathrm{H}_{5}$, and $\mathrm{C}_{2} \mathrm{H}_{6}$ in the order of increasing molecular mass up to $30 \mathrm{Da}$. The respective range of escape energy is from $0.32 \mathrm{eV}$ for $\mathrm{N}\left({ }^{4} \mathrm{~S}\right), \mathrm{N}\left({ }^{2} \mathrm{D}\right)$, and ${ }^{3} \mathrm{CH}_{2}$ to $0.68 \mathrm{eV}$ for $\mathrm{C}_{2} \mathrm{H}_{6}$, all refereed to the exobase at an altitude of about $1500 \mathrm{~km}$ (Westlake et al. 2011; Cui et al. 2011). Other species lighter than $30 \mathrm{Da}$ and all species heavier than $30 \mathrm{Da}$ are not considered in the present investigation, either because their production rates are much lower or because they are more strongly bound by Titan's gravity.

In previous studies of neutral $\mathrm{C}$ and $\mathrm{N}$ escape driven by exothermic chemistry, the pre-Cassini investigation of Cravens et al. (1997) included $\mathrm{CH},{ }^{3} \mathrm{CH}_{2}, \mathrm{CH}_{3}, \mathrm{CH}_{4}, \mathrm{C}_{2} \mathrm{H}, \mathrm{C}_{2} \mathrm{H}_{2}, \mathrm{C}_{2} \mathrm{H}_{3}$, $\mathrm{C}_{2} \mathrm{H}_{4}, \mathrm{C}_{3} \mathrm{H}_{2}, \mathrm{C}_{3} \mathrm{H}_{3}, \mathrm{C}_{4} \mathrm{H}_{3}, \mathrm{C}_{4} \mathrm{H}_{4}, \mathrm{C}_{5} \mathrm{H}_{4}, \mathrm{C}_{5} \mathrm{H}_{5}, \mathrm{~N}\left({ }^{4} \mathrm{~S}\right), \mathrm{N}\left({ }^{2} \mathrm{D}\right)$, $\mathrm{NH}, \mathrm{CN}, \mathrm{HCN}$, and $\mathrm{N}_{2}$, whereas the early post-Cassini investigation of De La Haye et al. (2007) included ${ }^{3} \mathrm{CH}_{2}, \mathrm{CH}_{3}, \mathrm{CH}_{4}$, $\mathrm{C}_{2} \mathrm{H}_{4}, \mathrm{C}_{2} \mathrm{H}_{5}, \mathrm{C}_{2} \mathrm{H}_{6}, \mathrm{~N}\left({ }^{4} \mathrm{~S}\right), \mathrm{NH}, \mathrm{N}_{2}$, and HCN. All species considered by De La Haye et al. (2007) have been properly included in the present study as well. When compared to Cravens et al. (1997), nine species including $\mathrm{CH}, \mathrm{C}_{2} \mathrm{H}, \mathrm{CN}$, and six additional species heavier than $30 \mathrm{Da}$ are not considered here because their contributions to total $\mathrm{C}$ or $\mathrm{N}$ escape are negligible. The $\mathrm{H}$ and $\mathrm{H}_{2}$ escape rates due to exothermic chemistry were also evaluated by De La Haye et al. (2007), but these escape rates are far less than the thermal evaporation rates (e.g. Cui et al. 2008; Hedelt et al. 2010; Strobel 2010).

The calculations of the hot neutral production rates are based on the combined list of exothermic chemical reactions presented in the literature (Cravens et al. 1997; De La Haye et al. 2007; Lavvas et al. 2008a,b; Vuitton et al. 2007, 2019). For each reaction, the kinetic energy release is evaluated from the enthalpy difference at room temperature between the reactants and products both assumed to be in their ground states (Baulch et al. 2005). The energy partition between different products is taken to be inversely proportional to the molecular mass. Here we consider a subset of these reactions that produce candidate hot neutrals with kinetic energies exceeding the respective escape energies, as listed in Table A.1 including 80 neutral-neutral reactions (of which 15 are three-body reactions), 31 ion-neutral reactions, and 35 DR reactions. The atmospheric and ionospheric chemical network implemented here is

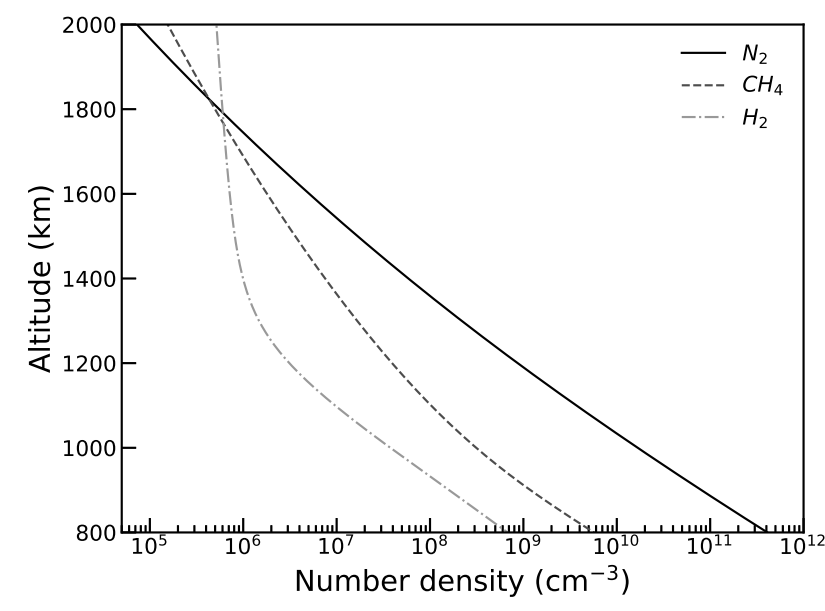

Fig. 1. Background neutral atmosphere of Titan for the three most abundant species, $\mathrm{N}_{2}, \mathrm{CH}_{4}$, and $\mathrm{H}_{2}$, over the altitude range of $800-2000 \mathrm{~km}$ based on dayside averaged Cassini INMS measurements in the CSN mode (Waite et al. 2005).

far more complicated and detailed than those adopted in Cravens et al. (1997) and De La Haye et al. (2007).

For both neutral-neutral and ion-neutral reactions, rate coefficients appropriate for a fixed temperature of $150 \mathrm{~K}$ are adopted (e.g. Snowden et al. 2013). The rate coefficient for a three-body reaction, $k_{3}$, is expressed as

$k_{3}=\frac{k_{\infty}\left(k_{0}[\mathrm{M}] X+k_{\mathrm{R}}\right)}{k_{\infty}+k_{0}[\mathrm{M}] X}$

where $[\mathrm{M}]$ is the density of the background neutral species assumed to be exclusively $\mathrm{N}_{2}, k_{0}$ and $k_{\infty}$ are the termolecular and bimolecular rate constants, $k_{\mathrm{R}}$ is an additional rate constant introduced to include radiative association (Vuitton et al. 2012), the non-dimensional parameter, $X$, is given by $X=F /(1-F)$ with $F$ defined as

$$
\log F=\frac{\log \left(F_{C}\right)}{1+\left[\frac{\log \left[P_{r}\right]+C}{N-0.14\left(\log \left[P_{r}\right]+C\right)}\right]^{2}} .
$$

In the above expression, $P_{r}=k_{0}[\mathrm{M}] / k_{\infty}, N=0.75-1.27 \log F_{C}$, and $C=-0.4-0.67 \log F_{C}$ with $F_{C}$ being a fixed parameter for a specific reaction. For several three-body reactions with no available information on radiative association $\left(\mathrm{R}_{d} 1, \mathrm{R}_{k} 1\right.$, and $\mathrm{R}_{m} 1$ in Table A.1), the conventional Lindemann-Hinshelwood expression is used with $k_{\mathrm{R}}=0$ and $X=1$ in Eq. (1) (e.g. Hörst et al. 2008). A further exception is the three-body reaction $\mathrm{R}_{k} 2$ in Table A.1 for which a constant value of $k_{3}[\mathrm{M}] \approx$ $2 \times 10^{-15} \mathrm{~cm}^{3} \mathrm{~s}^{-1}$ is used following Lavvas et al. (2008a) independent of altitude. Finally, the DR rate coefficient is usually assumed to be inversely proportional to a certain power of the electron temperature (e.g. Viggiano et al. 2005), with the power index in the range of $0.39-1.2$ (see Table A.1).

The background neutral atmosphere of Titan is displayed in Fig. 1 for the three most abundant species, $\mathrm{N}_{2}, \mathrm{CH}_{4}$, and $\mathrm{H}_{2}$, over the altitude range of $800-2000 \mathrm{~km}$ based on the dayside averaged Cassini Ion Neutral Mass Spectrometer (INMS) measurements in the closed source neutral (CSN) mode (Waite et al. 2005). All dayside INMS CSN data accumulated during 30 Cassini flybys with Titan, from TA on 26 October 2004 to T107 on 10 December 2014, are included and the neutral densities are extracted following the procedure described in 

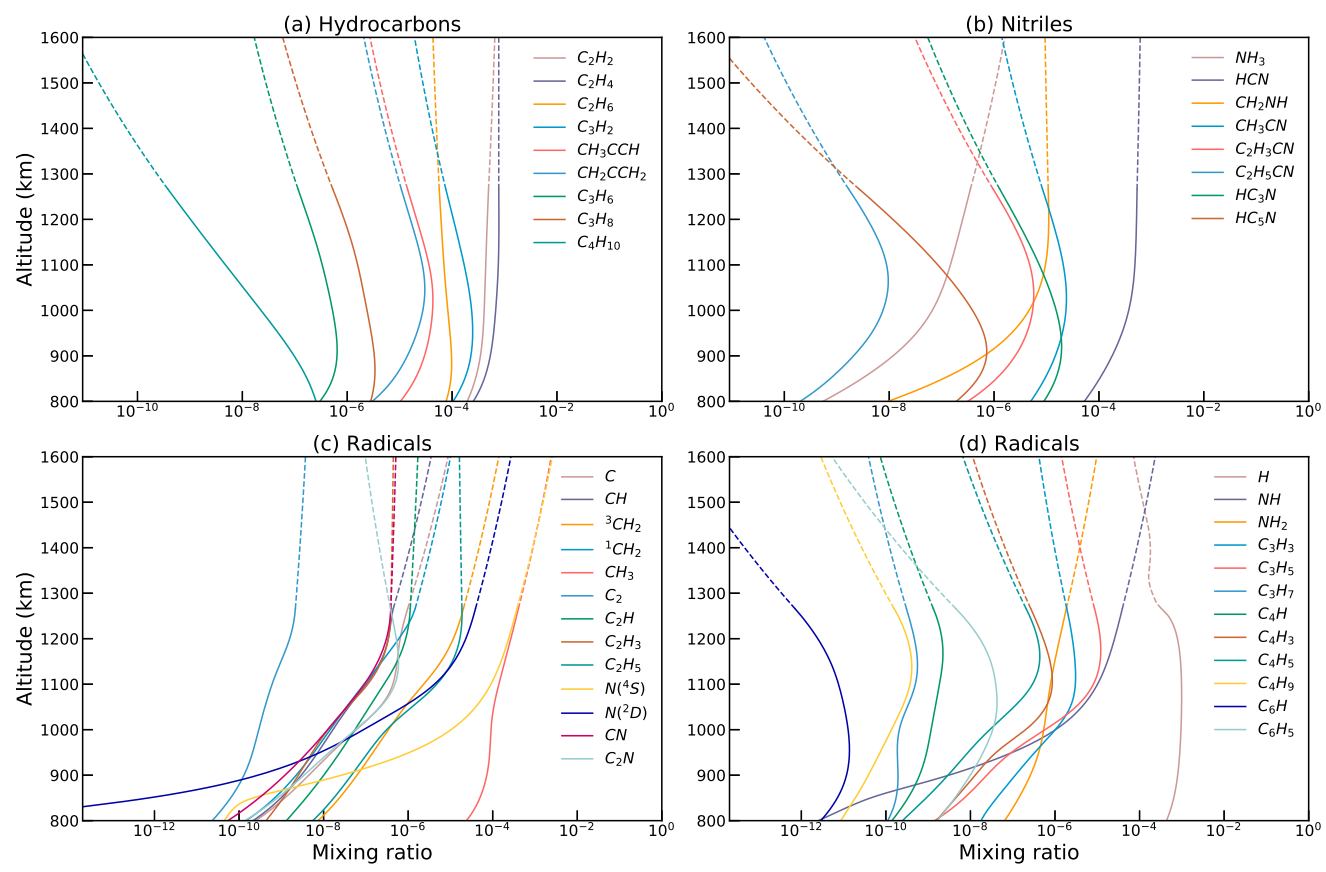

Fig. 2. Mixing ratio profiles of various neutral species in Titan's dayside upper atmosphere including hydrocarbons $(a)$, nitriles $(b)$, and radicals $(c$ and $d$ ), adapted from model results of Lavvas et al. (2008a,b) at 800-1300 km which have been updated with the improved chemical network in Titan's atmosphere and ionosphere. These mixing ratio profiles are extrapolated to higher altitudes assuming diffusive equilibrium (indicated by the dashed lines).

Cui et al. (2008, 2012). The outbound density data are excluded to avoid possible contamination by the INMS wall effects (Cui et al. 2009b). The mixing ratio profiles for various neutral reactants necessary for determining the hot neutral production rates are displayed in Fig. 2, adapted from the model results of Lavvas et al. $(2008 \mathrm{a}, \mathrm{b})$ up to an altitude of $1300 \mathrm{~km}$. These profiles have been updated with the improved chemical network in Titan's atmosphere and ionosphere, and found to be in reasonable agreement with the latest Cassini INMS measurements. The species displayed in Fig. 2 include 9 hydrocarbons $\left(\mathrm{C}_{2} \mathrm{H}_{2}, \mathrm{C}_{2} \mathrm{H}_{4}, \mathrm{C}_{2} \mathrm{H}_{6}\right.$, $\mathrm{C}_{3} \mathrm{H}_{2}, \mathrm{CH}_{3} \mathrm{CCH}, \mathrm{CH}_{2} \mathrm{CCH}_{2}, \mathrm{C}_{3} \mathrm{H}_{6}, \mathrm{C}_{3} \mathrm{H}_{8}, \mathrm{C}_{4} \mathrm{H}_{10}$ ) in panel a, 8 nitriles $\left(\mathrm{NH}_{3}, \mathrm{HCN}, \mathrm{CH}_{2} \mathrm{NH}, \mathrm{CH}_{3} \mathrm{CN}, \mathrm{C}_{2} \mathrm{H}_{3} \mathrm{CN}, \mathrm{C}_{2} \mathrm{H}_{5} \mathrm{CN}\right.$, $\left.\mathrm{HC}_{3} \mathrm{~N}, \mathrm{HC}_{5} \mathrm{~N}\right)$ in panel $\mathrm{b}$, and 25 radicals $\left(\mathrm{H}, \mathrm{C}, \mathrm{CH},{ }^{3} \mathrm{CH}_{2}\right.$, ${ }^{1} \mathrm{CH}_{2}, \mathrm{CH}_{3}, \mathrm{C}_{2}, \mathrm{C}_{2} \mathrm{H}, \mathrm{C}_{2} \mathrm{H}_{3}, \mathrm{C}_{2} \mathrm{H}_{5}, \mathrm{C}_{3} \mathrm{H}_{3}, \mathrm{C}_{3} \mathrm{H}_{5}, \mathrm{C}_{3} \mathrm{H}_{7}, \mathrm{C}_{4} \mathrm{H}$, $\mathrm{C}_{4} \mathrm{H}_{3}, \mathrm{C}_{4} \mathrm{H}_{5}, \mathrm{C}_{4} \mathrm{H}_{9}, \mathrm{C}_{6} \mathrm{H}, \mathrm{C}_{6} \mathrm{H}_{5}, \mathrm{CN}, \mathrm{C}_{2} \mathrm{~N}, \mathrm{~N}\left({ }^{4} \mathrm{~S}\right), \mathrm{N}\left({ }^{2} \mathrm{D}\right), \mathrm{NH}$, $\mathrm{NH}_{2}$ ) in panels $\mathrm{c}$ and $\mathrm{d}$, respectively. The mixing ratio profiles displayed in the figure are extrapolated to higher altitudes assuming diffusive equilibrium. Unlike ions (see below), the densities of most neutral reactants involved here are not directly measured by the INMS instrument (especially radicals) and, accordingly, we choose to use directly the model results.

The density profiles of ion reactants used in this study are shown in Fig. 3, extracted from the Cassini INMS measurements in the open source ion (OSI) mode (Mandt et al. 2012) according to the mass-to-charge ratio, M/Z. All dayside INMS OSI data from TA to T107 are included. The identification of the ion species follows the scheme of Vuitton et al. (2007): $M / Z=14$ for $\mathrm{N}^{+}, 15$ for $\mathrm{CH}_{3}^{+}, 16$ for $\mathrm{CH}_{4}^{+}, 17$ for $\mathrm{CH}_{5}^{+}, 18$ for $\mathrm{NH}_{4}^{+}, 26$ for $\mathrm{CN}^{+}, 27$ for $\mathrm{C}_{2} \mathrm{H}_{3}^{+}$and $\mathrm{HCN}^{+}, 28$ for $\mathrm{C}_{2} \mathrm{H}_{4}^{+}, \mathrm{N}_{2}^{+}$, and $\mathrm{HCNH}^{+}$, 29 for $\mathrm{C}_{2} \mathrm{H}_{5}^{+}$and $\mathrm{N}_{2} \mathrm{H}^{+}, 30$ for $\mathrm{C}_{2} \mathrm{H}_{6}^{+}, 31$ for $\mathrm{C}_{2} \mathrm{H}_{7}^{+}, 32$ for $\mathrm{CH}_{3} \mathrm{NH}_{3}^{+}, 38$ for $\mathrm{CNC}^{+}, 40$ for $\mathrm{C}_{3} \mathrm{H}_{4}^{+}, 41$ for $\mathrm{C}_{3} \mathrm{H}_{5}^{+}, 42$ for $\mathrm{C}_{3} \mathrm{H}_{6}^{+}$, 43 for $\mathrm{C}_{3} \mathrm{H}_{7}^{+}, 44$ for $\mathrm{C}_{3} \mathrm{H}_{8}^{+}, 45$ for $\mathrm{C}_{3} \mathrm{H}_{9}^{+}, 51$ for $\mathrm{C}_{4} \mathrm{H}_{3}^{+}, 57$ for $\mathrm{C}_{4} \mathrm{H}_{9}^{+}$, and 63 for $\mathrm{C}_{5} \mathrm{H}_{3}^{+}$, respectively, all in unit of $\mathrm{Da}$. For those channels sampling more than one ion species, the percentage contributions as a function of altitude are taken from
Vuitton et al. (2019). For each species in Fig. 3, the raw INMS measurements (solid circles) show considerable variability, and a smooth empirical profile (solid line) based on the third-order polynomial fitting to logarithmic density is used instead.

The electron density and temperature profiles, as displayed in Fig. 4, are based on the Cassini Radio and Plasma Wave Science (RPWS) Langmuir Probe (LP) measurements made over the dayside of Titan (Wahlund et al. 2005). We note that the electron density is not necessarily identical to the total ion density due to the presence of positive ions heavier than $100 \mathrm{Da}$ not sampled by the INMS and also due to the presence of negative ions (e.g. Wahlund et al. 2009). In Fig. 4, the empirical electron density profile is obtained in a similar manner as the ion density profiles, whereas the empirical electron temperature profile is obtained by using the functional form of Ergun et al. (2015).

The total hot neutral production rates are calculated via the neutral, ion, and electron density profiles (in Figs. 1-4) and displayed in Figs. 5 and 6 for the 14 candidate escaping species quoted above. The contributions from all the 146 independent chemical channels listed in Table A.1 are shown separately in Figs. A.1 and A.2, where for clarification, the neutral-neutral, ion-neutral, and DR reactions are indicated by the solid, dashed, and dash-dotted lines, respectively. For each species, we identify the dominant production channels, which are addressed in detail below. Whenever possible, we compare our results to those of De La Haye et al. (2007) in terms of the relative importance of different channels in hot neutral production.

$N\left({ }^{4} S\right)$ and $N\left({ }^{2} D\right)$. The chemical production of hot $\mathrm{N}$ in the form of ground state $\mathrm{N}\left({ }^{4} \mathrm{~S}\right)$ mainly occurs via the neutral-neutral reactions

$$
\begin{array}{ll}
\mathrm{N}\left({ }^{2} \mathrm{D}\right)+\mathrm{N}_{2} \rightarrow \mathrm{N}\left({ }^{4} \mathrm{~S}\right)+\mathrm{N}_{2} & \left(\mathrm{R}_{a} 1\right), \\
\mathrm{NH}+\mathrm{CH}_{3} \rightarrow \mathrm{N}\left({ }^{4} \mathrm{~S}\right)+\mathrm{CH}_{4} & \left(\mathrm{R}_{a} 2\right),
\end{array}
$$



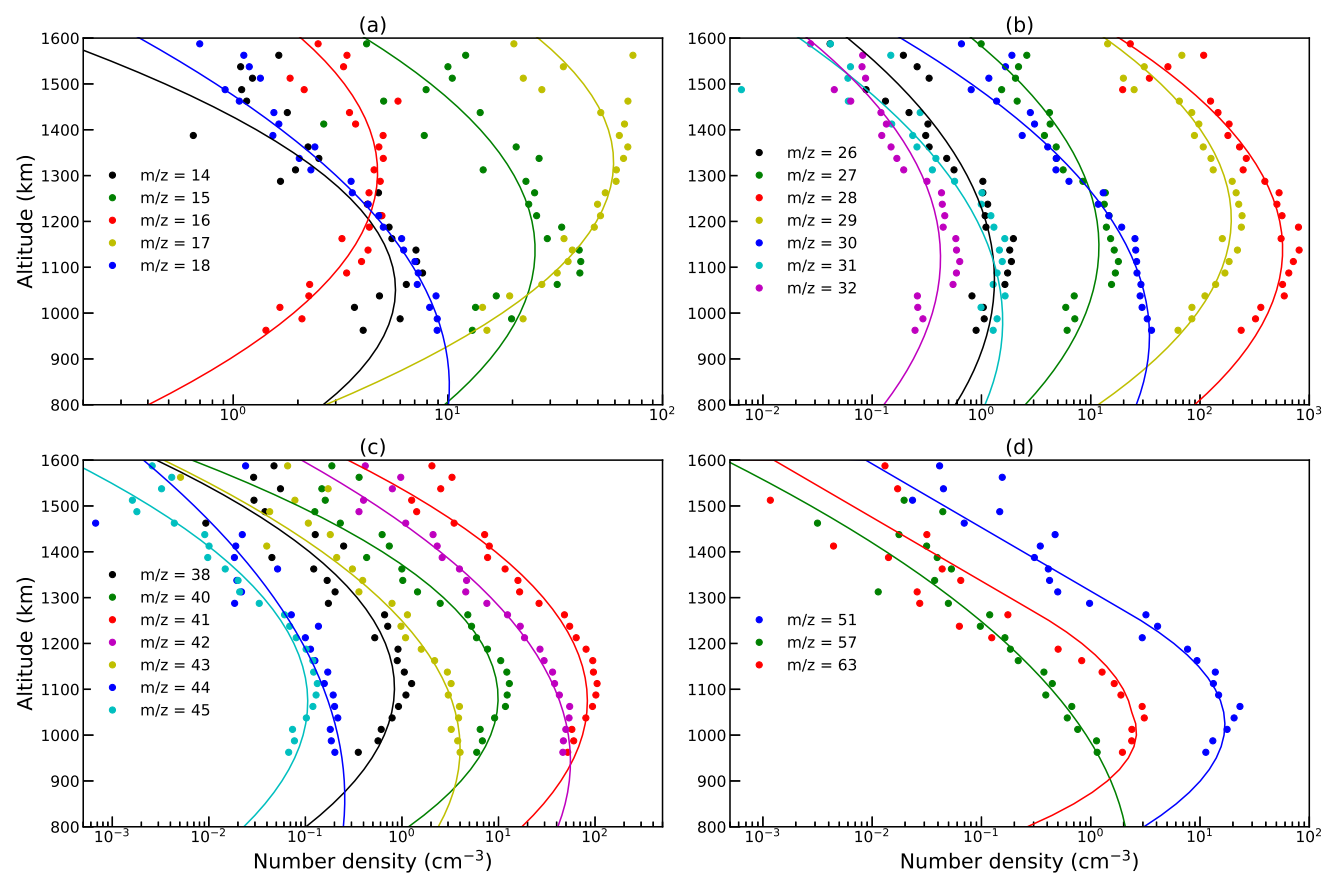

Fig. 3. Density profiles of ion reactants involved in this study, based on Cassini INMS measurements in the OSI mode (solid circles) according to the mass-to-charge ratio, M/Z (Mandt et al. 2012). Also shown are the smooth empirical profiles based on the third-order polynomial fittings to logarithmic density (solid lines).

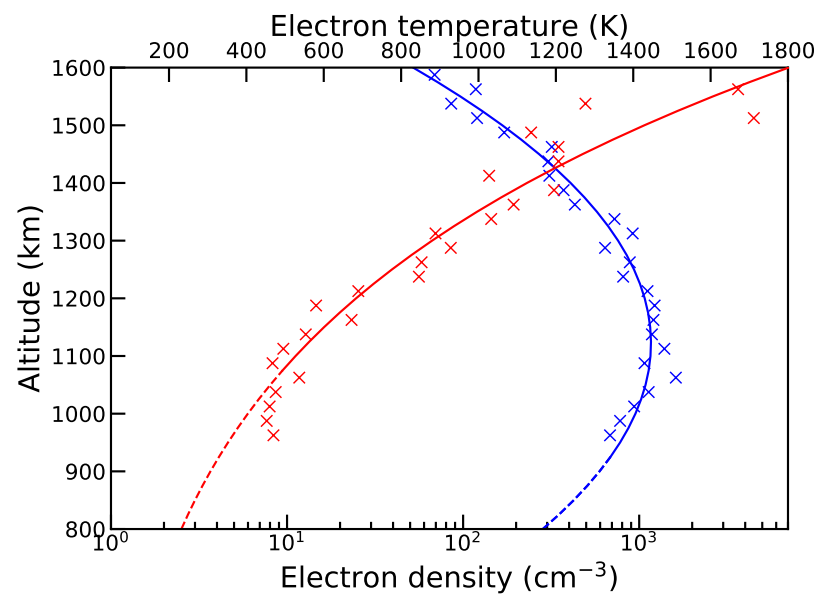

Fig. 4. Electron density and temperature profiles based on the Cassini RPWS LP measurements (crosses) averaged over the dayside of Titan (Wahlund et al. 2005). Empirical electron density profile (solid blue) is obtained in a similar manner as the ion density profiles in Fig. 3, whereas the empirical electron temperature profile (solid red) is obtained by using the functional form of Ergun et al. (2015).

followed by the ion-neutral reaction

$$
\mathrm{N}^{+}+\mathrm{CH}_{4} \rightarrow \mathrm{N}\left({ }^{4} \mathrm{~S}\right)+\mathrm{CH}_{4}^{+} \quad\left(\mathrm{R}_{a} 3\right)
$$

of which $\mathrm{R}_{a} 1$ and $\mathrm{R}_{a} 2$ dominate above $950 \mathrm{~km}$, whereas $\mathrm{R}_{a} 3$ dominates at lower altitudes. $\mathrm{R}_{a} 1$ essentially represents the collisional quenching of $\mathrm{N}\left({ }^{2} \mathrm{D}\right)$ to ground state $\mathrm{N}\left({ }^{4} \mathrm{~S}\right)$. The production of hot $\mathrm{N}$ in the form of excited state $\mathrm{N}\left({ }^{2} \mathrm{D}\right)$ is of minor importance, mainly via two DR reactions

$\mathrm{N}_{2}^{+}+\mathrm{e} \rightarrow \mathrm{N}\left({ }^{4} \mathrm{~S}\right)+\mathrm{N}\left({ }^{2} \mathrm{D}\right) \quad\left(\mathrm{R}_{a} 5\right)$

$\mathrm{N}_{2}^{+}+\mathrm{e} \rightarrow 2 \mathrm{~N}\left({ }^{2} \mathrm{D}\right) \quad\left(\mathrm{R}_{a} 6\right)$,

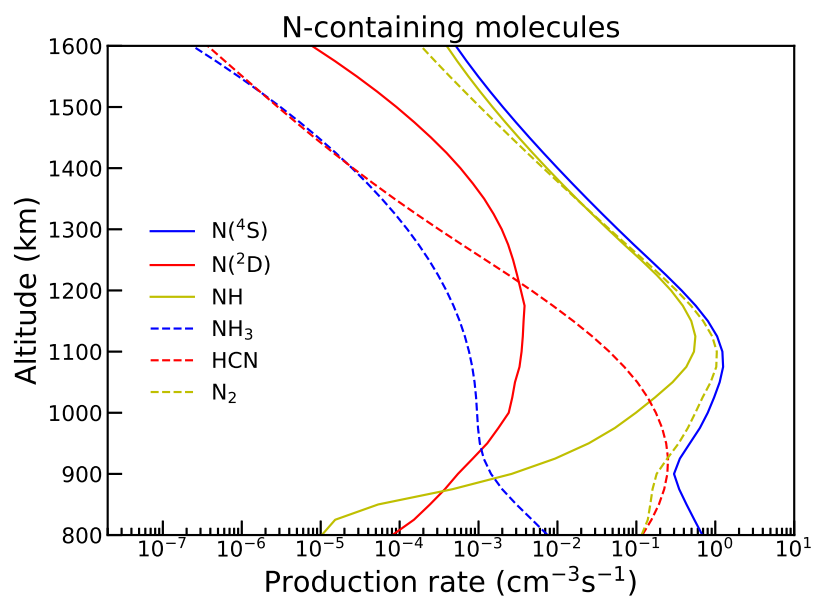

Fig. 5. Total hot neutral production rates for all the $\mathrm{N}$-containing species considered in this study.

which have comparable reaction rates at all altitudes of interest here.

$\mathrm{NH}$ and $\mathrm{NH}_{3}$. The dominant channels of hot NH production are two neutral-neutral reactions

$\mathrm{N}\left({ }^{4} \mathrm{~S}\right)+\mathrm{C}_{2} \mathrm{H}_{5} \rightarrow \mathrm{NH}+\mathrm{C}_{2} \mathrm{H}_{4} \quad\left(\mathrm{R}_{c} 3\right)$,
$\mathrm{N}\left({ }^{2} \mathrm{D}\right)+\mathrm{NH}_{3} \rightarrow \mathrm{NH}+\mathrm{NH}_{2} \quad\left(\mathrm{R}_{c} 4\right)$.

The production rate of hot $\mathrm{NH}_{3}$ is substantially lower, mainly contributed by the DR reaction

$\mathrm{CH}_{3} \mathrm{NH}_{3}^{+}+e \rightarrow \mathrm{NH}_{3}+\mathrm{CH}_{3} \quad\left(\mathrm{R}_{f} 2\right)$,

with a production rate at the exobase nearly three orders of magnitude smaller than the hot $\mathrm{NH}$ production rate at the same 


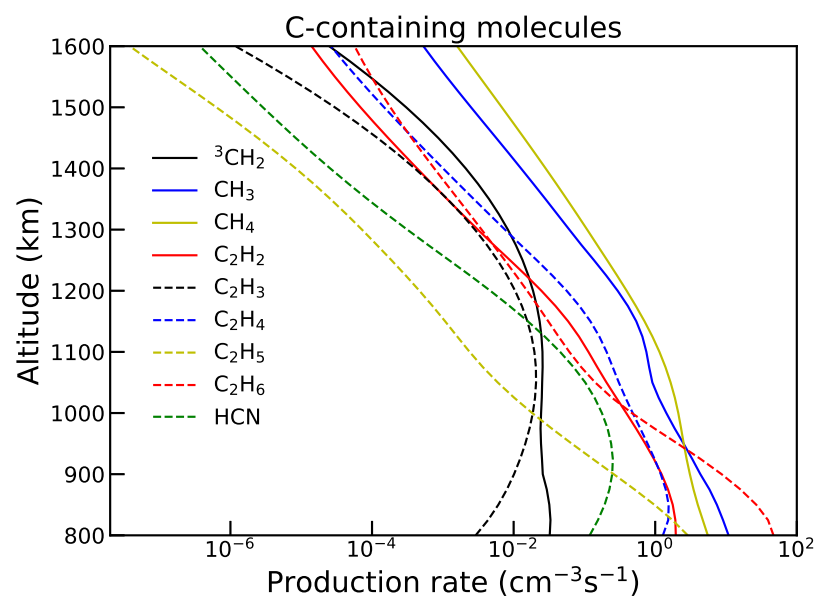

Fig. 6. Similar to Fig. 5 but for all the C-containing species considered in this study.

altitude. Note that $\mathrm{R}_{f} 2$ and $\mathrm{R}_{c} 3$ also produce hot $\mathrm{CH}_{3}$ and $\mathrm{C}_{2} \mathrm{H}_{4}$ in Titan's upper atmosphere (see below). $\mathrm{R}_{c} 6$ in Table A.1 does not contribute to $\mathrm{NH}_{3}$ escape because the respective kinetic energy of $0.34 \mathrm{eV}$ is below the $\mathrm{NH}_{3}$ escape energy of $0.39 \mathrm{eV}$ near Titan's exobase.

HCN. HCN is an effective coolant of Titan's upper atmosphere (Yelle 1991) and its abundance was recently obtained by Cui et al. (2016) at 1000-1400 km based on the Cassini INMS measurements in the CSN mode. For hot HCN production, the most important channel below $1400 \mathrm{~km}$ is the ion-neutral reaction

$\mathrm{HCNH}^{+}+\mathrm{C}_{3} \mathrm{H}_{3} \mathrm{~N} \rightarrow \mathrm{HCN}+\mathrm{C}_{3} \mathrm{H}_{4} \mathrm{~N}^{+} \quad\left(\mathrm{R}_{h} 9\right)$,

which is due to the relatively high abundance of $\mathrm{HCNH}^{+}$in Titan's ionosphere (Cravens et al. 2005). Above $1400 \mathrm{~km}$, hot $\mathrm{HCN}$ production is mainly contributed by the charge exchange reaction

$\mathrm{HCN}^{+}+\mathrm{C}_{2} \mathrm{H}_{2} \rightarrow \mathrm{HCN}+\mathrm{C}_{2} \mathrm{H}_{2}^{+} \quad\left(\mathrm{R}_{h} 7\right)$.

We also note that the ion-neutral reaction

$\mathrm{CH}_{3}^{+}+\mathrm{HC}_{3} \mathrm{~N} \rightarrow \mathrm{HCN}+\mathrm{c}-\mathrm{C}_{3} \mathrm{H}_{3}^{+} \quad\left(\mathrm{R}_{h} 5\right)$,

is likely the most important channel producing hot $\mathrm{HCN}$ below $800 \mathrm{~km}$ but this reaction should not contribute to HCN escape as the escape probability at such low altitudes is vanishingly small (see Sect. 3). De La Haye et al. (2007) identified the DR reaction

$\mathrm{HCNH}^{+}+\mathrm{e} \rightarrow \mathrm{HCN}+\mathrm{H}$

and the neutral-neutral reaction

$\mathrm{H}_{2} \mathrm{CN}+\mathrm{H} \rightarrow \mathrm{HCN}+\mathrm{H}_{2}$,

to be most important in hot $\mathrm{HCN}$ production above and below $1070 \mathrm{~km}$, respectively, but these two reactions do not drive HCN escape since the corresponding nascent kinetic energies are below the local escape energy.

$N_{2}$. The dominant channel for hot $\mathrm{N}_{2}$ production is the collisional quenching reaction $\mathrm{R}_{j} 2$ (or $\mathrm{R}_{a} 1$ quoted above). Such a reaction is seriously reduced below $900 \mathrm{~km}$ and a number of ion-neutral reactions become more important with

$\mathrm{N}^{+}+\mathrm{HCN} \rightarrow \mathrm{N}_{2}+\mathrm{CH}^{+} \quad\left(\mathrm{R}_{j} 3\right)$,

$\mathrm{N}_{2}^{+}+\mathrm{C}_{2} \mathrm{H}_{2} \rightarrow \mathrm{N}_{2}+\mathrm{C}_{2} \mathrm{H}_{2}^{+} \quad\left(\mathrm{R}_{j} 4\right)$,

providing the highest hot $\mathrm{N}_{2}$ production rates near the lower boundary. The importance of $\mathrm{R}_{j} 2$ (or $\mathrm{R}_{a} 1$ ) was also reported by De La Haye et al. (2007). However, those authors identified the ion-neutral reaction

$\mathrm{N}_{2} \mathrm{H}^{+}+\mathrm{CH}_{4} \rightarrow \mathrm{CH}_{5}^{+}+\mathrm{N}_{2}$,

to be more important above $1250 \mathrm{~km}$, while such a reaction is not considered here because the associated $\mathrm{N}_{2}$ products have insufficient energies for escape. Meanwhile, De La Haye et al. (2007) identified the collisional quenching reaction

${ }^{1} \mathrm{CH}_{2}+\mathrm{N}_{2} \rightarrow{ }^{3} \mathrm{CH}_{2}+\mathrm{N}_{2}$,

to be dominant near and below $1000 \mathrm{~km}$ but similarly, the kinetic energy release of this reaction is too low to drive $\mathrm{N}_{2}$ escape on Titan.

${ }^{3} \mathrm{CH}_{2}$. Two reactions make the most important contributions to hot ${ }^{3} \mathrm{CH}_{2}$ production, with the DR reaction

$\mathrm{C}_{2} \mathrm{H}_{5}^{+}+\mathrm{e} \rightarrow{ }^{3} \mathrm{CH}_{2}+\mathrm{CH}_{3} \quad\left(\mathrm{R}_{b} 5\right)$,

dominating above $970 \mathrm{~km}$ and the ion-neutral reaction

$\mathrm{N}^{+}+\mathrm{C}_{2} \mathrm{H}_{4} \rightarrow{ }^{3} \mathrm{CH}_{2}+\mathrm{HCNH}^{+} \quad\left(\mathrm{R}_{b} 2\right)$,

dominating at lower altitudes, respectively. $\mathrm{R}_{b} 5$ is also an important channel for the chemical loss of $\mathrm{C}_{2} \mathrm{H}_{5}^{+}$, making roughly one third of its total chemical loss at a representative altitude of $1050 \mathrm{~km}$ (Vuitton et al. 2007).

$\mathrm{CH}_{3}$. The production of hot $\mathrm{CH}_{3}$ in Titan's dayside upper atmosphere is very complicated and contributed by a large number of reactions. Below $1100 \mathrm{~km}$, the dominant channel is the ion-neutral reaction

$\mathrm{N}^{+}+\mathrm{CH}_{4} \rightarrow \mathrm{CH}_{3}+\mathrm{NH}^{+} \quad\left(\mathrm{R}_{d} 24\right)$,

whereas at higher altitudes, two neutral-neutral reactions

$\mathrm{N}\left({ }^{4} \mathrm{~S}\right)+\mathrm{C}_{2} \mathrm{H}_{5} \rightarrow \mathrm{CH}_{3}+\mathrm{H}_{2} \mathrm{CN} \quad\left(\mathrm{R}_{d} 17\right)$,

$\mathrm{N}\left({ }^{2} \mathrm{D}\right)+\mathrm{CH}_{4} \rightarrow \mathrm{CH}_{3}+\mathrm{NH} \quad\left(\mathrm{R}_{d} 19\right)$,

one ion-neutral reaction

$\mathrm{HCN}^{+}+\mathrm{CH}_{4} \rightarrow \mathrm{CH}_{3}+\mathrm{HCNH}^{+} \quad\left(\mathrm{R}_{d} 25\right)$,

and another DR reaction, which is $\mathrm{R}_{b} 5$ quoted above, become near equally important.

$\mathrm{CH}_{4}$. Hot $\mathrm{CH}_{4}$ production occurs mainly via the ionneutral reaction

$\mathrm{CH}_{5}^{+}+\mathrm{HCN} \rightarrow \mathrm{CH}_{4}+\mathrm{HCNH}^{+} \quad\left(\mathrm{R}_{e} 13\right)$,

followed by 3 additional ion-neutral reactions

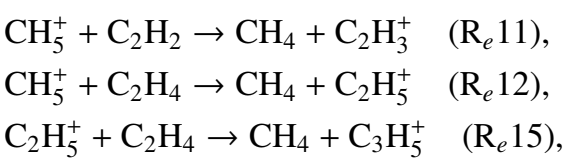


as well as the neutral-neutral reaction

$\mathrm{CH}_{3}+\mathrm{NH} \rightarrow \mathrm{CH}_{4}+\mathrm{N}\left({ }^{4} \mathrm{~S}\right) \quad\left(\mathrm{R}_{e} 7\right)$

of which the last one also contributes to hot $\mathrm{N}\left({ }^{4} \mathrm{~S}\right)$ production near Titan's exobase. According to Vuitton et al. (2007), the former 4 reactions are important chemical loss channels of $\mathrm{CH}_{5}^{+}$ and $\mathrm{C}_{2} \mathrm{H}_{5}^{+}$in Titan's ionosphere. A similar reaction, $\mathrm{R}_{e} 14$ in Table A.1, plays a minor role due to the relatively low rate coefficient (McEwan \& Anicich 2007). For comparison, De La Haye et al. (2007) identified the DR reaction $\mathrm{R}_{e} 17$ to be dominant but this reaction is unimportant according to our calculations. The difference is partly due to the overestimate of the $\mathrm{CH}_{5}^{+}$abundance near Titan's exobase by De La Haye et al. (2007), essentially based on the pre-Cassini model results of Keller et al. (1992), and partly due to the extremely high DR coefficient used by those authors, more than a factor of 10 higher than our value (see Table A.1). For the four ion-neutral reactions listed in Eqs. (20) and (21), the relative contributions from reactions $\mathrm{R}_{e} 12$ and $\mathrm{R}_{e} 15$ comparable to our estimates were obtained by De La Haye et al. (2007) whereas reactions $\mathrm{R}_{e} 11$ and $\mathrm{R}_{e} 13$ were not considered by those authors. The neutral-neutral reaction $\mathrm{R}_{e} 7$ was also not included in their study.

$\mathrm{C}_{2} \mathrm{H}_{2}$. Hot $\mathrm{C}_{2} \mathrm{H}_{2}$ is mainly produced via the neutralneutral reaction

$\mathrm{CH}_{3}+\mathrm{C}_{2} \mathrm{H}_{3} \rightarrow \mathrm{C}_{2} \mathrm{H}_{2}+\mathrm{CH}_{4} \quad\left(\mathrm{R}_{g} 7\right)$,

above $1150 \mathrm{~km}$ and via another neutral-neutral reaction

$\mathrm{C}_{2} \mathrm{H}+\mathrm{CH}_{2} \mathrm{CCH}_{2} \rightarrow \mathrm{C}_{2} \mathrm{H}_{2}+\mathrm{C}_{3} \mathrm{H}_{3} \quad\left(\mathrm{R}_{g} 11\right)$,

at lower altitudes. $\mathrm{R}_{g} 7$ is also capable of driving $\mathrm{CH}_{4}$ escape on Titan.

$\mathrm{C}_{2} \mathrm{H}_{3}$. The production of hot $\mathrm{C}_{2} \mathrm{H}_{3}$ is dominated by the DR reaction

$\mathrm{C}_{3} \mathrm{H}_{5}^{+}+\mathrm{e} \rightarrow \mathrm{C}_{2} \mathrm{H}_{3}+{ }^{3} \mathrm{CH}_{2} \quad\left(\mathrm{R}_{i} 5\right)$,

at all altitudes of interest here, which is also the third most important channel for ${ }^{3} \mathrm{CH}_{2}$ production above $1100 \mathrm{~km}$. In addition, the neutral-neutral reaction

$\mathrm{C}_{2} \mathrm{H}_{3} \mathrm{CN}+\mathrm{C}_{2} \rightarrow \mathrm{C}_{2} \mathrm{H}_{3}+\mathrm{C}_{3} \mathrm{~N} \quad\left(\mathrm{R}_{i} 3\right)$,

is an important channel producing hot $\mathrm{C}_{2} \mathrm{H}_{3}$ at low altitudes and does not contribute appreciably to $\mathrm{C}_{2} \mathrm{H}_{3}$ escape on Titan.

$\mathrm{C}_{2} \mathrm{H}_{4}$. Hot $\mathrm{C}_{2} \mathrm{H}_{4}$ production in Titan's dayside upper atmosphere is mainly driven by two neutral-neutral reactions

$\mathrm{CH}+\mathrm{C}_{2} \mathrm{H}_{6} \rightarrow \mathrm{C}_{2} \mathrm{H}_{4}+\mathrm{CH}_{3} \quad\left(\mathrm{R}_{k} 3\right)$,

$\mathrm{CH}_{3}+\mathrm{C}_{2} \mathrm{H}_{5} \rightarrow \mathrm{C}_{2} \mathrm{H}_{4}+\mathrm{CH}_{4} \quad\left(\mathrm{R}_{k} 9\right)$,

and two ion-neutral reactions

$$
\begin{aligned}
& \mathrm{C}_{2} \mathrm{H}_{5}^{+}+\mathrm{CH}_{3} \mathrm{CN} \rightarrow \mathrm{C}_{2} \mathrm{H}_{4}+\mathrm{CH}_{3} \mathrm{CNH}^{+} \quad\left(\mathrm{R}_{k} 24\right), \\
& \mathrm{C}_{2} \mathrm{H}_{5}^{+}+\mathrm{HC}_{3} \mathrm{~N} \rightarrow \mathrm{C}_{2} \mathrm{H}_{4}+\mathrm{HC}_{3} \mathrm{NH}^{+} \quad\left(\mathrm{R}_{k} 25\right) .
\end{aligned}
$$

The relative importance of different reactions vary with altitude, with $\mathrm{R}_{k} 9$ dominating above $1100 \mathrm{~km}, \mathrm{R}_{k} 24$ at $960-1100 \mathrm{~km}$, and $\mathrm{R}_{k} 3$ below $960 \mathrm{~km}$, respectively. $\mathrm{R}_{k} 3$ and $\mathrm{R}_{k} 9$ also contribute to hot $\mathrm{CH}_{3}$ and $\mathrm{CH}_{4}$ production, though of minor importance only.
$\mathrm{C}_{2} \mathrm{H}_{5}$. The production of hot $\mathrm{C}_{2} \mathrm{H}_{5}$ occurs mainly via two DR reactions

$\mathrm{C}_{3} \mathrm{H}_{6}^{+}+\mathrm{e} \rightarrow \mathrm{C}_{2} \mathrm{H}_{5}+\mathrm{CH} \quad\left(\mathrm{R}_{l} 6\right)$,

$\mathrm{C}_{3} \mathrm{H}_{8}^{+}+\mathrm{e} \rightarrow \mathrm{C}_{2} \mathrm{H}_{5}+\mathrm{CH}_{3} \quad\left(\mathrm{R}_{l} 7\right)$,

and one neutral-neutral reaction

$\mathrm{C}_{2} \mathrm{H}+\mathrm{C}_{2} \mathrm{H}_{6} \rightarrow \mathrm{C}_{2} \mathrm{H}_{5}+\mathrm{C}_{2} \mathrm{H}_{2} \quad\left(\mathrm{R}_{l} 4\right)$.

However, hot $\mathrm{C}_{2} \mathrm{H}_{5}$ production below $930 \mathrm{~km}$ is dominated by the three-body reaction

$\mathrm{H}+\mathrm{C}_{2} \mathrm{H}_{4}+\mathrm{M} \rightarrow \mathrm{C}_{2} \mathrm{H}_{5}+\mathrm{M} \quad\left(\mathrm{R}_{l} 1\right)$.

Clearly, $\mathrm{C}_{2} \mathrm{H}_{5}$ escape on Titan is primarily driven by the former three reactions. We note also that $\mathrm{R}_{l} 7$ makes only a minor contribution to hot $\mathrm{CH}_{3}$ production. Our calculations highlight the impact of radiative association on hot neutral production in the tenuous part of Titan's upper atmosphere. For instance, the conventional Lindemann-Hinshelwood formalism that does not include radiative association predicts a $\mathrm{C}_{2} \mathrm{H}_{5}$ production rate via Reaction $\mathrm{R}_{l} 1$ about 4 orders of magnitude too low near the exobase.

$\mathrm{C}_{2} \mathrm{H}_{6}$. Hot $\mathrm{C}_{2} \mathrm{H}_{6}$ production at all altitudes is dominated by the three-body reaction

$2 \mathrm{CH}_{3}+\mathrm{M} \rightarrow \mathrm{C}_{2} \mathrm{H}_{6}+\mathrm{M} \quad\left(\mathrm{R}_{m} 2\right)$,

followed by the DR reaction

$\mathrm{C}_{3} \mathrm{H}_{7}^{+}+\mathrm{e} \rightarrow \mathrm{C}_{2} \mathrm{H}_{6}+\mathrm{CH} \quad\left(\mathrm{R}_{m} 8\right)$.

In contrast, De La Haye et al. (2007) reported the latter reaction to be dominant at high altitudes as those authors did not include radiative association and, therefore, seriously underestimated hot $\mathrm{C}_{2} \mathrm{H}_{6}$ production near and above the exobase.

Finally, it is noteworthy that in most cases, three-body reactions are only important in the relatively dense regions of Titan's upper atmosphere where escape becomes difficult (see Sect. 3). Accordingly, their contributions to total $\mathrm{N}$ escape (in the form of $\mathrm{N}_{2}$ recoils) is ignored in Table A.1 and throughout this paper. An exception is reaction $\mathrm{R}_{m} 2$ which dominates $\mathrm{C}_{2} \mathrm{H}_{6}$ production at sufficiently high altitudes, but this reaction should not contribute substantially to $\mathrm{N}$ escape in the form of $\mathrm{N}_{2}$ recoils because the respective production rate is well below the $\mathrm{N}_{2}$ production rate via the collisional quenching reaction $\mathrm{R}_{j} 2$ (see above).

\section{Hot neutral escape probabilities}

For each species discussed in Sect. 2, the respective escape probability in Titan's dayside upper atmosphere is required to rigorously calculate the escape rate. The ideal exobase approximation was adopted by both Cravens et al. (1997) and De La Haye et al. (2007), essentially reflecting a sharp transition in escape probability from 0 to 0.5 at the exobase. Here, to capture the realistic behavior of escaping neutrals over a broad transition region near the exobase, a more sophisticated test particle Monte Carlo model is constructed to obtain the escape probabilities of hot neutrals produced via each exothermic chemical channel. The model is analogous to previous models of atomic O escape on the dayside of Mars (e.g. Fox \& Hać 2009, 2014, 2018), and is modified from our existing model of atmospheric sputtering on Titan (Gu et al. 2019). We also mention 
that analytic models capable of capturing the near exobase transition of escape probability in an approximate manner have also been proposed such as the single collision model of Cravens et al. (2017) and the multiple collision model of Cui et al. (2019).

The plane parallel background atmosphere used in this study is displayed in Fig. 1, over the altitude range of 800-2000 km and containing $\mathrm{N}_{2}, \mathrm{CH}_{4}$, and $\mathrm{H}_{2}$. Below $800 \mathrm{~km}$, the mean free path for collision is sufficiently short that the energy of a typical hot neutral is degraded rapidly to the local thermal energy over a length scale not exceeding $0.5 \mathrm{~km}$, a situation consistent with local thermalization. At $2000 \mathrm{~km}$, the collision probability drops to around $1 \%$, implying that Titan's atmosphere above this altitude does not exert an appreciable influence on the derived escape probabilities. For the energy range encountered in this study, inelastic collision processes such as excitation and dissociation could be safely ignored. Similar to De La Haye et al. (2007), the collisions between hot neutrals and ambient neutrals are modeled under the hard sphere approximation for elastic collisions, with the appropriate hard sphere radii of relevant neutrals estimated from existing laboratory measurements of pure gas viscosity (e.g. Flynn \& Thodos 1961; Fenghour et al. 1995; Rowley et al. 2003). Whenever no viscosity measurements have been made for a certain species, its hard sphere radius is either approximated by the known radius of a species in the same chemical group or taken from the American Chemical Society website on http: //center . acs.org/periodic/tools/PT.html.

At a given altitude, a hot neutral particle is released in a random direction, assuming isotropic production and with a prescribed nascent velocity depending on the chemical channel involved. The trajectory of this particle is followed under the influence of Titan's gravity and the position where it makes a further collision with ambient neutrals is determined in a stochastic manner with the aid of the known information of the collision cross section and the known structure of the background atmosphere. The collision partner, $\mathrm{N}_{2}, \mathrm{CH}_{4}$, or $\mathrm{H}_{2}$, is also decided stochastically based on the column density ratio between different ambient species over the path length of hot neutral free propagation. The post-collision velocities of both the hot neutral and the ambient neutral could then be favorably determined from the momentum and energy conservation laws, where the precollision velocity of the ambient neutral is assumed to be zero since its thermal energy (Snowden et al. 2013) and wind-driven bulk kinetic energy (Müller-Wodarg et al. 2008) are both well below the kinetic energy release from exothermic chemistry. The post-collision velocity direction of the hot neutral is also chosen randomly under the assumption of isotropic scattering. The above procedure is repeated until one of the following conditions is satisfied: (1) when the hot neutral reaches the lower boundary or when its kinetic energy falls below the local escape energy via a cascade of collisions anywhere within the simulation box, it is no longer traced in our model calculations; (2) when the hot neutral reaches the upper boundary, it is either assumed to be lost from the atmosphere or reflected downward elastically, depending on whether its kinetic energy is above or below the local escape energy.

The entire background atmosphere of Titan is divided into 17 altitude grids, each covering a depth of $50 \mathrm{~km}$, to allow the full altitude profile of escape probability to be constructed. For each species, we consider a range of energy (see Table A.2) that incorporates the range of nascent kinetic energy for various source reactions (see Sect. 2). For a unique combination of the nascent energy and the altitude of production, a total number of 100000 hot neutrals are modelled independently to achieve statistically robust results for each species and each reaction.
In Fig. 7, we show the escape probability as a function of altitude for each candidate escaping species quoted in Sect. 2 and for a sequence of nascent kinetic energy quoted in the figure legend. Several interesting features can immediately be seen in the figure. First, all profiles reveal the presence of a broad transition region with a depth of nearly $200 \mathrm{~km}$ around the ideal exobase at $1500 \mathrm{~km}$ (Westlake et al. 2011). The escape probability is vanishingly small at the lower end of the transition region and is around 0.5 at the upper end. The latter is consistent with the expected scenario that nearly all particles moving upward are able to escape (e.g. Cravens et al. 1997). The actual escape probability at the upper end might be modestly different from the ideal value of 0.5 due to non-negligible backscattering. Second, the escape probability increases with increasing energy at all altitudes, which is interpreted by the fact that a more energetic particle allows a greater number of collisions before its energy falls below the local escape energy (e.g. Cui et al. 2019). Third, the escape probability also varies from species to species due to the difference in collision cross section. As intuitively expected, the escape probabilities of small hot particles tend to be higher than those of large hot particles as small ones are less likely to collide with ambient neutrals (e.g. Fox \& Hać 2014).

Despite the variations with both energy and collision cross section, we find that the modelled altitude profile of the escape probability, $\zeta_{\text {esc }}$, could be reasonably described by a common functional form of

$\zeta_{\text {esc }}=a_{1} \tanh \left(\frac{z-a_{2}}{160}\right)+a_{3}$,

where $z$ is the altitude in $\mathrm{km}, a_{1}, a_{2}$, and $a_{3}$ are free parameters to be constrained by the Monte Carlo model results. As motivated by Fig. 7, we adopt a common depth of $160 \mathrm{~km}$ for the transition region for all species and at all nascent energies. In the equation, $a_{2}$ denotes the central location of the transition region, whereas $a_{3}+a_{1}$ represents the asymptotic escape probability at sufficiently high altitudes. Ideally, one may expect that the asymptotic escape probability at low altitudes, given by $a_{3}-a_{1}$ according to Eq. (34), should be zero, thus implying $a_{1}=a_{3}$. However, such a condition does not always lead to satisfactory fits to the modelled escape probability profiles. Accordingly, Eq. (34) cannot be extrapolated to arbitrarily low altitudes where the predicted escape probability could sometimes be negative. The best-fit profiles of escape probability are indicated by the dashed lines in Fig. 7 for reference.

Since the location of the transition region appears to be energy independent according to Fig. 7, we assume for simplicity a constant value of $a_{2}$ for any given species, as listed in Table A.2. $a_{1}$ and $a_{3}$ are clearly energy dependent and described in this study by

$a_{1}=b_{1} \exp (-E)+b_{2}$

(a),

$a_{1}=b_{1} \ln E+b_{2}$

$a_{3}=b_{3} \ln E+b_{4}$

where $E$ is the nascent energy of a hot particle in $\mathrm{eV}, b_{1}, b_{2}$, $b_{3}$, and $b_{4}$ are free parameters to be constrained by the values listed in Table A.2. Note that Eq. (35a) is used to describe the $a_{1}$ parameters of relatively light species including $\mathrm{N}\left({ }^{4} \mathrm{~S}\right)$, $\mathrm{N}\left({ }^{2} \mathrm{D}\right),{ }^{3} \mathrm{CH}_{2}, \mathrm{CH}_{3}, \mathrm{CH}_{4}, \mathrm{NH}$, and $\mathrm{NH}_{3}$, whereas Eq. (35b) is used for heavier species considered in this study. Combining Eqs. (34) and (35), we are able to obtain the escape probability profile for any candidate escaping species and at any nascent energy. 

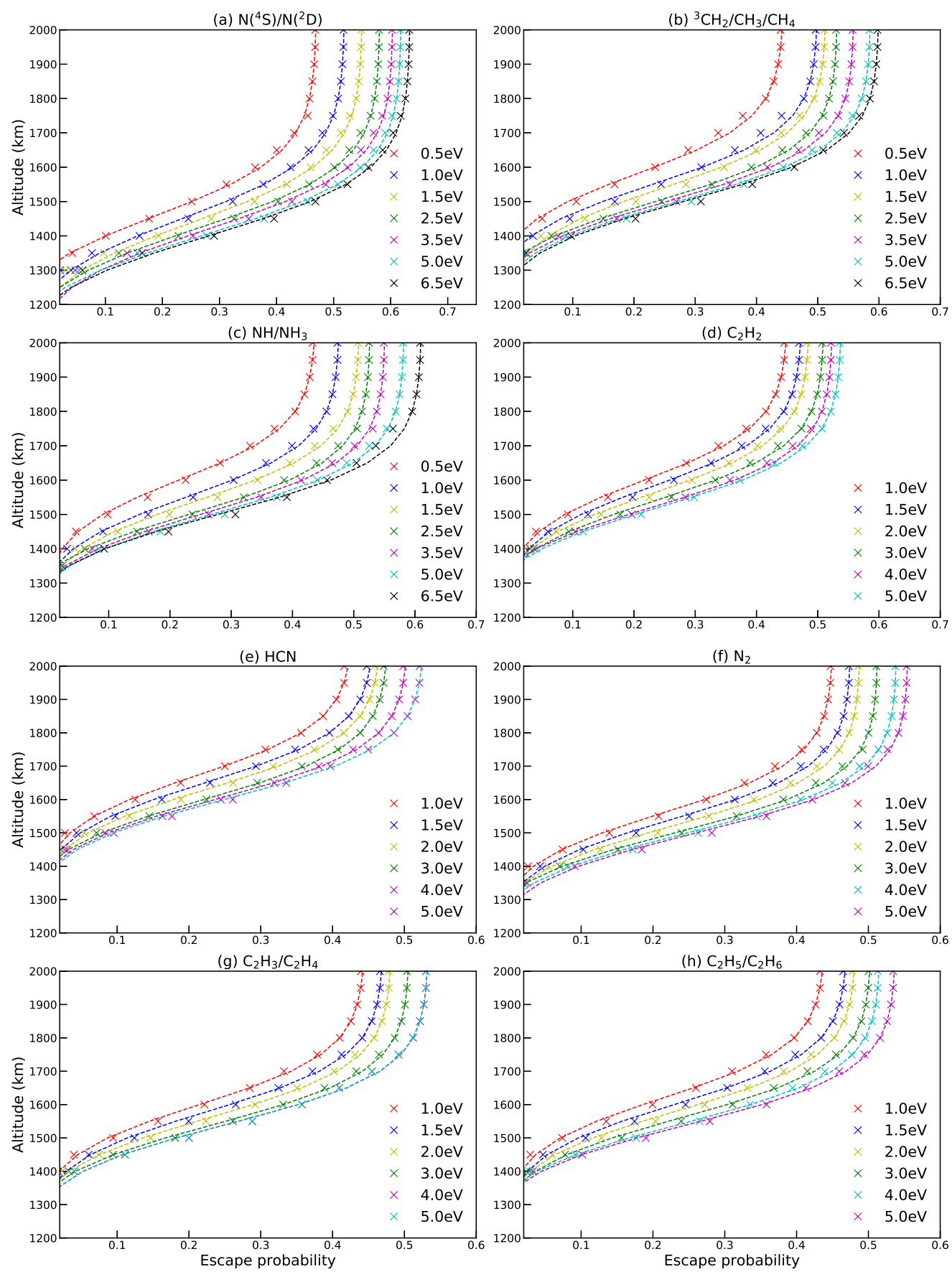

Fig. 7. Escape probability profiles for various hot neutrals and covering the range of nascent kinetic energy encountered in this study. Crosses are adapted from test particle Monte Carlo calculations whereas the dashed lines indicate the best empirical fits (see text for details).

\section{Neutral escape rates driven by exothermic chemistry}

The escape rate for a given species and a given chemical channel in Titan's dayside upper atmosphere, as listed in Table A.1, is estimated via

$\Phi_{\mathrm{esc}}=\int_{800 \mathrm{~km}}^{1600 \mathrm{~km}} 2 \pi\left(R_{\mathrm{T}}+z\right)^{2} \zeta_{\mathrm{esc}}(z) P_{\mathrm{hot}}(z) \mathrm{d} z$,

where $R_{\mathrm{T}}$ is Titan's solid body radius, $P_{\text {hot }}$ is the hot neutral production rate, and the other parameters are defined above. Combining the calculations for all the 14 species and all the 146 independent chemical channels, we are able to obtain the total
$\mathrm{C}$ and $\mathrm{N}$ escape rates, as well as determine the relative contribution of each channel. For reference, we provide in Table A.1 the escape rates of all neutral species via all chemical channels involved in this study, along with the respective fractional contributions to total $\mathrm{C}$ or $\mathrm{N}$ escape. We caution that a channel with a large column integrated hot neutral production rate does not necessarily contribute substantially to neutral escape since peak production may occur at low altitudes where the escape probability is small.

Table A.1 reveals that for $\mathrm{N}$ escape, the most important channel is the collisional quenching reaction $\mathrm{R}_{a} 1$ which contributes to $80 \%$ of total $\mathrm{N}$ escape via exothermic chemistry, in the form of both hot $\mathrm{N}\left({ }^{4} \mathrm{~S}\right)$ and hot $\mathrm{N}_{2}$ (note that the $\mathrm{N}_{2}$ escape rate listed in 

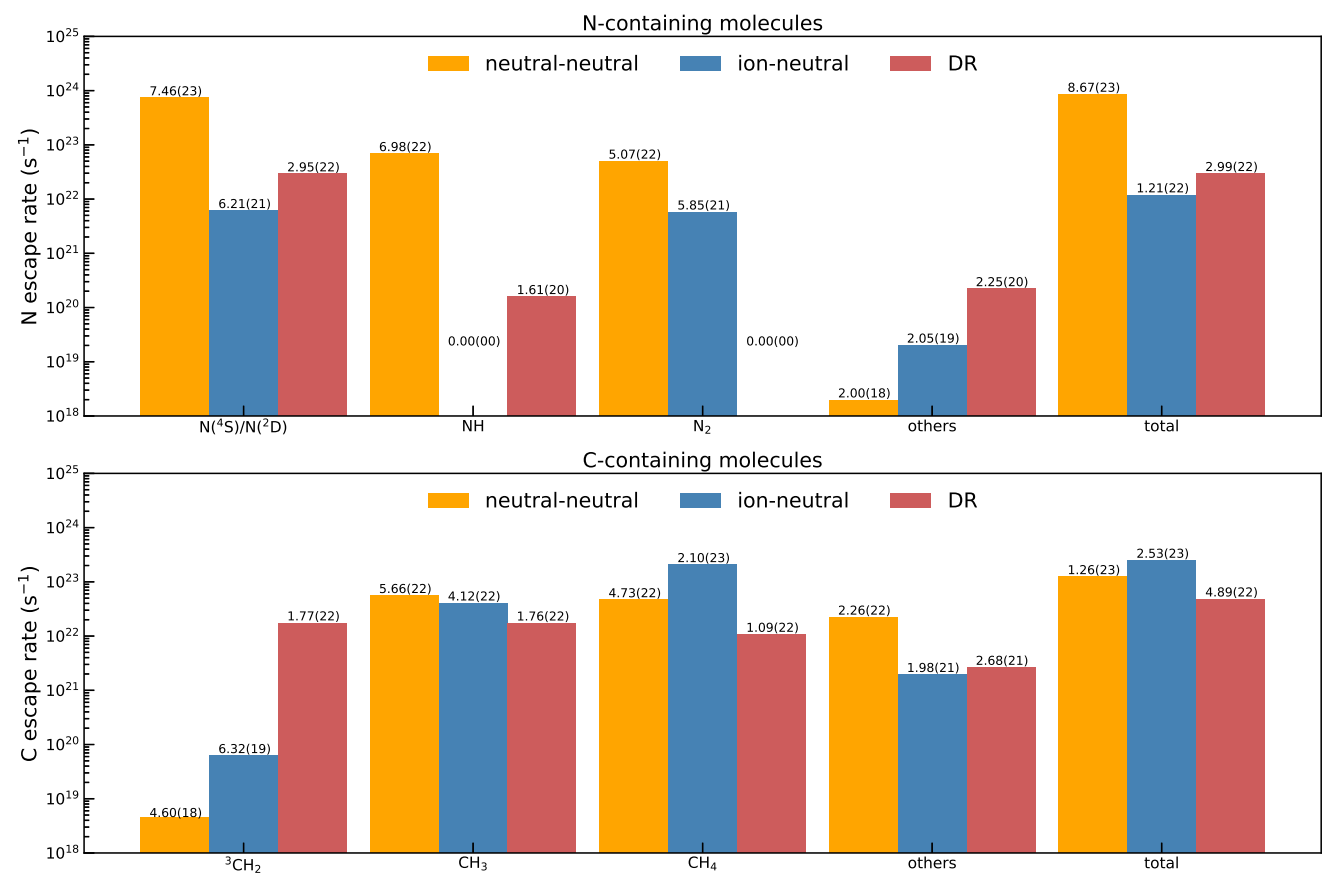

Fig. 8. $\mathrm{C}$ and $\mathrm{N}$ escape rates via the production of different $\mathrm{N}$ - and $\mathrm{C}$-containing species, with the contributions from neutral-neutral, ion-neutral, and DR reactions indicated separately.

Table A. 1 for $\mathrm{R}_{j} 2$ is multiplied by 2 to represent the net $\mathrm{N}$ escape rate). The second most important channel is the neutral-neutral reaction $\mathrm{R}_{a} 2$ that produces hot $\mathrm{N}\left({ }^{4} \mathrm{~S}\right)$ and accounts for $12 \%$ of total $\mathrm{N}$ escape. Two other neutral-neutral reactions, $\mathrm{R}_{c} 3$ and $\mathrm{R}_{c} 5$, contribute non-negligibly to $8 \%$ of total $\mathrm{N}$ escape by producing hot NH. It is interesting to note that the contribution from hot $\mathrm{NH}$ production to total $\mathrm{N}$ escape is higher than the contribution from hot $\mathrm{N}_{2}$ production. This is an unexpected result that was not reported by Cravens et al. (1997) and De La Haye et al. (2007) despite both studies having included NH-related chemistry. Ionneutral and DR reactions are less important than neutral-neutral reactions in driving $\mathrm{N}$ escape. Specifically, the most important ion-neutral reaction is $\mathrm{R}_{a} 3$ and the most important DR reaction is $\mathrm{R}_{a} 5$, but they only contribute to 0.6 and $2.6 \%$ of total $\mathrm{N}$ escape by producing either hot $\mathrm{N}\left({ }^{4} \mathrm{~S}\right)$ or hot $\mathrm{N}\left({ }^{2} \mathrm{D}\right)$.

Total C escape in Titan's dayside upper atmosphere driven by exothermic chemistry occurs in a more complicated manner, with 16 reactions making fractional contributions above $1 \%$ including 6 neutral-neutral, 7 ion-neutral and 3 DR reactions. The most important channel is the ion-neutral reaction $\mathrm{R}_{e} 13$ producing hot $\mathrm{CH}_{4}$ and Table A.1 indicates that this reaction contributes to about $30 \%$ of total $\mathrm{C}$ escape. The next two important channels are the neutral-neutral reactions $\mathrm{R}_{e} 7$ and $\mathrm{R}_{e} 12$ that also produce hot $\mathrm{CH}_{4}$, each contributing to $9 \%$ of total $\mathrm{C}$ escape. In addition, several other channels of hot $\mathrm{CH}_{3}$ and $\mathrm{CH}_{4}$ production account for a non-negligible fraction of total $\mathrm{C}$ escape no less than $5 \%$, mainly via 2 neutral-neutral reactions $\mathrm{R}_{d} 17, \mathrm{R}_{d} 19$, and 2 ion-neutral reactions $\mathrm{R}_{d} 25$ and $\mathrm{R}_{e} 11$. Reaction $\mathrm{R}_{e} 7$ is also the second most important channel driving total $\mathrm{N}$ escape $\left(\mathrm{R}_{a} 2\right.$ quoted above) since this reaction produces both hot $\mathrm{CH}_{4}$ and hot $\mathrm{N}\left({ }^{4} \mathrm{~S}\right)$. The contribution from DR reactions to total $\mathrm{C}$ escape is less important, mainly via $\mathrm{R}_{b} 5$ (which is also $\mathrm{R}_{d} 29$ in Table A.1) producing both hot ${ }^{3} \mathrm{CH}_{2}$ and hot $\mathrm{CH}_{3}$, and via $\mathrm{R}_{e} 19$ producing hot $\mathrm{CH}_{4}$.

The $\mathrm{C}$ and $\mathrm{N}$ escape rates due to the production of different hot neutral species are compared schematically in Fig. 8, with the contributions from neutral-neutral, ion-neutral, and
DR reactions indicated separately. The total dayside $\mathrm{N}$ escape rate is $9.1 \times 10^{23} \mathrm{~s}^{-1}$ with more than $95 \%$ from neutral-neutral reactions and the remaining fraction partitioned between ionneutral and DR reactions. The total dayside $\mathrm{C}$ escape rate is $4.3 \times 10^{23} \mathrm{~s}^{-1}$ with $60 \%$ from ion-neutral reactions, $29 \%$ from neutral-neutral reactions, and the remaining $11 \%$ from DR reactions, respectively. Our calculations indicate that about $86 \%$ of total $\mathrm{N}$ escape is contributed by hot $\mathrm{N}\left({ }^{4} \mathrm{~S}\right)$ and $\mathrm{N}\left({ }^{2} \mathrm{D}\right)$ production, followed by nearly $8 \%$ from hot $\mathrm{NH}$ production and $6 \%$ from hot $\mathrm{N}_{2}$ production. We note that ion-neutral reactions do not contribute to $\mathrm{NH}$ escape and DR reactions do not contribute to $\mathrm{N}_{2}$ escape according to Fig. 8. Total $\mathrm{C}$ escape is partitioned mostly among three species: $63 \%$ from $\mathrm{CH}_{4}$ escape, $27 \%$ from $\mathrm{CH}_{3}$ escape, and $4 \%$ from ${ }^{3} \mathrm{CH}_{2}$ escape. The combined fractional contribution from the remaining $\mathrm{C}$-containing species is only $6 \%$.

For all the three categories of exothermic chemistry considered here, we find that neutral-neutral reactions drive $\mathrm{N}$ escape nearly a factor of 7 stronger than $\mathrm{C}$ escape, ion-neutral reactions drive $\mathrm{C}$ escape nearly a factor of 20 stronger than $\mathrm{N}$ escape, whereas DR reactions drive comparable $\mathrm{C}$ and $\mathrm{N}$ escape, respectively. We emphasize that both ion-neutral and DR reactions could be ignored, with an uncertainty no more than $5 \%$, to describe properly total $\mathrm{N}$ escape, whereas to poperly describe total $\mathrm{C}$ escape, all categories of exothermic reaction have to be taken into account.

\section{Discussions and concluding remarks}

Atmospheric escape is a key process that controls the evolution of climate and habitability on terrestrial planets. One of the important mechanisms driving atmospheric escape is exothermic chemistry, which may produce hot neutrals sufficiently energetic to overcome the gravitational potential of the central body (e.g. Johnson et al. 2008, and references therein). This mechanism is especially interesting for Titan, the largest satellite of Saturn, due to its extremely complicated atmospheric and ionospheric 
composition as revealed by the Cassini INMS measurements in both the CSN and OSI modes (e.g. Waite et al. 2005; Cravens et al. 2005). The total $\mathrm{C}$ and $\mathrm{N}$ escape rates on the dayside of Titan driven by exothermic chemistry were computed in the pre-Cassini investigation of Cravens et al. (1997) and the early post-Cassini investigation of De La Haye et al. (2007) (when the data from a very limited number of close Titan flybys were available). The present investigation is intended for an updated evaluation of the same issue by virtue of the extensive Cassini INMS measurements of Titan's upper atmospheric structure (e.g Cui et al. 2009b,a; Magee et al. 2009; Mandt et al. 2012), as well as the improved understanding of the associated chemical network over the past decade (e.g. Wilson \& Atreya 2004; Vuitton et al. 2006a,b, 2007, 2008, 2019; Lavvas et al. 2008a,b; Krasnopolsky 2014).

A total number of 14 candidate escaping neutral species are considered in this study including $\mathrm{N}\left({ }^{4} \mathrm{~S}\right), \mathrm{N}\left({ }^{2} \mathrm{D}\right),{ }^{3} \mathrm{CH}_{2}$, $\mathrm{CH}_{3}, \mathrm{NH}, \mathrm{CH}_{4}, \mathrm{NH}_{3}, \mathrm{C}_{2} \mathrm{H}_{2}, \mathrm{C}_{2} \mathrm{H}_{3}, \mathrm{HCN}, \mathrm{C}_{2} \mathrm{H}_{4}, \mathrm{~N}_{2}, \mathrm{C}_{2} \mathrm{H}_{5}$, and $\mathrm{C}_{2} \mathrm{H}_{6}$ in the order of increasing molecular mass up to $30 \mathrm{Da}$. A total number of 146 exothermic chemical reactions are evaluated, all of which are capable of producing hot neutrals with nascent kinetic energies above the respective local escape energies. These reactions fall into three categories, including 80 neutral-neutral reactions (of which 15 are three-body reactions), 31 ion-neutral reactions, and 35 DR reactions. The atmospheric and ionospheric chemical network implemented here is far more complicated than those of Cravens et al. (1997) and De La Haye et al. (2007).

Combining the state-of-the-art INMS measurements of neutral and ion densities, the RPWS LP measurements of electron density and temperature, as well as the photochemical model results of Lavvas et al. (2008a,b) updated with the improved chemical network, we are able to calculate the hot neutral production rate as a function of altitude for each species and each chemical channel in Titan's dayside upper atmosphere. A test particle Monte Carlo model is further constructed to determine the corresponding profile of escape probability under the assumption of isotropic hard sphere approximation, which properly describes the realistic dynamical behavior of escaping neutrals over a broad transition region near Titan's exobase (e.g. Strobel \& Cui 2014). Our model results are consistent with the intuitively expected trend that at any given altitude, the escape probability increases with the nascent kinetic energy and decreases with the size of the escaping particle. Calculations of the hot neutral production rate and the escape probability are combined to provide a reasonable estimate of the escape rate for each species and each channel.

Our calculations suggest a total $\mathrm{N}$ escape rate of $9.1 \times$ $10^{23} \mathrm{~s}^{-1}$ and a total $\mathrm{C}$ escape rate of $4.3 \times 10^{23} \mathrm{~s}^{-1}$ on the dayside of Titan, driven by exothermic chemistry. Total $\mathrm{N}$ escape is primarily contributed by neutral-neutral reactions, with a fractional contribution of less than 5\% from ion-neutral and DR reactions. The situation for $\mathrm{C}$ escape is different in that all categories of reaction are non-negligible, with $60 \%$ from ionneutral, $29 \%$ from neutral-neutral, and the remaining $11 \%$ from DR reactions, respectively. Meanwhile, the bulk of $\mathrm{N}$ escape is associated with hot $\mathrm{N}\left({ }^{4} \mathrm{~S}\right)$ production and driven by the quenching of excited state $\mathrm{N}\left({ }^{2} \mathrm{D}\right)$ via collisions with atmospheric $\mathrm{N}_{2}$. Such a process, denoted as $\mathrm{R}_{a} 1$ in Table A.1, accounts for $80 \%$ of dayside $\mathrm{N}$ escape on Titan. Hot NH production also contributes non-negligibly to $\mathrm{N}$ escape and plays an even more important role than hot $\mathrm{N}_{2}$ production, a result that was not obtained in previous investigations (Cravens et al. 1997; De La Haye et al. 2007). Dayside $\mathrm{C}$ escape is mostly associated with hot $\mathrm{CH}_{3}$ and
$\mathrm{CH}_{4}$ production, responsible for 27 and $63 \%$ of total $\mathrm{C}$ escape, respectively. Our calculations highlight the importance of one ion-neutral reaction: $\mathrm{R}_{e} 13$ that produces hot $\mathrm{CH}_{4}$ from $\mathrm{CH}_{5}^{+}$and $\mathrm{HCN}$, which accounts for more than $30 \%$ of dayside $\mathrm{C}$ escape on Titan. While the importance of reaction $\mathrm{R}_{a} 1$ in driving $\mathrm{N}$ escape was also obtained by De La Haye et al. (2007), the situation for $\mathrm{C}$ escape is to be distinguished in that those authors identified $\mathrm{CH}_{5}^{+} \mathrm{DR}$ as the most important chemical channel but we find it to be negligible. Such a difference is likely linked to the different choices of the DR coefficient and $\mathrm{CH}_{5}^{+}$density. It is noteworthy that the De La Haye et al. (2007) results were obtained based on the early photochemical model calculations of Keller et al. (1992) and our current understandings of Titan's atmospheric and ionospheric chemistry are much more robust (e.g. Vuitton et al. 2019).

It is instructive to compare the total dayside $\mathrm{N}$ and $\mathrm{C}$ escape rates driven by exothermic chemistry to those by other viable mechanisms, especially the non-thermal ones (Johnson et al. 2008). Specifically, $\mathrm{N}_{2}$ photodissociation is ignored in this study but existing works indicate that this process likely leads to a dayside averaged $\mathrm{N}$ escape rate much higher than the value reported here. For instance, the calculations of Shematovich et al. (2003) suggest an $\mathrm{N}$ escape rate of $9 \times 10^{24} \mathrm{~s}^{-1}$ driven by $\mathrm{N}_{2}$ photodissociation, which is an order of magnitude higher than our estimate of the chemically driven $\mathrm{N}$ escape rate. Without going into details, we remark that the photochemical model implemented in Sect. 3 leads to a comparable dayside $\mathrm{N}$ escape rate of $8 \times 10^{24} \mathrm{~s}^{-1}$ via $\mathrm{N}\left({ }^{4} \mathrm{~S}\right)$ production from $\mathrm{N}_{2}$ photodissociation, where the escape probability profile appropriate for $0.82 \mathrm{eV}$ is used, based on the mean kinetic energy release to $\mathrm{N}\left({ }^{4} \mathrm{~S}\right)$ weighted by the solar EUV/X-ray flux above the $\mathrm{N}_{2}$ dissociation threshold, for a reference altitude of $1400 \mathrm{~km}$. Photoelectron impact dissociation of $\mathrm{N}_{2}$, which was evaluated by Cravens et al. (1997), may increase further the above $\mathrm{N}$ escape rate. Similarly, we estimate the dayside $\mathrm{C}$ escape rate to be $2 \times 10^{24} \mathrm{~s}^{-1}$ via $\mathrm{CH}_{3}$ production from $\mathrm{CH}_{4}$ photodissociation, where a weighted mean kinetic energy of $0.46 \mathrm{eV}$ is used to obtain the $\mathrm{CH}_{3}$ escape probability profile. Clearly, $\mathrm{C}$ escape driven by exothermic chemistry is not negligibly small as compared to $\mathrm{C}$ escape driven by $\mathrm{CH}_{4}$ photodissociation.

Atmospheric sputtering, as another viable escape mechanism, was modelled by a number of authors based on Monte Carlo calculations (e.g. Shematovich et al. 2001, 2003; Michael et al. 2005). The sputter-induced total $\mathrm{N}$ escape rate, contributed by both $\mathrm{N}$ and $\mathrm{N}_{2}$, was predicted to be $4 \times 10^{25} \mathrm{~s}^{-1}$ by the one-dimensional calculations of Shematovich et al. (2003) and $2.5 \times 10^{25} \mathrm{~s}^{-1}$ by the three-dimensional calculations of Michael et al. (2005). Recently, Gu et al. (2019) have estimated the $\mathrm{CH}_{4}$ to- $\mathrm{N}_{2}$ sputtering yield ratio in Titan's upper atmosphere to be $10-20 \%$, which should be close to the respective ratio in escape rate. When compared with the $\mathrm{N}$ and $\mathrm{C}$ escape rates derived here, we may conclude that sputter-induced $\mathrm{N}$ and $\mathrm{C}$ escape is much stronger than chemically driven escape. However, we note that the sputter-induced escape rates quoted above are appropriate for the ramside of Titan which could be either the dayside or the nightside depending on the relative orientation between solar EUV/X-ray radiation and magnetospheric ion precipitation (Sittler et al. 2010, and references therein). This means that when Titan is in an orbital configuration with the dayside coincident with the wakeside, $\mathrm{N}$ and $\mathrm{C}$ escape driven by exothermic chemistry is likely much stronger than sputter-induced escape.

Clearly, all exothermic chemical reactions evaluated in this study, along with many other reactions ignored due to the nonescaping nature of their products, may provide an important 
heat source of Titan's upper atmosphere. For instance, the calculations of De La Haye et al. (2008) suggested that on both the dayside and nightside of the satellite, neutral heating via exothermic chemistry was dominated by ion-neutral and DR reactions above $\sim 1100 \mathrm{~km}$, by two-body neutral-neutral reactions at $\sim 750-1100 \mathrm{~km}$, and by three-body neutral-neutral reactions at lower altitudes, respectively (see their Fig. A.2). These authors estimated a peak heating rate in Titan's dayside upper atmosphere of $\sim 5 \times 10^{-9}$ ergs $\mathrm{cm}^{-3} \mathrm{~s}^{-1}$ near $950 \mathrm{~km}$ driven by exothermic chemistry, well above the peak heating rate of no more than $10^{-10}$ ergs $\mathrm{cm}^{-3} \mathrm{~s}^{-1}$ near $1050 \mathrm{~km}$ driven by photoelectron and magnetospheric electron impact. Similarly, the DR reaction of $\mathrm{O}_{2}^{+}$, the dominant species of the Venusian ionosphere (Taylor et al. 1980), was suggested to contribute significantly to dayside neutral heating, surpassing other important heating mechanisms such as the collisional quenching of excited state $\mathrm{O}\left({ }^{1} \mathrm{D}\right)$ and the photodissociation of background $\mathrm{CO}_{2}$ above $135 \mathrm{~km}$ (e.g. Fox 1988). Similar calculations as implemented here, also by virtue of the extensive Cassini INMS measurements of Titan's atmospheric neutral and ion densities (e.g. Cui et al. 2009b; Mandt et al. 2012), the improved understandings of Titan's atmospheric and ionospheric chemistry (e.g. Vuitton et al. 2019), as well as the realistic Monte Carlo modelling of energy deposition including transport (e.g. Michael \& Johnson 2005), should be able to reveal more rigorously the importance of various exothermic chemical reactions in the local energy budget of Titan's upper atmosphere, which we leave aside for follow-up investigations.

Acknowledgements. This work is supported by the Strategic Priority Research Program of the Chinese Academy of Sciences (XDA17010201). J.C. and Y.W. acknowledge supports from the National Science Foundation of China (NSFC) through grants 41525015,41774186 , and 41525016 .

\section{References}

Adams, N. G., Smith, D., Millar, T. J., \& Williams, D. A. 1988, Rate Coefficients in Astrochemistry (Kluwer, Dordrecht: Springer), 173

Angelova, G., Novotny, O., Mitchell, J. B. A., et al. 2004, Int. J. Mass Spectr., 232, 195

Anicich, V. G. 1993, J. Phys. Chem. Ref. Data, 22, 1469

Baulch, D. L., Cobos, C. J., Cox, R. A., et al. 1992, J. Phys. Chem. Ref. Data, 21, 411

Baulch, D. L., Cobos, C. J., Cox, R. A., et al. 1994, J. Phys. Chem. Ref. Data, 23 , 847

Baulch, D. L., Bowman, C. T., Cobos, C. J., et al. 2005, J. Phys. Chem. Ref. Data, 34,757

Bell, J. M., Bougher, S. W., Waite, J. H. Jr., et al. 2010, J. Geophys. Res. Planets, 115,12018

Bell, J. M., Bougher, S. W., Waite, J. H. Jr., et al. 2011, J. Geophys. Res. Planets, 116, E11002

Brown, R. L. 1973, Int. J. Chem. Kinet., 5, 663

Brownsword, R. A., Canosa, A., Rowe, B. R., et al. 1997, J. Chem. Phys., 106, 7662

Canosa, A., Sims, I. R., Travers, D., Smith, I. W. M., \& Rowe, B. R. 1997, A\&A, 323, 644

Carty, D., Le Page, V., Sims, I. R., \& Smith, I. W. M. 2001, Chem. Phys. Lett., 344,310

Chang, Y. W., \& Wang, N. S. 1995, Chem. Phys., 200, 431

Clyne, M. A., \& Stedman, D. H. 1967, J. Phys. Chem., 71, 3071

Cravens, T. E., Keller, C. N., \& Ray, B. 1997, Planet. Space Sci., 45, 889

Cravens, T. E., Robertson, I. P., Clark, J., et al. 2005, Geophys. Res. Lett., 32, L12108

Cravens, T. E., Rahmati, A., Fox, J. L., et al. 2017, J. Geophys. Res. Space Phys., 122, 1102

Cui, J., Yelle, R. V., \& Volk, K. 2008, J. Geophys. Res. Planets, 113, E10004

Cui, J., Galand, M., Yelle, R. V., et al. 2009a, J. Geophys. Res. Space Phys., 114, A06310

Cui, J., Yelle, R. V., Vuitton, V., et al. 2009b, Icarus, 200, 581

Cui, J., Yelle, R. V., Müller-Wodarg, I. C. F., Lavvas, P. P., \& Galand, M. 2011, J. Geophys. Res. Space Phys., 116, A11324
Cui, J., Yelle, R. V., Strobel, D. F., et al. 2012, J. Geophys. Res. Planets, 117, E11006

Cui, J., Cao, Y. T., Lavvas, P. P., \& Koskinen, T. T. 2016, ApJ, 826, L5

Cui, J., Wu, X. S., Gu, H., Jiang, F. Y., \& Wei, Y. 2019, A\&A, 621, A23

De La Haye, V., Waite, J. H., Cravens, T. E., et al. 2007, Icarus, 191, 236

De La Haye, V., Waite, J. H., Cravens, T. E., et al. 2008, J. Geophys. Res. Space Phys., 113, A11314

Dutuit, O., Carrasco, N., Thissen, R., et al. 2013, ApJS, 204, 20

Edwards, S. J., Freeman, C. G., \& McEwan, M. J. 2008, Int. J. Mass Spectr., 272, 86

Ehlerding, A., Hellberg, F., Thomas, R., et al. 2004, Phys. Chem. Chem. Phys., 6, 949

Ergun, R. E., Morooka, M. W., Andersson, L. A., et al. 2015, Geophys. Res. Lett., 42, 8846

Fahr, A., Laufer, A., Klein, R., \& Braun, W. 1991, J. Phys. Chem., 95, 3218

Fenghour, A., Wakeham, W. A., Vesovic, V., et al. 1995, J. Phys. Chem. Ref. Data, 24, 1649

Flynn, L. W., \& Thodos, G. 1961, J. Chem. Eng. Data, 6, 457

Fox, J. L. 1988, Planet. Space Sci., 36, 37

Fox, J. L., \& Hać, A. B. 2009, Icarus, 204, 527

Fox, J. L., \& Hać, A. B. 2014, Icarus, 228, 375

Fox, J. L., \& Hać, A. B. 2018, Icarus, 300, 411

Fox, J. L., Galand, M. I., \& Johnson, R. E. 2008, Space Sci. Rev., 139, 3

Fulle, D., \& Hippler, H. 1997, J. Chem. Phys., 106, 8691

Gannon, K. L., Glowacki, D. R., Blitz, M. A., et al. 2007, J. Phys. Chem. A, 111, 6679

Geppert, W., Ehlerding, A., Hellberg, F., et al. 2004a, Phys. Rev. Lett., 93, 153201

Geppert, W. D., Thomas, R., Ehlerding, A., et al. 2004b, Int. J. Mass Spectr., 237, 25

Goulay, F., Osborn, D. L., Taatjes, C. A., et al. 2007, Phys. Chem. Chem. Phys., 9, 4291

Gu, H., Cui, J., Niu, D. D., et al. 2019, A\&A, 623, A18

Harding, L. B., Georgievskii, Y., \& Klippenstein, S. J. 2005, J. Phys. Chem. A, 109,4646

Harding, L. B., Guadagnini, R., \& Schatz, G. C. 1993, J. Phys. Chem., 97, 5472

Hedelt, P., Ito, Y., Keller, H. U., et al. 2010, Icarus, 210, 424

Herron, J. T. 1999, J. Phys. Chem. Ref. Data, 28, 1453

Hess, W. P., Durant Jr, J. L., \& Tully, F. P. 1989, J. Phys. Chem., 93, 6402

Hoobler, R. J., \& Leone, S. R. 1997, J. Geophys. Res., 102, 28717

Hoobler, R. J., Opansky, B. J., \& Leone, S. R. 1997, J. Phys. Chem. A, 101, 1338

Hörst, S. M., Vuitton, V., \& Yelle, R. V. 2008, J. Geophys. Res. Planets, 113, E10006

Husain, D., \& Kirsch, L. J. 1971, Trans. Faraday Soc., 67, 2025

Husain, D., \& Young, A. N. 1975, J. Chem. Soc. Faraday Trans. 2 Mol. Chem. Phys., 71, 525

Jamieson, J. W. S., Brown, G. R., \& Tanner, J. S. 1970, Can. J. Chem., 48, 3619

Janev, R. K., \& Reiter, D. 2004, Phys. Plasmas, 11, 780

Jiang, F., Cui, J., \& Xu, J. 2017, AJ, 154, 271

Johnson, R. E., Combi, M. R., Fox, J. L., et al. 2008, Space Sci. Rev., 139, 355

Kalhori, S., Viggiano, A. A., Arnold, S. T., et al. 2002, A\&A, 391, 1159

Kamińska, M., Zhaunerchyk, V., Vigren, E., et al. 2010, Phys. Rev. A, 81, 062701

Keller, C. N., Cravens, T. E., \& Gan, L. 1992, J. Geophys. Res., 97, 12117

Kerr, J. A., \& Parsonage, M. J. 1972, Evaluated Kinetic Data on Gas Phase Addition Reactions (London: Butterworths)

Kinsman, A. C., \& Roscoe, J. M. 1994, Int. J. Chem. Kinet., 26, 191

Klippenstein, S. J., Harding, L. B., Ruscic, B., et al. 2009, J. Phys. Chem. A, 113, 10241

Krasnopolsky, V. A. 2014, Icarus, 236, 83

Lammer, H., \& Bauer, S. J. 1993, Planet. Space Sci., 41, 657

Larsson, M., Ehlerding, A., Geppert, W. D., et al. 2005, J. Chem. Phys., 122, 156101

Laufer, A. H., \& Fahr, A. 2004, Chem. Rev., 104, 2813

Laufer, A. H., Gardner, E. P., Kwok, T. L., \& Yung, Y. L. 1983, Icarus, 56, 560

Lavvas, P. P., Coustenis, A., \& Vardavas, I. M. 2008a, Planet. Space Sci., 56, 27

Lavvas, P. P., Coustenis, A., \& Vardavas, I. M. 2008b, Planet. Space Sci., 56, 67

Le Padellec, A., Mitchell, J. B. A., Al-Khalili, A., et al. 1999, J. Chem. Phys., 110,890

Levine, J. S., McDougal, D. S., Anderson, D. E., \& Barker, E. S. 1978, Science, 200, 1048

Loison, J.-C., Bergeat, A., Caralp, F., \& Hannachi, Y. 2006, J. Phys. Chem. A, 110,13500

Magee, B. A., Waite, J. H., Mandt, K. E., et al. 2009, Planet. Space Sci., 57, 1895

Mandt, K. E., Gell, D. A., Perry, M., et al. 2012, J. Geophys. Res. Planets, 117, E10006

Mantei, K. A., \& Bair, E. J. 1968, J. Chem. Phys., 49, 3248

McEwan, M. J., \& Anicich, V. G. 2007, Mass Spectr. Rev., 26, 281

McKee, K., Blitz, M. A., Hughes, K. J., et al. 2003, J. Phys. Chem. A, 107, 5710 
McLain, J. L., Poterya, V., Molek, C. D., Babcock, L. M., \& Adams, N. G. 2004, J. Phys. Chem. A, 108, 6704

Michael, M., \& Johnson, R. E. 2005, Planet. Space Sci., 53, 1510

Michael, M., Johnson, R. E., Leblanc, F., et al. 2005, Icarus, 175, 263

Mitchell, J. B. A. 1990, Phys. Rep., 186, 215

Monks, P. S., Nesbitt, F. L., Payne, W. A., Scanlon, M., \& Stief, L. F. 1995, J. Phys. Chem., 99, 17151

Müller-Wodarg, I. C. F., Yelle, R. V., Cui, J., \& Waite, J. H. 2008, J. Geophys. Res. Planets, 113, E10005

Murphy, J. E., Vakhtin, A. B., \& Leone, S. R. 2003, Icarus, 163, 175

Niemann, H. B., Atreya, S. K., Bauer, S. J., et al. 2005, Nature, 438, 779

Nizamov, B., \& Leone, S. R. 2004, J. Phys. Chem. A, 108, 1746

Payne, W. A., Monks, P. S., Nesbitt, F. L., \& Stief, L. J. 1996, J. Chem. Phys., 104, 9808

Peterson, J. R., Le Padellec, A., Danared, H., et al. 1998, J. Chem. Phys., 108 , 1978

Petrie, S., Chirnside, T. J., Freeman, C. G., \& McEwan, M. J. 1991, Int. J. Mass Spectr. Ion Proc., 107, 319

Petrie, S., Freeman, C. G., \& McEwan, M. J. 1992, MNRAS, 257, 438

Reisler, H., Mangir, M. S., \& Wittig, C. 1980, J. Chem. Phys., 73, 2280

Rowley, R. L., Wilding, W. V., Oscarson, J. L., \& Yang, Y. 2003, Core Edition Plus Supplements (New York: Taylor and Francis), 1

Schaufelberger, A., Wurz, P., Lammer, H., \& Kulikov, Y. N. 2012, Planet. Space Sci., 61, 79

Semaniak, J., Larson, Å., Le Padellec, A., et al. 1998, ApJ, 498, 886

Sheehan, C. H., \& St.-Maurice, J. P. 2004, J. Geophys. Res. Space Phys., 109 A03302

Shematovich, V. I., Tully, C., \& Johnson, R. E. 2001, Adv. Space Res., 27, 1875

Shematovich, V. I., Johnson, R. E., Michael, M., \& Luhmann, J. G. 2003 J. Geophys. Res. Planets, 108, 5087

Sillesen, A., Ratajczak, E., \& Pagsberg, P. 1993, Chem. Phys. Lett., 201, 171

Sims, I. R., Queffelec, J.-L., Travers, D., et al. 1993, Chem. Phys. Lett., 211, 461

Sittler, E. C., Hartle, R. E., Bertucci, C., et al. 2010, Energy Deposition Processes in Titan's Upper Atmosphere and its Induced Magnetosphere (Dordrecht: Springer), 393

Snowden, D., Yelle, R. V., Cui, J., et al. 2013, Icarus, 226, 552

Stief, L. J., Nesbitt, F. L., Payne, W. A., et al. 1995, J. Chem. Phys., 102, 5309

Stoliarov, S. I., Knyazev, V. D., \& Slagle, I. R. 2000, J. Phys. Chem. A, 104, 9687

Strobel, D. F. 2009, Icarus, 202, 632

Strobel, D. F. 2010, Icarus, 208, 878

Strobel, D. F. 2012a, Can. J. Phys., 90, 795
Strobel, D. F. 2012b, in Titan Through Time; Unlocking Titan's Past, Present and Future, eds. V. Cottini, C. Nixon, \& R. Lorenz (Washington: NASA), 89

Strobel, D. F., \& Cui, J. 2014, Titan's upper Atmosphere/Exosphere, escape Processes, and Rates (Cambridge: Cambridge University Press), 355

Taylor, H. A., Brinton, H. C., Bauer, S. J., et al. 1980, J. Geophys. Res., 85, 7765

Teng, L., \& Jones, W. E. 1972, J. Chem. Soc., Faraday Trans. 1 Phys. Chem. Condens. Phases, 68, 1267

Thomas, R. D., Hellberg, F., Neau, A., et al. 2005, Phys. Rev. A, 71, 032711

Tsang, W. 1988, J. Phys. Chem. Ref. Data, 17, 887

Tsang, W. 1991, J. Phys. Chem. Ref. Data, 20, 221

Tsang, W. 1992, J. Phys. Chem. Ref. Data, 21, 753

Tsang, W., \& Hampson, R. F. 1986, J. Phys. Chem. Ref. Data, 15, 1087

Tucker, O. J., \& Johnson, R. E. 2009, Planet. Space Sci., 57, 1889

Viggiano, A. A., Ehlerding, A., Arnold, S. T., \& Larsson, M. 2005, J. Phys. Conf. Ser., 4, 191

Vuitton, V., Doussin, J. F., Bénilan, Y., Raulin, F., \& Gazeau, M. C. 2006a, Icarus, 185, 287

Vuitton, V., Yelle, R. V., \& Anicich, V. G. 2006b, ApJ, 647, L175

Vuitton, V., Yelle, R. V., \& McEwan, M. J. 2007, Icarus, 191, 722

Vuitton, V., Yelle, R. V., \& Cui, J. 2008, J. Geophys. Res. Planets, 113, E05007

Vuitton, V., Yelle, R. V., Lavvas, P., \& Klippenstein, S. J. 2012, ApJ, 744, 11

Vuitton, V., Yelle, R. V., Klippenstein, S. J., Hörst, S. M., \& Lavvas, P. 2019, Icarus, 324, 120

Wagener, R. 1990, Z. Naturforschung Teil A, 45, 649

Wahlund, J. E., Boström, R., Gustafsson, G., et al. 2005, Science, 308, 986

Wahlund, J. E., Galand, M., Müller-Wodarg, I., et al. 2009, Planet. Space Sci., 57,1857

Waite, J. H., Niemann, H., Yelle, R. V., et al. 2005, Science, 308, 982

Wakelam, V., Loison, J. C., Herbst, E., et al. 2015, ApJS, 217, 20

Wallis, M. K. 1978, Planet. Space Sci., 26, 949

Wang, H., \& Frenklach, M. 1994, J. Phys. Chem., 98, 11465

Westlake, J. H., Bell, J. M., Waite, J. H. J., et al. 2011, J. Geophys. Res. Space Phys., 116, A03318

Wilson, E. H., \& Atreya, S. K. 2004, J. Geophys. Res. Planets, 109, E06002

Xu, Z. F., Fang, D. C., \& Fu, X. Y. 1998, Int. J. Quant. Chem., 70, 321

Yang, D. L., Yu, T., Wang, N. S., \& Lin, M. C. 1992, Chem. Phys., 160, 307

Yelle, R. V. 1991, ApJ, 383, 380

Yelle, R. V., Cui, J., \& Müller-Wodarg, I. C. F. 2008, J. Geophys. Res. Planets, 113, E10003

Zetzsch, C., \& Stuhl, F. 1981, Berichte der Bunsengesellschaft für physikalische Chemie, 85, 564

Zhu, R. S., Xu, Z. F., \& Lin, M. C. 2004, J. Chem. Phys., 120, 6566 


\section{Appendix A: Supplementary information on the hot neutral production rates and the escape probabilities}

For easy reference, we compile detailed information in this appendix on the hot neutral production rates, as well as the escape probabilities used for deriving the $\mathrm{C}$ and $\mathrm{N}$ escape fluxes. In Table A.1, we list all the 146 independent exothermic chemical reactions investigated in the present study, as well as the kinetic energy release, the rate coefficient, the escape flux referred to the surface, the fractional contribution to total $\mathrm{N}$ or $\mathrm{C}$ escape, and the appropriate references, grouped by species. We note that some reactions are repetitively listed since they are able to produce more than one escaping species. The hot neutral production rates as a function of altitude for all channels are displayed in Fig. A.1 for N-containing species and in Fig. A.2 for $\mathrm{C}$-containing species, also grouped by species. These figures provide the necessary information for deciding on the dominant channel for the production of each species considered here.

In Table A.2, we list the parameters $\left(a_{1}, a_{2}\right.$, and $\left.a_{3}\right)$ used to describe the altitude dependence of escape probability for each species and for a range of selected nascent energy according to Eq. (34) in Sect. 3. For an arbitrary nascent energy within the prescribed range, the escape probability profile could be determined with the aid of Eq. (35) using a set of parameters $\left(b_{1}\right.$, $b_{2}, b_{3}$, and $\left.b_{4}\right)$. These parameters are listed in Table A.3 for reference.

Table A.1. Information on the exothermic reactions considered in this study that potentially produce escaping $\mathrm{N}\left({ }^{4} \mathrm{~S}\right), \mathrm{N}\left({ }^{2} \mathrm{D}\right),{ }^{3} \mathrm{CH}_{2}, \mathrm{CH}_{3}, \mathrm{NH} \mathrm{CH}_{4}$, $\mathrm{NH}_{3}, \mathrm{C}_{2} \mathrm{H}_{2}, \mathrm{C}_{2} \mathrm{H}_{3}, \mathrm{HCN}, \mathrm{C}_{2} \mathrm{H}_{4}, \mathrm{~N}_{2}, \mathrm{C}_{2} \mathrm{H}_{5}$, and $\mathrm{C}_{2} \mathrm{H}_{6}$ in Titan's dayside upper atmosphere.

\begin{tabular}{|c|c|c|c|c|c|c|}
\hline No. & Reaction & $\begin{array}{c}\Delta E \\
(\mathrm{eV})\end{array}$ & $\begin{array}{c}k \\
\left(\mathrm{~cm}^{3} \mathrm{~s}^{-1}\right)\end{array}$ & $\begin{array}{l}\Phi_{\mathrm{esc}} \\
\left(\mathrm{s}^{-1}\right)\end{array}$ & $\Phi_{\mathrm{esc}} / \Phi_{\mathrm{esc}}^{(\mathrm{tot})}$ & References \\
\hline $\mathrm{R}_{a} 1 / \mathrm{R}_{j} 2$ & $\mathrm{~N}\left({ }^{2} \mathrm{D}\right)+\mathrm{N}_{2} \rightarrow \mathrm{N}\left({ }^{4} \mathrm{~S}\right)+\mathrm{N}_{2}$ & 1.58 & $1.70 \times 10^{-14}$ & $6.43 \times 10^{23}$ & 0.708 & 1 \\
\hline $\mathrm{R}_{a} 2 / \mathrm{R}_{e} 7$ & $\mathrm{NH}+\mathrm{CH}_{3} \rightarrow \mathrm{N}\left({ }^{4} \mathrm{~S}\right)+\mathrm{CH}_{4}$ & 0.67 & $1.00 \times 10^{-11}$ & $1.03 \times 10^{23}$ & 0.113 & 20 \\
\hline $\mathrm{R}_{a} 3$ & $\mathrm{~N}^{+}+\mathrm{CH}_{4} \rightarrow \mathrm{N}\left({ }^{4} \mathrm{~S}\right)+\mathrm{CH}_{4}^{+}$ & 1.08 & $5.00 \times 10^{-11}$ & $5.34 \times 10^{21}$ & $5.88 \times 10^{-3}$ & 2,10 \\
\hline $\mathrm{R}_{a} 4$ & $\mathrm{~N}^{+}+\mathrm{HCN} \rightarrow \mathrm{N}\left({ }^{4} \mathrm{~S}\right)+\mathrm{HCN}^{+}$ & 0.62 & $2.40 \times 10^{-9}$ & $8.68 \times 10^{20}$ & $9.56 \times 10^{-4}$ & 3 \\
\hline $\mathrm{R}_{a} 5$ & $\mathrm{~N}_{2}^{+}+\mathrm{e} \rightarrow \mathrm{N}\left({ }^{4} \mathrm{~S}\right)+\mathrm{N}\left({ }^{2} \mathrm{D}\right)$ & 1.73 & $1.14 \times 10^{-7}\left(300 / T_{\mathrm{e}}\right)^{0.39}$ & $2.26 \times 10^{22}$ & 0.025 & 4,5 \\
\hline $\mathrm{R}_{a} 6$ & $\mathrm{~N}_{2}^{+}+\mathrm{e} \rightarrow 2 \mathrm{~N}\left({ }^{2} \mathrm{D}\right)$ & 0.53 & $1.06 \times 10^{-7}\left(300 / T_{\mathrm{e}}\right)^{0.39}$ & $5.94 \times 10^{21}$ & $6.54 \times 10^{-4}$ & 4,5 \\
\hline $\mathrm{R}_{a} 7$ & $\mathrm{CN}^{+}+\mathrm{e} \rightarrow \mathrm{N}\left({ }^{4} \mathrm{~S}\right)+\mathrm{C}$ & 3.39 & $1.36 \times 10^{-8}\left(300 / T_{\mathrm{e}}\right)^{0.55}$ & $2.71 \times 10^{17}$ & $2.99 \times 10^{-7}$ & 6 \\
\hline $\mathrm{R}_{a} 8$ & $\mathrm{CN}^{+}+\mathrm{e} \rightarrow \mathrm{N}\left({ }^{2} \mathrm{D}\right)+\mathrm{C}$ & 2.11 & $3.26 \times 10^{-7}\left(300 / T_{\mathrm{e}}\right)^{0.55}$ & $2.88 \times 10^{18}$ & $3.17 \times 10^{-6}$ & 6 \\
\hline $\mathbf{R}_{a} 9 / \mathbf{R}_{c} 8$ & $\mathrm{~N}_{2} \mathrm{H}^{+}+\mathrm{e} \rightarrow \mathrm{N}\left({ }^{4} \mathrm{~S}\right)+\mathrm{NH}$ & 1.11 & $2.47 \times 10^{-7}\left(300 / T_{\mathrm{e}}\right)^{0.84}$ & $8.53 \times 10^{20}$ & $9.38 \times 10^{-4}$ & 7 \\
\hline $\mathrm{R}_{a} 10$ & $\mathrm{CNC}^{+}+\mathrm{e} \rightarrow \mathrm{N}\left({ }^{4} \mathrm{~S}\right)+\mathrm{C}_{2}$ & 2.03 & $2.00 \times 10^{-8}\left(300 / T_{\mathrm{e}}\right)^{0.70}$ & $7.30 \times 10^{19}$ & $8.04 \times 10^{-5}$ & 7 \\
\hline \multicolumn{7}{|c|}{${ }^{3} \mathrm{CH}_{2}$} \\
\hline $\mathrm{R}_{b} 1$ & $\mathrm{H}_{2}+\mathrm{C}+\mathrm{M} \rightarrow{ }^{3} \mathrm{CH}_{2}+\mathrm{M}$ & 2.26 & $\begin{array}{c}k_{0}=2.50 \times 10^{-28} \\
k_{\infty}=1.41 \times 10^{-11} \\
k_{\mathrm{R}}=6.00 \times 10^{-16} \\
F_{c}=0.40\end{array}$ & $4.60 \times 10^{18}$ & $1.07 \times 10^{-5}$ & 8,9 \\
\hline $\mathrm{R}_{b} 2$ & $\mathrm{~N}^{+}+\mathrm{C}_{2} \mathrm{H}_{4} \rightarrow{ }^{3} \mathrm{CH}_{2}+\mathrm{HCNH}^{+}$ & 4.13 & $1.58 \times 10^{-10}$ & $6.31 \times 10^{19}$ & $1.47 \times 10^{-4}$ & 10 \\
\hline $\mathrm{R}_{b} 3$ & $\mathrm{C}_{2} \mathrm{H}_{3}^{+}+\mathrm{e} \rightarrow{ }^{3} \mathrm{CH}_{2}+\mathrm{CH}$ & 0.67 & $1.50 \times 10^{-8}\left(300 / T_{\mathrm{e}}\right)^{0.84}$ & $4.70 \times 10^{19}$ & $1.10 \times 10^{-4}$ & 11 \\
\hline $\mathrm{R}_{b} 4$ & $\mathrm{C}_{2} \mathrm{H}_{4}^{+}+\mathrm{e} \rightarrow 2{ }^{3} \mathrm{CH}_{2}$ & 1.52 & $2.24 \times 10^{-8}\left(300 / T_{\mathrm{e}}\right)^{0.76}$ & $2.15 \times 10^{21}$ & $5.02 \times 10^{-3}$ & 12 \\
\hline $\mathrm{R}_{b} 5 / \mathrm{R}_{d} 29$ & $\mathrm{C}_{2} \mathrm{H}_{5}^{+}+\mathrm{e} \rightarrow{ }^{3} \mathrm{CH}_{2}+\mathrm{CH}_{3}$ & 2.02 & $2.08 \times 10^{-7}\left(300 / T_{\mathrm{e}}\right)^{1.20}$ & $1.51 \times 10^{22}$ & 0.035 & 13,14 \\
\hline $\mathrm{R}_{b} 6 / \mathrm{R}_{e} 20$ & $\mathrm{C}_{2} \mathrm{H}_{6}^{+}+\mathrm{e} \rightarrow{ }^{3} \mathrm{CH}_{2}+\mathrm{CH}_{4}$ & 3.98 & $4.00 \times 10^{-8}\left(300 / T_{e}\right)^{0.70}$ & $3.55 \times 10^{13}$ & $8.27 \times 10^{-12}$ & 15,16 \\
\hline $\mathrm{R}_{b} 7 / \mathrm{R}_{g} 22$ & $\mathrm{C}_{3} \mathrm{H}_{4}^{+}+\mathrm{e} \rightarrow{ }^{3} \mathrm{CH}_{2}+\mathrm{C}_{2} \mathrm{H}_{2}$ & 3.89 & $1.77 \times 10^{-7}\left(300 / T_{\mathrm{e}}\right)^{0.67}$ & $6.51 \times 10^{19}$ & $1.52 \times 10^{-4}$ & 17 \\
\hline $\mathrm{R}_{b} 8 / \mathrm{R}_{i} 5$ & $\mathrm{C}_{3} \mathrm{H}_{5}^{+}+\mathrm{e} \rightarrow{ }^{3} \mathrm{CH}_{2}+\mathrm{C}_{2} \mathrm{H}_{3}$ & 1.90 & $3.00 \times 10^{-8}\left(300 / T_{\mathrm{e}}\right)^{0.70}$ & $2.75 \times 10^{20}$ & $6.40 \times 10^{-4}$ & 15,16 \\
\hline
\end{tabular}

Notes. $\Delta E$ is the kinetic energy release, $k$ is the reaction coefficient, $T_{\mathrm{e}}$ is the electron temperature, $\Phi_{\text {esc }}$ is the escape rate of a neutral species via a certain chemical channel, $\Phi_{\text {esc }} / \Phi_{\text {esc }}^{\text {(tot) }}$ is the corresponding fractional contribution to total C or total $N$ escape. When not stated explicitly, all rate coefficients refer to a neutral temperature of $150 \mathrm{~K}$. For three-body reactions, several parameters are provided, which could be used to obtain the appropriate rate coefficients with the aid of Eqs. (1) and (2) in Sect. 2.

References. ${ }^{(1)}$ Herron (1999), ${ }^{(2)}$ Cravens et al. (1997), ${ }^{(3)}$ McEwan \& Anicich (2007), ${ }^{(4)}$ Sheehan \& St. -Maurice (2004), ${ }^{(5)}$ Peterson et al. (1998), ${ }^{(6)}$ Le Padellec et al. (1999), ${ }^{(7)}$ Wakelam et al. (2015), ${ }^{(8)}$ Husain \& Young (1975), ${ }^{(9)}$ Harding et al. (1993), ${ }^{(10)}$ Dutuit et al. (2013), ${ }^{(11)}$ Kalhori et al. (2002), ${ }^{(12)}$ Ehlerding et al. (2004), ${ }^{(13)}$ McLain et al. (2004), ${ }^{(14)}$ Geppert et al. $(2004 a),{ }^{(15)}$ Vuitton et al. (2019), ${ }^{(16)}$ Janev \& Reiter (2004), ${ }^{(17)}$ Geppert et al. (2004b), ${ }^{(18)}$ Angelova et al. (2004), ${ }^{(19)}$ Brown (1973), ${ }^{(20)}$ De La Haye et al. (2007), ${ }^{(21)}$ Payne et al. (1996), ${ }^{(22)}$ Stief et al. (1995), ${ }^{(23)}$ Xu et al. (1998), ${ }^{(24)}$ Mitchell (1990), ${ }^{(25)}$ Thomas et al. (2005), ${ }^{(26)}$ Zhu et al. (2004), ${ }^{(27)}$ Lavvas et al. (2008a), ${ }^{(28)}$ Laufer et al. (1983), ${ }^{(29)}$ Fulle \& Hippler (1997), ${ }^{(30)}$ Brownsword et al. (1997), ${ }^{(31)}$ Canosa et al. (1997), ${ }^{(32)}$ Baulch et al. (1992), ${ }^{\left({ }^{33}\right)}$ Baulch et al. (1994), ${ }^{(34)}$ Baulch et al. (2005), ${ }^{(35)}$ Kerr \& Parsonage (1972), ${ }^{(36)}$ Kinsman \& Roscoe (1994), ${ }^{(37)}$ Tsang \& Hampson (1986), ${ }^{(38)}$ Tsang (1988), ${ }^{\left({ }^{(3)}\right.}$ Tsang $(1991),{ }^{(40)}$ Tsang $(1992),{ }^{(41)}$ Sims et al. (1993), ${ }^{(42)}$ Adams et al. (1988), ${ }^{(43)}$ Anicich (1993), ${ }^{(44)}$ Vuitton et al. $(2006 a),{ }^{(45)} \mathrm{Fahr}$ et al. $(1991),{ }^{(46)} \mathrm{Hess}$ et al. $(1989),{ }^{(47)}$ Monks et al. $(1995)$, ${ }^{(48)}$ Larsson et al. (2005), ${ }^{(49)}$ Jamieson et al. (1970), ${ }^{(50)}$ Kamińska et al. $(2010),{ }^{(51)}$ Semaniak et al. (1998), ${ }^{(52)}$ Murphy et al. (2003), ${ }^{(53)}$ Hoobler et al. (1997), ${ }^{(54)}$ Zetzsch \& Stuhl (1981), ${ }^{(55)}$ Chang \& Wang (1995), ${ }^{(56)}$ Petrie et al. $(1991),{ }^{(57)}$ Petrie et al. $(1992),{ }^{(58)}$ Clyne \& Stedman $(1967),{ }^{(59)}$ Reisler et al. (1980), ${ }^{(60)}$ Hoobler \& Leone (1997), ${ }^{(61)}$ Edwards et al. $(2008),{ }^{(62)}$ Teng \& Jones (1972), ${ }^{(63)}$ Sillesen et al. (1993), ${ }^{(64)}$ Mantei \& Bair $(1968)$, ${ }^{(65)}$ Wang \& Frenklach (1994), ${ }^{(66)}$ Laufer \& Fahr (2004), ${ }^{(67)}$ Husain \& Kirsch (1971), ${ }^{(68)}$ McKee et al. (2003), ${ }^{(69)}$ Gannon et al. (2007), ${ }^{(70)}$ Loison et al. (2006), ${ }^{(71)}$ Wagener (1990), ${ }^{(72)}$ Carty et al. $(2001),{ }^{(73)}$ Goulay et al. (2007), ${ }^{(74)}$ Yang et al. (1992), ${ }^{(75)}$ Nizamov \& Leone (2004), ${ }^{(76)}$ Klippenstein et al. (2009), ${ }^{(77)}$ Vuitton et al. (2012), ${ }^{(78)}$ Stoliarov et al. (2000), ${ }^{(79)}$ Harding et al. (2005). 
Table A.1. continued.

\begin{tabular}{|c|c|c|c|c|c|c|}
\hline No. & Reaction & $\begin{array}{c}\Delta E \\
(\mathrm{eV})\end{array}$ & $\begin{array}{c}k \\
\left(\mathrm{~cm}^{3} \mathrm{~s}^{-1}\right)\end{array}$ & $\begin{array}{l}\Phi_{\mathrm{esc}} \\
\left(\mathrm{s}^{-1}\right)\end{array}$ & $\Phi_{\mathrm{esc}} / \Phi_{\mathrm{esc}}^{(\mathrm{tot})}$ & Reference \\
\hline $\mathrm{R}_{b} 9 / \mathrm{R}_{k} 28$ & $\mathrm{C}_{3} \mathrm{H}_{6}^{+}+\mathrm{e} \rightarrow{ }^{3} \mathrm{CH}_{2}+\mathrm{C}_{2} \mathrm{H}_{4}$ & 3.64 & $1.20 \times 10^{-7}\left(300 / T_{\mathrm{e}}\right)^{0.70}$ & $1.05 \times 10^{16}$ & $2.45 \times 10^{-8}$ & 18 \\
\hline $\mathrm{R}_{b} 10 / \mathrm{R}_{m} 9$ & $\mathrm{C}_{3} \mathrm{H}_{8}^{+}+\mathrm{e} \rightarrow{ }^{3} \mathrm{CH}_{2}+\mathrm{C}_{2} \mathrm{H}_{6}$ & 5.46 & $1.60 \times 10^{-7}\left(300 / T_{e}\right)^{0.70}$ & $7.76 \times 10^{19}$ & $1.81 \times 10^{-4}$ & 15 \\
\hline \multicolumn{7}{|c|}{ NH } \\
\hline $\mathrm{R}_{c} 1$ & $\mathrm{H}+\mathrm{N}+\mathrm{M} \rightarrow \mathrm{NH}+\mathrm{M}$ & 2.26 & $\begin{array}{c}k_{0}=5.00 \times 10^{-32} \\
k_{\infty}=5.00 \times 10^{-16} \\
k_{\mathrm{R}}=5.00 \times 10^{-16} \\
F_{c}=0.40\end{array}$ & $3.19 \times 10^{18}$ & $3.52 \times 10^{-6}$ & 15,19 \\
\hline $\mathrm{R}_{c} 2 / \mathrm{R}_{g} 21$ & $\mathrm{~N}\left({ }^{4} \mathrm{~S}\right)+\mathrm{C}_{2} \mathrm{H}_{3} \rightarrow \mathrm{NH}+\mathrm{C}_{2} \mathrm{H}_{2}$ & 1.23 & $1.31 \times 10^{-11}$ & $1.94 \times 10^{20}$ & $2.13 \times 10^{-4}$ & 10,21 \\
\hline $\mathrm{R}_{c} 3 / \mathbf{R}_{k} 21$ & $\mathrm{~N}\left({ }^{4} \mathrm{~S}\right)+\mathrm{C}_{2} \mathrm{H}_{5} \rightarrow \mathrm{NH}+\mathrm{C}_{2} \mathrm{H}_{4}$ & 1.25 & $7.10 \times 10^{-11}$ & $4.17 \times 10^{22}$ & 0.046 & 22 \\
\hline $\mathrm{R}_{c} 4$ & $\mathrm{~N}\left({ }^{2} \mathrm{D}\right)+\mathrm{NH}_{3} \rightarrow \mathrm{NH}+\mathrm{NH}_{2}$ & 0.59 & $5.00 \times 10^{-11}$ & $1.50 \times 10^{20}$ & $1.65 \times 10^{-4}$ & 1 \\
\hline $\mathrm{R}_{c} 5 / \mathrm{R}_{d} 19$ & $\mathrm{~N}\left({ }^{2} \mathrm{D}\right)+\mathrm{CH}_{4} \rightarrow \mathrm{NH}+\mathrm{CH}_{3}$ & 0.69 & $6.47 \times 10^{-14}$ & $2.77 \times 10^{22}$ & 0.031 & 1 \\
\hline $\mathbf{R}_{c} 6$ & $2 \mathrm{NH}_{2} \rightarrow \mathrm{NH}+\mathrm{NH}_{3}$ & 0.38 & $7.05 \times 10^{-17}$ & $3.71 \times 10^{13}$ & $4.09 \times 10^{-11}$ & 23,76 \\
\hline $\mathrm{R}_{c} 7$ & $\mathrm{NH}_{2}^{+}+\mathrm{e} \rightarrow \mathrm{NH}+\mathrm{H}$ & 0.45 & $1.29 \times 10^{-7}\left(300 / T_{\mathrm{e}}\right)^{0.50}$ & $3.42 \times 10^{18}$ & $3.76 \times 10^{-6}$ & 24,25 \\
\hline $\mathbf{R}_{c} 8 / \mathbf{R}_{a} 9$ & $\mathrm{~N}_{2} \mathrm{H}^{+}+\mathrm{e} \rightarrow \mathrm{N}\left({ }^{4} \mathrm{~S}\right)+\mathrm{NH}$ & 1.04 & $2.47 \times 10^{-7}\left(300 / T_{\mathrm{e}}\right)^{0.84}$ & $1.57 \times 10^{20}$ & $1.73 \times 10^{-4}$ & 7 \\
\hline \multicolumn{7}{|c|}{$\mathrm{CH}_{3}$} \\
\hline $\mathrm{R}_{d} 1$ & $\mathrm{H}+{ }^{3} \mathrm{CH}_{2}+\mathrm{M} \rightarrow \mathrm{CH}_{3}+\mathrm{M}$ & 2.98 & $\begin{array}{l}k_{0}=2.06 \times 10^{-29} \\
k_{\infty}=1.76 \times 10^{-9}\end{array}$ & $4.61 \times 10^{11}$ & $1.08 \times 10^{-12}$ & $27,28,29$ \\
\hline $\mathrm{R}_{d} 2$ & $\mathrm{H}_{2}+\mathrm{CH}+\mathrm{M} \rightarrow \mathrm{CH}_{3}+\mathrm{M}$ & 2.90 & $\begin{array}{c}k_{0}=1.73 \times 10^{-30} \\
k_{\infty}=1.13 \times 10^{-10} \\
k_{\mathrm{R}}=6.00 \times 10^{-16} \\
F_{c}=0.63\end{array}$ & $1.98 \times 10^{18}$ & $4.61 \times 10^{-6}$ & 15,30 \\
\hline $\mathrm{R}_{d} 3 / \mathrm{R}_{k} 3$ & $\mathrm{CH}+\mathrm{C}_{2} \mathrm{H}_{6} \rightarrow \mathrm{CH}_{3}+\mathrm{C}_{2} \mathrm{H}_{4}$ & 2.30 & $3.09 \times 10^{-10}$ & $9.04 \times 10^{20}$ & $2.11 \times 10^{-3}$ & 31,68 \\
\hline $\mathrm{R}_{d} 4$ & $\mathrm{CH}+\mathrm{C}_{3} \mathrm{H}_{8} \rightarrow \mathrm{CH}_{3}+\mathrm{C}_{3} \mathrm{H}_{6}$ & 2.41 & $9.21 \times 10^{-11}$ & $8.10 \times 10^{18}$ & $1.89 \times 10^{-6}$ & 32,70 \\
\hline $\mathrm{R}_{d} 5$ & $\mathrm{CH}+\mathrm{C}_{4} \mathrm{H}_{10} \rightarrow \mathrm{CH}_{3}+\mathrm{C}_{4} \mathrm{H}_{8}$ & 2.58 & $2.89 \times 10^{-10}$ & $7.20 \times 10^{15}$ & $1.68 \times 10^{-9}$ & 32,70 \\
\hline $\mathrm{R}_{d} 6 / \mathrm{R}_{g} 4$ & ${ }^{1} \mathrm{CH}_{2}+\mathrm{C}_{2} \mathrm{H}_{3} \rightarrow \mathrm{CH}_{3}+\mathrm{C}_{2} \mathrm{H}_{2}$ & 3.66 & $3.00 \times 10^{-11}$ & $3.23 \times 10^{18}$ & $7.53 \times 10^{-6}$ & 37 \\
\hline $\mathrm{R}_{d} 7 / \mathrm{R}_{k} 4$ & ${ }^{1} \mathrm{CH}_{2}+\mathrm{C}_{2} \mathrm{H}_{5} \rightarrow \mathrm{CH}_{3}+\mathrm{C}_{2} \mathrm{H}_{4}$ & 2.56 & $1.50 \times 10^{-11}$ & $5.09 \times 10^{19}$ & $1.19 \times 10^{-4}$ & 37 \\
\hline $\mathrm{R}_{d} 8$ & ${ }^{1} \mathrm{CH}_{2}+\mathrm{C}_{2} \mathrm{H}_{6} \rightarrow \mathrm{CH}_{3}+\mathrm{C}_{2} \mathrm{H}_{5}$ & 0.50 & $2.46 \times 10^{-10}$ & $9.25 \times 10^{20}$ & $2.16 \times 10^{-3}$ & 27,71 \\
\hline $\mathrm{R}_{d} 9$ & ${ }^{1} \mathrm{CH}_{2}+\mathrm{C}_{3} \mathrm{H}_{7} \rightarrow \mathrm{CH}_{3}+\mathrm{C}_{3} \mathrm{H}_{6}$ & 2.68 & $1.71 \times 10^{-11}$ & $3.13 \times 10^{14}$ & $7.29 \times 10^{-10}$ & 38 \\
\hline $\mathrm{R}_{d} 10 / \mathrm{R}_{g} 6$ & ${ }^{3} \mathrm{CH}_{2}+\mathrm{C}_{2} \mathrm{H}_{3} \rightarrow \mathrm{CH}_{3}+\mathrm{C}_{2} \mathrm{H}_{2}$ & 3.41 & $3.00 \times 10^{-11}$ & $4.22 \times 10^{19}$ & $9.84 \times 10^{-5}$ & 37 \\
\hline $\mathrm{R}_{d} 11 / \mathrm{R}_{k} 7$ & ${ }^{3} \mathrm{CH}_{2}+\mathrm{C}_{2} \mathrm{H}_{5} \rightarrow \mathrm{CH}_{3}+\mathrm{C}_{2} \mathrm{H}_{4}$ & 2.28 & $3.00 \times 10^{-11}$ & $1.31 \times 10^{21}$ & $3.06 \times 10^{-3}$ & 37 \\
\hline $\mathrm{R}_{d} 12$ & ${ }^{3} \mathrm{CH}_{2}+\mathrm{C}_{3} \mathrm{H}_{7} \rightarrow \mathrm{CH}_{3}+\mathrm{C}_{3} \mathrm{H}_{6}$ & 2.40 & $3.00 \times 10^{-12}$ & $6.89 \times 10^{14}$ & $1.61 \times 10^{-9}$ & 38 \\
\hline $\mathrm{R}_{d} 13$ & $\mathrm{C}_{2} \mathrm{H}+\mathrm{CH}_{4} \rightarrow \mathrm{CH}_{3}+\mathrm{C}_{2} \mathrm{H}_{2}$ & 0.73 & $4.49 \times 10^{-13}$ & $1.62 \times 10^{21}$ & $3.79 \times 10^{-3}$ & 34 \\
\hline $\mathrm{R}_{d} 14$ & $\mathrm{C}_{2} \mathrm{H}+\mathrm{C}_{2} \mathrm{H}_{5} \rightarrow \mathrm{CH}_{3}+\mathrm{C}_{3} \mathrm{H}_{3}$ & 1.44 & $3.00 \times 10^{-11}$ & $2.06 \times 10^{19}$ & $4.81 \times 10^{-5}$ & 37 \\
\hline $\mathrm{R}_{d} 15$ & $\mathrm{C}_{2} \mathrm{H}+\mathrm{CH}_{3} \mathrm{CCH} \rightarrow \mathrm{CH}_{3}+\mathrm{C}_{4} \mathrm{H}_{2}$ & 1.06 & $1.55 \times 10^{-10}$ & $2.57 \times 10^{19}$ & $5.99 \times 10^{-5}$ & 72,73 \\
\hline $\mathrm{R}_{d} 16 / \mathrm{R}_{h} 2$ & $\mathrm{~N}\left({ }^{4} \mathrm{~S}\right)+\mathrm{C}_{2} \mathrm{H}_{4} \rightarrow \mathrm{CH}_{3}+\mathrm{HCN}$ & 1.62 & $3.18 \times 10^{-16}$ & $9.70 \times 10^{19}$ & $2.26 \times 10^{-4}$ & 35 \\
\hline $\mathrm{R}_{d} 17$ & $\mathrm{~N}\left({ }^{4} \mathrm{~S}\right)+\mathrm{C}_{2} \mathrm{H}_{5} \rightarrow \mathrm{CH}_{3}+\mathrm{H} 2 \mathrm{CN}$ & 1.34 & $3.90 \times 10^{-11}$ & $2.37 \times 10^{22}$ & 0.055 & 22 \\
\hline $\mathrm{R}_{d} 18$ & $\mathrm{~N}\left({ }^{4} \mathrm{~S}\right)+\mathrm{CH}_{3} \mathrm{CCH} \rightarrow \mathrm{CH}_{3}+\mathrm{CHCN}$ & 2.25 & $8.01 \times 10^{-16}$ & $1.89 \times 10^{17}$ & $4.40 \times 10^{-7}$ & 35 \\
\hline $\mathrm{R}_{d} 19 / \mathrm{R}_{c} 5$ & $\mathrm{~N}\left({ }^{2} \mathrm{D}\right)+\mathrm{CH}_{4} \rightarrow \mathrm{CH}_{3}+\mathrm{NH}$ & 0.69 & $6.47 \times 10^{-14}$ & $2.77 \times 10^{22}$ & 0.065 & 1 \\
\hline $\mathrm{R}_{d} 20$ & $\mathrm{CN}+\mathrm{CH}_{4} \rightarrow \mathrm{CH}_{3}+\mathrm{HCN}$ & 0.50 & $6.37 \times 10^{-14}$ & $5.78 \times 10^{19}$ & $1.35 \times 10^{-4}$ & 41,69 \\
\hline $\mathrm{R}_{d} 21$ & $\mathrm{C}_{2} \mathrm{~N}+\mathrm{CH}_{4} \rightarrow \mathrm{CH}_{3}+\mathrm{CHCN}$ & 0.97 & $6.00 \times 10^{-14}$ & $2.42 \times 10^{19}$ & $5.65 \times 10^{-5}$ & 60 \\
\hline $\mathrm{R}_{d} 22$ & $\mathrm{CH}_{3} \mathrm{CN}+\mathrm{C}_{2} \mathrm{H} \rightarrow \mathrm{CH}_{3}+\mathrm{HC}_{3} \mathrm{~N}$ & 2.09 & $1.06 \times 10^{-13}$ & $1.64 \times 10^{16}$ & $3.83 \times 10^{-8}$ & 26 \\
\hline $\mathrm{R}_{d} 23$ & $\mathrm{C}_{2} \mathrm{H}_{4}^{+}+\mathrm{C}_{2} \mathrm{H}_{4} \rightarrow \mathrm{CH}_{3}+\mathrm{C}_{3} \mathrm{H}_{5}^{+}$ & 0.40 & $7.03 \times 10^{-10}$ & $4.67 \times 10^{21}$ & 0.011 & 3 \\
\hline $\mathrm{R}_{d} 24$ & $\mathrm{~N}^{+}+\mathrm{CH}_{4} \rightarrow \mathrm{CH}_{3}+\mathrm{NH}^{+}$ & 1.43 & $5.00 \times 10^{-10}$ & $1.40 \times 10^{22}$ & 0.033 & 10,26 \\
\hline $\mathrm{R}_{d} 25$ & $\mathrm{HCN}^{+}+\mathrm{CH}_{4} \rightarrow \mathrm{CH}_{3}+\mathrm{HCNH}^{+}$ & 1.90 & $1.14 \times 10^{-9}$ & $2.26 \times 10^{22}$ & 0.053 & 3 \\
\hline $\mathrm{R}_{d} 26$ & $\mathrm{CH}_{4}^{+}+\mathrm{e} \rightarrow \mathrm{CH}_{3}+\mathrm{H}$ & 0.50 & $3.08 \times 10^{-7}\left(300 / T_{\mathrm{e}}\right)^{0.66}$ & $1.44 \times 10^{20}$ & $3.37 \times 10^{-4}$ & 25 \\
\hline $\mathrm{R}_{d} 27$ & $\mathrm{C}_{2} \mathrm{H}_{3}^{+}+\mathrm{e} \rightarrow \mathrm{CH}_{3}+\mathrm{C}$ & 1.19 & $3.00 \times 10^{-9}\left(300 / T_{\mathrm{e}}\right)^{0.84}$ & $1.33 \times 10^{19}$ & $3.10 \times 10^{-5}$ & 11 \\
\hline $\mathrm{R}_{d} 28$ & $\mathrm{C}_{2} \mathrm{H}_{4}^{+}+\mathrm{e} \rightarrow \mathrm{CH}_{3}+\mathrm{CH}$ & 0.42 & $1.12 \times 10^{-8}\left(300 / T_{\mathrm{e}}\right)^{0.76}$ & $2.33 \times 10^{20}$ & $5.45 \times 10^{-5}$ & 12 \\
\hline $\mathrm{R}_{d} 29 / \mathrm{R}_{b} 5$ & $\mathrm{C}_{2} \mathrm{H}_{5}^{+}+\mathrm{e} \rightarrow \mathrm{CH}_{3}+{ }^{3} \mathrm{CH}_{2}$ & 1.89 & $2.08 \times 10^{-7}\left(300 / T_{\mathrm{e}}\right)^{1.20}$ & $1.43 \times 10^{22}$ & 0.034 & 13,14 \\
\hline $\mathrm{R}_{d} 30$ & $\mathrm{C}_{2} \mathrm{H}_{6}^{+}+\mathrm{e} \rightarrow 2 \mathrm{CH}_{3}$ & 3.40 & $8.00 \times 10^{-8}\left(300 / T_{\mathrm{e}}\right)^{0.70}$ & $1.20 \times 10^{13}$ & $2.81 \times 10^{-11}$ & 15,16 \\
\hline $\mathrm{R}_{d} 31 / \mathrm{R}_{e} 21$ & $\mathrm{C}_{2} \mathrm{H}_{7}^{+}+\mathrm{e} \rightarrow \mathrm{CH}_{3}+\mathrm{CH}_{4}$ & 4.20 & $5.00 \times 10^{-7}\left(300 / T_{\mathrm{e}}\right)^{0.70}$ & $2.38 \times 10^{20}$ & $5.56 \times 10^{-4}$ & 15 \\
\hline $\mathrm{R}_{d} 32 / \mathbf{R}_{g} 23$ & $\mathrm{C}_{3} \mathrm{H}_{5}^{+}+\mathrm{e} \rightarrow \mathrm{CH}_{3}+\mathrm{C}_{2} \mathrm{H}_{2}$ & 4.43 & $3.00 \times 10^{-8}\left(300 / T_{\mathrm{e}}\right)^{0.70}$ & $6.41 \times 10^{20}$ & $1.50 \times 10^{-3}$ & 15,16 \\
\hline $\mathrm{R}_{d} 33 / \mathrm{R}_{i} 6$ & $\mathrm{C}_{3} \mathrm{H}_{6}^{+}+\mathrm{e} \rightarrow \mathrm{CH}_{3}+\mathrm{C}_{2} \mathrm{H}_{3}$ & 3.69 & $1.20 \times 10^{-8}\left(300 / T_{\mathrm{e}}\right)^{0.70}$ & $1.07 \times 10^{15}$ & $2.50 \times 10^{-9}$ & 18 \\
\hline $\mathrm{R}_{d} 34 / \mathrm{R}_{k} 29$ & $\mathrm{C}_{3} \mathrm{H}_{7}^{+}+\mathrm{e} \rightarrow \mathrm{CH}_{3}+\mathrm{C}_{2} \mathrm{H}_{4}$ & 5.41 & $3.80 \times 10^{-8}\left(300 / T_{\mathrm{e}}\right)^{0.68}$ & $3.03 \times 10^{20}$ & $7.06 \times 10^{-4}$ & 12 \\
\hline $\mathrm{R}_{d} 35 / \mathrm{R}_{l} 7$ & $\mathrm{C}_{3} \mathrm{H}_{8}^{+}+\mathrm{e} \rightarrow \mathrm{CH}_{3}+\mathrm{C}_{2} \mathrm{H}_{5}$ & 5.31 & $1.60 \times 10^{-7}\left(300 / T_{\mathrm{e}}\right)^{0.70}$ & $7.46 \times 10^{19}$ & $1.74 \times 10^{-4}$ & 18 \\
\hline $\mathrm{R}_{d} 36 / \mathrm{R}_{m} 10$ & $\mathrm{C}_{3} \mathrm{H}_{9}^{+}+\mathrm{e} \rightarrow \mathrm{CH}_{3}+\mathrm{C}_{2} \mathrm{H}_{6}$ & 5.34 & $5.00 \times 10^{-7}\left(300 / T_{\mathrm{e}}\right)^{0.70}$ & $3.07 \times 10^{19}$ & $7.17 \times 10^{-5}$ & 15 \\
\hline $\mathrm{R}_{d} 37 / \mathrm{R}_{f} 2$ & $\mathrm{CH}_{3} \mathrm{NH}_{3}^{+}+\mathrm{e} \rightarrow \mathrm{CH}_{3}+\mathrm{NH}_{3}$ & 2.92 & $7.00 \times 10^{-7}\left(300 / T_{\mathrm{e}}\right)^{0.70}$ & $2.60 \times 10^{20}$ & $6.08 \times 10^{-4}$ & 15,42 \\
\hline
\end{tabular}


Table A.1. continued.

\begin{tabular}{|c|c|c|c|c|c|c|}
\hline No. & Reaction & $\begin{array}{c}\Delta E \\
(\mathrm{eV})\end{array}$ & $\begin{array}{c}k \\
\left(\mathrm{~cm}^{3} \mathrm{~s}^{-1}\right)\end{array}$ & $\begin{array}{l}\Phi_{\mathrm{esc}} \\
\left(\mathrm{s}^{-1}\right)\end{array}$ & $\Phi_{\mathrm{esc}} / \Phi_{\mathrm{esc}}^{(\mathrm{tot})}$ & Reference \\
\hline \multicolumn{7}{|c|}{$\mathrm{CH}_{4}$} \\
\hline $\mathrm{R}_{e} 1$ & $\mathrm{H}+\mathrm{CH}_{3}+\mathrm{M} \rightarrow \mathrm{CH}_{4}+\mathrm{M}$ & 2.87 & $\begin{array}{c}k_{0}=1.62 \times 10^{-28} \\
k_{\infty}=2.95 \times 10^{-10} \\
k_{\mathrm{R}}=1.80 \times 10^{-16} \\
F_{c}=0.56\end{array}$ & $1.36 \times 10^{18}$ & $3.17 \times 10^{-6}$ & 33,77 \\
\hline $\mathrm{R}_{e} 2 / \mathrm{R}_{g} 7$ & $\mathrm{CH}_{3}+\mathrm{C}_{2} \mathrm{H}_{3} \rightarrow \mathrm{CH}_{4}+\mathrm{C}_{2} \mathrm{H}_{2}$ & 1.88 & $1.95 \times 10^{-10}$ & $3.44 \times 10^{21}$ & $8.03 \times 10^{-3}$ & 45,78 \\
\hline $\mathrm{R}_{e} 3 / \mathrm{R}_{k} 9$ & $\mathrm{CH}_{3}+\mathrm{C}_{2} \mathrm{H}_{5} \rightarrow \mathrm{CH}_{4}+\mathrm{C}_{2} \mathrm{H}_{4}$ & 1.92 & $6.87 \times 10^{-12}$ & $4.88 \times 10^{21}$ & 0.011 & 15,26 \\
\hline $\mathrm{R}_{e} 4$ & $\mathrm{CH}_{3}+\mathrm{C}_{3} \mathrm{H}_{5} \rightarrow \mathrm{CH}_{4}+\mathrm{CH}_{2} \mathrm{CCH}_{2}$ & 1.49 & $1.56 \times 10^{-12}$ & $1.53 \times 10^{20}$ & $3.57 \times 10^{-4}$ & 39 \\
\hline $\mathrm{R}_{e} 5$ & $\mathrm{CH}_{3}+\mathrm{C}_{3} \mathrm{H}_{6} \rightarrow \mathrm{CH}_{4}+\mathrm{C}_{3} \mathrm{H}_{5}$ & 0.53 & $4.85 \times 10^{-26}$ & $2.86 \times 10^{4}$ & $6.67 \times 10^{-20}$ & 36 \\
\hline $\mathrm{R}_{e} 6$ & $\mathrm{CH}_{3}+\mathrm{C}_{3} \mathrm{H}_{7} \rightarrow \mathrm{CH}_{4}+\mathrm{C}_{3} \mathrm{H}_{6}$ & 2.19 & $1.00 \times 10^{-11}$ & $3.90 \times 10^{16}$ & $9.11 \times 10^{-8}$ & 15,38 \\
\hline $\mathrm{R}_{e} 7 / \mathrm{R}_{a} 2$ & $\mathrm{CH}_{3}+\mathrm{NH} \rightarrow \mathrm{CH}_{4}+\mathrm{N}\left({ }^{4} \mathrm{~S}\right)$ & 0.59 & $1.00 \times 10^{-11}$ & $3.88 \times 10^{22}$ & 0.091 & 20 \\
\hline $\mathrm{R}_{e} 8$ & $\mathrm{CH}_{3}^{+}+\mathrm{C}_{2} \mathrm{H}_{6} \rightarrow \mathrm{CH}_{4}+\mathrm{C}_{2} \mathrm{H}_{5}^{+}$ & 1.22 & $1.43 \times 10^{-9}$ & $5.35 \times 10^{20}$ & $1.25 \times 10^{-3}$ & 3 \\
\hline $\mathrm{R}_{e} 9$ & $\mathrm{CH}_{4}^{+}+\mathrm{C}_{2} \mathrm{H}_{2} \rightarrow \mathrm{CH}_{4}+\mathrm{C}_{2} \mathrm{H}_{2}^{+}$ & 0.67 & $1.44 \times 10^{-9}$ & $2.04 \times 10^{21}$ & $4.77 \times 10^{-3}$ & 3 \\
\hline $\mathrm{R}_{e} 10$ & $\mathrm{CH}_{4}^{+}+\mathrm{C}_{2} \mathrm{H}_{4} \rightarrow \mathrm{CH}_{4}+\mathrm{C}_{2} \mathrm{H}_{4}^{+}$ & 1.28 & $1.70 \times 10^{-9}$ & $4.17 \times 10^{21}$ & $9.73 \times 10^{-3}$ & 3 \\
\hline $\mathrm{R}_{e} 11$ & $\mathrm{CH}_{5}^{+}+\mathrm{C}_{2} \mathrm{H}_{2} \rightarrow \mathrm{CH}_{4}+\mathrm{C}_{2} \mathrm{H}_{3}^{+}$ & 0.57 & $1.48 \times 10^{-9}$ & $2.50 \times 10^{22}$ & 0.058 & 3 \\
\hline $\mathrm{R}_{e} 12$ & $\mathrm{CH}_{5}^{+}+\mathrm{C}_{2} \mathrm{H}_{4} \rightarrow \mathrm{CH}_{4}+\mathrm{C}_{2} \mathrm{H}_{5}^{+}$ & 0.84 & $1.50 \times 10^{-9}$ & $3.86 \times 10^{22}$ & 0.090 & 3 \\
\hline $\mathrm{R}_{e} 13$ & $\mathrm{CH}_{5}^{+}+\mathrm{HCN} \rightarrow \mathrm{CH}_{4}+\mathrm{HCNH}^{+}$ & 1.10 & $5.80 \times 10^{-9}$ & $1.30 \times 10^{23}$ & 0.304 & 15 \\
\hline $\mathrm{R}_{e} 14$ & $\mathrm{C}_{2} \mathrm{H}_{5}^{+}+\mathrm{C}_{2} \mathrm{H}_{2} \rightarrow \mathrm{CH}_{4}+\mathrm{c}-\mathrm{C}_{3} \mathrm{H}_{3}^{+}$ & 0.96 & $6.84 \times 10^{-11}$ & $1.50 \times 10^{21}$ & $3.51 \times 10^{-3}$ & 3 \\
\hline $\mathrm{R}_{e} 15$ & $\mathrm{C}_{2} \mathrm{H}_{5}^{+}+\mathrm{C}_{2} \mathrm{H}_{4} \rightarrow \mathrm{CH}_{4}+\mathrm{C}_{3} \mathrm{H}_{5}^{+}$ & 0.63 & $3.55 \times 10^{-10}$ & $7.83 \times 10^{21}$ & 0.018 & 3 \\
\hline $\mathrm{R}_{e} 16$ & $\mathrm{~N}^{+}+\mathrm{C}_{2} \mathrm{H}_{6} \rightarrow \mathrm{CH}_{4}+\mathrm{HCNH}^{+}$ & 6.10 & $1.60 \times 10^{-10}$ & $7.20 \times 10^{18}$ & $1.68 \times 10^{-5}$ & 10 \\
\hline $\mathrm{R}_{e} 17$ & $\mathrm{CH}_{5}^{+}+\mathrm{e} \rightarrow \mathrm{CH}_{4}+\mathrm{H}$ & 0.49 & $5.34 \times 10^{-8}\left(300 / T_{\mathrm{e}}\right)^{0.72}$ & $3.11 \times 10^{21}$ & $7.26 \times 10^{-3}$ & 50,51 \\
\hline $\mathrm{R}_{e} 18$ & $\mathrm{C}_{2} \mathrm{H}_{4}^{+}+\mathrm{e} \rightarrow \mathrm{CH}_{4}+\mathrm{C}$ & 1.92 & $5.60 \times 10^{-7}\left(300 / T_{\mathrm{e}}\right)^{1.20}$ & $3.03 \times 10^{20}$ & $7.07 \times 10^{-4}$ & 12 \\
\hline $\mathrm{R}_{e} 19$ & $\mathrm{C}_{2} \mathrm{H}_{5}^{+}+\mathrm{e} \rightarrow \mathrm{CH}_{4}+\mathrm{CH}$ & 1.79 & $1.00 \times 10^{-9}\left(300 / T_{\mathrm{e}}\right)^{0.76}$ & $6.73 \times 10^{21}$ & 0.016 & 13,14 \\
\hline $\mathrm{R}_{e} 20 / \mathrm{R}_{b} 6$ & $\mathrm{C}_{2} \mathrm{H}_{6}^{+}+\mathrm{e} \rightarrow \mathrm{CH}_{4}+{ }^{3} \mathrm{CH}_{2}$ & 3.48 & $4.00 \times 10^{-8}\left(300 / T_{\mathrm{e}}\right)^{0.70}$ & $6.17 \times 10^{12}$ & $1.44 \times 10^{-11}$ & 15,16 \\
\hline $\mathrm{R}_{e} 21 / \mathrm{R}_{d} 31$ & $\mathrm{C}_{2} \mathrm{H}_{7}^{+}+\mathrm{e} \rightarrow \mathrm{CH}_{4}+\mathrm{CH}_{3}$ & 3.94 & $5.00 \times 10^{-7}\left(300 / T_{\mathrm{e}}\right)^{0.70}$ & $2.25 \times 10^{20}$ & $5.25 \times 10^{-4}$ & 15 \\
\hline $\mathrm{R}_{e} 22$ & $\mathrm{C}_{3} \mathrm{H}_{4}^{+}+\mathrm{e} \rightarrow \mathrm{CH}_{4}+\mathrm{C}_{2}$ & 2.28 & $1.00 \times 10^{-8}\left(300 / T_{\mathrm{e}}\right)^{0.67}$ & $1.97 \times 10^{18}$ & $4.60 \times 10^{-6}$ & 17 \\
\hline $\mathrm{R}_{e} 23$ & $\mathrm{C}_{3} \mathrm{H}_{5}^{+}+\mathrm{e} \rightarrow \mathrm{CH}_{4}+\mathrm{C}_{2} \mathrm{H}$ & 3.46 & $3.00 \times 10^{-8}\left(300 / T_{\mathrm{e}}\right)^{0.70}$ & $4.83 \times 10^{20}$ & $1.13 \times 10^{-3}$ & 15,16 \\
\hline \multicolumn{7}{|c|}{$\mathrm{NH}_{3}$} \\
\hline $\mathrm{R}_{f} 1$ & $\mathrm{NH}_{2}+\mathrm{H}+\mathrm{M} \rightarrow \mathrm{NH}_{3}+\mathrm{M}$ & 1.78 & $\begin{array}{c}k_{0}=2.52 \times 10^{-28} \\
k_{\infty}=2.84 \times 10^{-10} \\
k_{\mathrm{R}}=2.82 \times 10^{-16} \\
F_{c}=0.42\end{array}$ & $6.11 \times 10^{15}$ & $6.73 \times 10^{-9}$ & $15,54,64$ \\
\hline $\mathrm{R}_{f} 2 / \mathrm{R}_{d} 37$ & $\mathrm{CH}_{3} \mathrm{NH}_{3}^{+}+\mathrm{e} \rightarrow \mathrm{NH}_{3}+\mathrm{CH}_{3}$ & 2.58 & $7.00 \times 10^{-7}\left(300 / T_{\mathrm{e}}\right)^{0.70}$ & $2.25 \times 10^{20}$ & $2.48 \times 10^{-4}$ & 15,42 \\
\hline \multicolumn{7}{|c|}{$\mathrm{C}_{2} \mathrm{H}_{2}$} \\
\hline $\mathrm{R}_{g} 1$ & $\mathrm{H}+\mathrm{C}_{2} \mathrm{H}+\mathrm{M} \rightarrow \mathrm{C}_{2} \mathrm{H}_{2}+\mathrm{M}$ & 2.99 & $\begin{array}{c}k_{0}=9.00 \times 10^{-26} \\
k_{\infty}=1.85 \times 10^{-10} \\
k_{\mathrm{R}}=1.00 \times 10^{-13} \\
F_{c}=0.40\end{array}$ & $1.66 \times 10^{15}$ & $7.74 \times 10^{-9}$ & 37,79 \\
\hline $\mathrm{R}_{g} 2$ & $\mathrm{H}+\mathrm{C}_{6} \mathrm{H}_{5} \rightarrow \mathrm{C}_{2} \mathrm{H}_{2}+\mathrm{C}_{4} \mathrm{H}_{4}$ & 2.03 & $6.08 \times 10^{-12}$ & $1.65 \times 10^{15}$ & $7.68 \times 10^{-9}$ & 65 \\
\hline $\mathrm{R}_{g} 3$ & ${ }^{1} \mathrm{CH}_{2}+\mathrm{C}_{2} \mathrm{H} \rightarrow \mathrm{C}_{2} \mathrm{H}_{2}+\mathrm{CH}$ & 1.03 & $3.00 \times 10^{-11}$ & $3.19 \times 10^{18}$ & $1.49 \times 10^{-5}$ & 37 \\
\hline $\mathrm{R}_{g} 4 / \mathrm{R}_{d} 6$ & ${ }^{1} \mathrm{CH}_{2}+\mathrm{C}_{2} \mathrm{H}_{3} \rightarrow \mathrm{C}_{2} \mathrm{H}_{2}+\mathrm{CH}_{3}$ & 2.11 & $3.00 \times 10^{-11}$ & $1.34 \times 10^{18}$ & $6.27 \times 10^{-6}$ & 37 \\
\hline $\mathrm{R}_{g} 5$ & ${ }^{3} \mathrm{CH}_{2}+\mathrm{C}_{2} \mathrm{H} \rightarrow \mathrm{C}_{2} \mathrm{H}_{2}+\mathrm{CH}$ & 0.90 & $3.00 \times 10^{-11}$ & $4.11 \times 10^{19}$ & $1.92 \times 10^{-4}$ & 37 \\
\hline $\mathrm{R}_{g} 6 / \mathrm{R}_{d} 10$ & ${ }^{3} \mathrm{CH}_{2}+\mathrm{C}_{2} \mathrm{H}_{3} \rightarrow \mathrm{C}_{2} \mathrm{H}_{2}+\mathrm{CH}_{3}$ & 1.97 & $3.00 \times 10^{-11}$ & $1.78 \times 10^{19}$ & $8.30 \times 10^{-5}$ & 37 \\
\hline $\mathrm{R}_{g} 7 / \mathrm{R}_{e} 2$ & $\mathrm{CH}_{3}+\mathrm{C}_{2} \mathrm{H}_{3} \rightarrow \mathrm{C}_{2} \mathrm{H}_{2}+\mathrm{CH}_{4}$ & 1.16 & $1.95 \times 10^{-10}$ & $1.51 \times 10^{21}$ & $7.09 \times 10^{-3}$ & 45,78 \\
\hline $\mathrm{R}_{g} 8$ & $\mathrm{C}_{2} \mathrm{H}+\mathrm{C}_{2} \mathrm{H}_{3} \rightarrow 2 \mathrm{C}_{2} \mathrm{H}_{2}$ & 2.13 & $1.60 \times 10^{-12}$ & $3.67 \times 10^{16}$ & $1.71 \times 10^{-7}$ & 37 \\
\hline $\mathrm{R}_{g} 9 / \mathrm{R}_{k} 10$ & $\mathrm{C}_{2} \mathrm{H}+\mathrm{C}_{2} \mathrm{H}_{5} \rightarrow \mathrm{C}_{2} \mathrm{H}_{2}+\mathrm{C}_{2} \mathrm{H}_{4}$ & 2.19 & $3.00 \times 10^{-12}$ & $1.40 \times 10^{18}$ & $6.55 \times 10^{-6}$ & 37 \\
\hline $\mathrm{R}_{g} 10 / \mathrm{R}_{l} 4$ & $\mathrm{C}_{2} \mathrm{H}+\mathrm{C}_{2} \mathrm{H}_{6} \rightarrow \mathrm{C}_{2} \mathrm{H}_{2}+\mathrm{C}_{2} \mathrm{H}_{5}$ & 0.73 & $4.15 \times 10^{-11}$ & $1.37 \times 10^{19}$ & $6.37 \times 10^{-5}$ & 34,52 \\
\hline $\mathrm{R}_{g} 11$ & $\mathrm{C}_{2} \mathrm{H}+\mathrm{CH}_{2} \mathrm{CCH}_{2} \rightarrow \mathrm{C}_{2} \mathrm{H}_{2}+\mathrm{C}_{3} \mathrm{H}_{3}$ & 1.16 & $2.58 \times 10^{-10}$ & $2.88 \times 10^{19}$ & $1.34 \times 10^{-4}$ & 60 \\
\hline $\mathbf{R}_{g} 12$ & $\mathrm{C}_{2} \mathrm{H}+\mathrm{C}_{3} \mathrm{H}_{5} \rightarrow \mathrm{C}_{2} \mathrm{H}_{2}+\mathrm{CH}_{2} \mathrm{CCH}_{2}$ & 2.00 & $1.20 \times 10^{-11}$ & $8.15 \times 10^{17}$ & $3.80 \times 10^{-6}$ & 39 \\
\hline $\mathbf{R}_{g} 13$ & $\mathrm{C}_{2} \mathrm{H}+\mathrm{C}_{3} \mathrm{H}_{7} \rightarrow \mathrm{C}_{2} \mathrm{H}_{2}+\mathrm{C}_{3} \mathrm{H}_{6}$ & 2.61 & $1.00 \times 10^{-11}$ & $2.71 \times 10^{13}$ & $1.27 \times 10^{-11}$ & 38 \\
\hline $\mathrm{R}_{g} 14$ & $\mathrm{C}_{2} \mathrm{H}+\mathrm{C}_{3} \mathrm{H}_{8} \rightarrow \mathrm{C}_{2} \mathrm{H}_{2}+\mathrm{C}_{3} \mathrm{H}_{7}$ & 0.93 & $6.10 \times 10^{-11}$ & $5.73 \times 10^{16}$ & $2.67 \times 10^{-7}$ & 34,52 \\
\hline $\mathbf{R}_{g} 15$ & $\mathrm{C}_{2} \mathrm{H}+\mathrm{C}_{4} \mathrm{H}_{1} 0 \rightarrow \mathrm{C}_{2} \mathrm{H}_{2}+\mathrm{C}_{4} \mathrm{H}_{9}$ & 0.88 & $1.15 \times 10^{-10}$ & $1.51 \times 10^{13}$ & $7.07 \times 10^{-11}$ & 53,75 \\
\hline $\mathrm{R}_{g} 16 / \mathrm{R}_{k} 11$ & $2 \mathrm{C}_{2} \mathrm{H}_{3} \rightarrow \mathrm{C}_{2} \mathrm{H}_{2}+\mathrm{C}_{2} \mathrm{H}_{4}$ & 1.72 & $3.50 \times 10^{-11}$ & $9.72 \times 10^{16}$ & $4.53 \times 10^{-7}$ & 66 \\
\hline $\mathrm{R}_{g} 17 / \mathrm{R}_{m} 3$ & $\mathrm{C}_{2} \mathrm{H}_{3}+\mathrm{C}_{2} \mathrm{H}_{5} \rightarrow \mathrm{C}_{2} \mathrm{H}_{2}+\mathrm{C}_{2} \mathrm{H}_{6}$ & 1.76 & $8.00 \times 10^{-13}$ & $8.96 \times 10^{16}$ & $4.18 \times 10^{-7}$ & 37 \\
\hline $\mathrm{R}_{g} 18$ & $\mathrm{C}_{2} \mathrm{H}_{3}+\mathrm{C}_{3} \mathrm{H}_{3} \rightarrow \mathrm{C}_{2} \mathrm{H}_{2}+\mathrm{CH}_{3} \mathrm{CCH}$ & 1.44 & $8.00 \times 10^{-12}$ & $3.09 \times 10^{16}$ & $1.44 \times 10^{-7}$ & 27,44 \\
\hline $\mathbf{R}_{g} 19$ & $\mathrm{C}_{2} \mathrm{H}_{3}+\mathrm{C}_{3} \mathrm{H}_{5} \rightarrow \mathrm{C}_{2} \mathrm{H}_{2}+\mathrm{C}_{3} \mathrm{H}_{6}$ & 1.43 & $8.00 \times 10^{-12}$ & $1.17 \times 10^{17}$ & $5.44 \times 10^{-7}$ & 39 \\
\hline $\mathrm{R}_{g} 20$ & $\mathrm{C}_{2} \mathrm{H}_{3}+\mathrm{C}_{3} \mathrm{H}_{7} \rightarrow \mathrm{C}_{2} \mathrm{H}_{2}+\mathrm{C}_{3} \mathrm{H}_{8}$ & 1.73 & $2.00 \times 10^{-12}$ & $1.03 \times 10^{12}$ & $4.79 \times 10^{-12}$ & 38 \\
\hline
\end{tabular}


Table A.1. continued.

\begin{tabular}{|c|c|c|c|c|c|c|}
\hline No. & Reaction & $\begin{array}{c}\Delta E \\
(\mathrm{eV})\end{array}$ & $\begin{array}{c}k \\
\left(\mathrm{~cm}^{3} \mathrm{~s}^{-1}\right) \\
\end{array}$ & $\begin{array}{l}\Phi_{\text {esc }} \\
\left(\mathrm{s}^{-1}\right) \\
\end{array}$ & $\Phi_{\mathrm{esc}} / \Phi_{\mathrm{esc}}^{(\mathrm{tot})}$ & Reference \\
\hline $\mathrm{R}_{g} 21 / \mathbf{R}_{c} 2$ & $\mathrm{~N}\left({ }^{4} \mathrm{~S}\right)+\mathrm{C}_{2} \mathrm{H}_{3} \rightarrow \mathrm{C}_{2} \mathrm{H}_{2}+\mathrm{NH}$ & 0.71 & $1.31 \times 10^{-11}$ & $7.88 \times 10^{19}$ & $3.68 \times 10^{-4}$ & 10,21 \\
\hline $\mathrm{R}_{g} 22 / \mathrm{R}_{b} 7$ & $\mathrm{C}_{3} \mathrm{H}_{4}^{+}+\mathrm{e} \rightarrow \mathrm{C}_{2} \mathrm{H}_{2}+{ }^{3} \mathrm{CH}_{2}$ & 2.09 & $1.77 \times 10^{-7}\left(300 / T_{\mathrm{e}}\right)^{0.67}$ & $1.37 \times 10^{19}$ & $6.40 \times 10^{-5}$ & 17 \\
\hline $\mathrm{R}_{g} 23 / \mathbf{R}_{d} 32$ & $\mathrm{C}_{3} \mathrm{H}_{5}^{+}+\mathrm{e} \rightarrow \mathrm{C}_{2} \mathrm{H}_{2}+\mathrm{CH}_{3}$ & 2.56 & $3.00 \times 10^{-8}\left(300 / T_{\mathrm{e}}\right)^{0.70}$ & $1.71 \times 10^{20}$ & $8.00 \times 10^{-4}$ & 15,16 \\
\hline \multicolumn{7}{|c|}{$\mathrm{HCN}$} \\
\hline $\mathrm{R}_{h} 1$ & $\mathrm{H}+\mathrm{CN}+\mathrm{M} \rightarrow \mathrm{HCN}+\mathrm{M}$ & 2.74 & $\begin{array}{c}k_{0}=8.78 \times 10^{-31} \\
k_{\infty}=2.44 \times 10^{-10} \\
k_{\mathrm{R}}=1.00 \times 10^{-13} \\
F_{c}=0.40\end{array}$ & $3.94 \times 10^{16}$ & $4.33 \times 10^{-8} / 9.19 \times 10^{-8}$ & 40 \\
\hline $\mathrm{R}_{h} 2 / \mathrm{R}_{d} 16$ & $\mathrm{~N}\left({ }^{4} \mathrm{~S}\right)+\mathrm{C}_{2} \mathrm{H}_{4} \rightarrow \mathrm{HCN}+\mathrm{CH}_{3}$ & 0.90 & $3.18 \times 10^{-16}$ & $1.62 \times 10^{18}$ & $1.78 \times 10^{-6} / 3.78 \times 10^{-5}$ & 35 \\
\hline $\mathrm{R}_{h} 3$ & $\mathrm{CN}+\mathrm{C}_{3} \mathrm{H}_{8} \rightarrow \mathrm{HCN}+\mathrm{C}_{3} \mathrm{H}_{7}$ & 0.67 & $1.18 \times 10^{-10}$ & $9.91 \times 10^{15}$ & $1.09 \times 10^{-8} / 2.31 \times 10^{-9}$ & 46,74 \\
\hline $\mathrm{R}_{h} 4$ & $\mathrm{CN}+\mathrm{CH}_{2} \mathrm{NH} \rightarrow \mathrm{HCN}+\mathrm{H}_{2} \mathrm{CN}$ & 0.76 & $2.80 \times 10^{-11}$ & $3.30 \times 10^{17}$ & $3.62 \times 10^{-7} / 7.70 \times 10^{-7}$ & 55,75 \\
\hline $\mathrm{R}_{h} 5$ & $\mathrm{CH}_{3}^{+}+\mathrm{HC}_{3} \mathrm{~N} \rightarrow \mathrm{HCN}+\mathrm{c}-\mathrm{C}_{3} \mathrm{H}_{3}^{+}$ & 1.45 & $1.43 \times 10^{-9}$ & $2.53 \times 10^{17}$ & $2.79 \times 10^{-7} / 5.91 \times 10^{-7}$ & 3 \\
\hline $\mathrm{R}_{h} 6$ & $\mathrm{CN}^{+}+\mathrm{CH}_{4} \rightarrow \mathrm{HCN}+\mathrm{CH}_{3}^{+}$ & 1.83 & $5.00 \times 10^{-10}$ & $3.51 \times 10^{18}$ & $3.86 \times 10^{-6} / 8.19 \times 10^{-6}$ & 3 \\
\hline $\mathrm{R}_{h} 7$ & $\mathrm{HCN}^{+}+\mathrm{C}_{2} \mathrm{H}_{2} \rightarrow \mathrm{HCN}+\mathrm{C}_{2} \mathrm{H}_{2}^{+}$ & 1.07 & $1.15 \times 10^{-9}$ & $1.37 \times 10^{19}$ & $1.51 \times 10^{-5} / 3.20 \times 10^{-5}$ & 3 \\
\hline $\mathrm{R}_{h} 8$ & $\mathrm{CNC}^{+}+\mathrm{C}_{2} \mathrm{H}_{4} \rightarrow \mathrm{HCN}+\mathrm{c}-\mathrm{C}_{3} \mathrm{H}_{3}^{+}$ & 2.86 & $1.95 \times 10^{-10}$ & $1.07 \times 10^{18}$ & $1.18 \times 10^{-6} / 2.50 \times 10^{-6}$ & 43 \\
\hline $\mathrm{R}_{h} 9$ & $\mathrm{HCNH}^{+}+\mathrm{C}_{3} \mathrm{H}_{3} \mathrm{~N} \rightarrow \mathrm{HCN}+\mathrm{C}_{3} \mathrm{H}_{4} \mathrm{~N}^{+}$ & 1.14 & $4.50 \times 10^{-9}$ & $2.02 \times 10^{18}$ & $2.22 \times 10^{-6} / 4.70 \times 10^{-6}$ & 56,57 \\
\hline \multicolumn{7}{|c|}{$\mathrm{C}_{2} \mathrm{H}_{3}$} \\
\hline $\mathrm{R}_{i} 1$ & $\mathrm{H}+\mathrm{C}_{2} \mathrm{H}_{2}+\mathrm{M} \rightarrow \mathrm{C}_{2} \mathrm{H}_{3}+\mathrm{M}$ & 0.77 & $\begin{array}{c}k_{0}=5.88 \times 10^{-30} \\
k_{\infty}=3.74 \times 10^{-15} \\
k_{\mathrm{R}}=2.16 \times 10^{-18} \\
F_{c}=0.18\end{array}$ & $3.79 \times 10^{13}$ & $1.77 \times 10^{-10}$ & 32,77 \\
\hline $\mathrm{R}_{i} 2 / \mathrm{R}_{k} 5$ & ${ }^{1} \mathrm{CH}_{2}+\mathrm{C}_{3} \mathrm{H}_{5} \rightarrow \mathrm{C}_{2} \mathrm{H}_{3}+\mathrm{C}_{2} \mathrm{H}_{4}$ & 1.25 & $6.67 \times 10^{-11}$ & $1.34 \times 10^{19}$ & $6.07 \times 10^{-5}$ & 39 \\
\hline $\mathrm{R}_{i} 3$ & $\mathrm{C}_{2} \mathrm{H}_{3} \mathrm{CN}+\mathrm{C}_{2} \rightarrow \mathrm{C}_{2} \mathrm{H}_{3}+\mathrm{C}_{3} \mathrm{~N}$ & 1.62 & $4.4 \times 10^{-10}$ & $3.53 \times 10^{15}$ & $1.65 \times 10^{-8}$ & 49,59 \\
\hline $\mathrm{R}_{i} 4$ & $\mathrm{C}_{3} \mathrm{H}_{4}^{+}+\mathrm{e} \rightarrow \mathrm{C}_{2} \mathrm{H}_{3}+\mathrm{CH}$ & 2.09 & $2.95 \times 10^{-8}\left(300 / T_{\mathrm{e}}\right)^{0.67}$ & $4.51 \times 10^{18}$ & $2.10 \times 10^{-5}$ & 17 \\
\hline $\mathrm{R}_{i} 5 / \mathrm{R}_{b} 8$ & $\mathrm{C}_{3} \mathrm{H}_{5}^{+}+\mathrm{e} \rightarrow \mathrm{C}_{2} \mathrm{H}_{3}+{ }^{3} \mathrm{CH}_{2}$ & 0.99 & $3.00 \times 10^{-8}\left(300 / T_{\mathrm{e}}\right)^{0.70}$ & $8.31 \times 10^{19}$ & $3.37 \times 10^{-4}$ & 15,16 \\
\hline $\mathrm{R}_{i} 6 / \mathrm{R}_{d} 33$ & $\mathrm{C}_{3} \mathrm{H}_{6}^{+}+\mathrm{e} \rightarrow \mathrm{C}_{2} \mathrm{H}_{3}+\mathrm{CH}_{3}$ & 2.05 & $1.20 \times 10^{-8}\left(300 / T_{\mathrm{e}}\right)^{0.70}$ & $4.70 \times 10^{14}$ & $1.92 \times 10^{-8}$ & 18 \\
\hline $\mathrm{R}_{i} 7 / \mathrm{R}_{m} 11$ & $\mathrm{C}_{4} \mathrm{H}_{9}^{+}+\mathrm{e} \rightarrow \mathrm{C}_{2} \mathrm{H}_{3}+\mathrm{C}_{2} \mathrm{H}_{6}$ & 3.69 & $8.70 \times 10^{-9}\left(300 / T_{\mathrm{e}}\right)^{0.59}$ & $8.15 \times 10^{18}$ & $3.81 \times 10^{-5}$ & 18,48 \\
\hline \multicolumn{7}{|c|}{$\mathrm{N}_{2}$} \\
\hline $\mathrm{R}_{j} 1$ & $2 \mathrm{~N}\left({ }^{4} S\right)+\mathrm{M} \rightarrow \mathrm{N}_{2}+\mathrm{M}$ & 4.91 & $\begin{array}{c}k_{0}=4.46 \times 10^{-32} \\
k_{\infty}=5.00 \times 10^{-16} \\
k_{\mathrm{R}}=5.00 \times 10^{-16} \\
F_{c}=0.40\end{array}$ & $4.63 \times 10^{19}$ & $1.02 \times 10^{-4}$ & 58 \\
\hline $\mathrm{R}_{j} 2 / \mathrm{R}_{a} 1$ & $\mathrm{~N}\left({ }^{2} \mathrm{D}\right)+\mathrm{N}_{2} \rightarrow \mathrm{N}_{2}+\mathrm{N}\left({ }^{4} \mathrm{~S}\right)$ & 0.79 & $1.70 \times 10^{-14}$ & $2.53 \times 10^{22}$ & 0.056 & 1 \\
\hline $\mathrm{R}_{j} 3$ & $\mathrm{~N}^{+}+\mathrm{HCN} \rightarrow \mathrm{N}_{2}+\mathrm{CH}^{+}$ & 1.28 & $1.29 \times 10^{-9}$ & $1.11 \times 10^{20}$ & $2.43 \times 10^{-4}$ & 3 \\
\hline $\mathrm{R}_{j} 4$ & $\mathrm{~N}_{2}^{+}+\mathrm{C}_{2} \mathrm{H}_{2} \rightarrow \mathrm{N}_{2}+\mathrm{C}_{2} \mathrm{H}_{2}^{+}$ & 2.02 & $9.40 \times 10^{-10}$ & $1.93 \times 10^{21}$ & $4.26 \times 10^{-3}$ & 10 \\
\hline $\mathrm{R}_{j} 5$ & $\mathrm{~N}_{2}^{+}+\mathrm{HCN} \rightarrow \mathrm{N}_{2}+\mathrm{HCN}^{+}$ & 0.99 & $3.90 \times 10^{-10}$ & $4.31 \times 10^{20}$ & $9.48 \times 10^{-4}$ & 3 \\
\hline $\mathrm{R}_{j} 6$ & $\mathrm{~N}_{2} \mathrm{H}^{+}+\mathrm{HCN} \rightarrow \mathrm{N}_{2}+\mathrm{HCNH}^{+}$ & 1.16 & $3.20 \times 10^{-9}$ & $4.48 \times 10^{20}$ & $9.86 \times 10^{-4}$ & 3 \\
\hline \multicolumn{7}{|c|}{$\mathrm{C}_{2} \mathrm{H}_{4}$} \\
\hline $\mathrm{R}_{k} 1$ & $\mathrm{H}+\mathrm{C}_{2} \mathrm{H}_{3}+\mathrm{M} \rightarrow \mathrm{C}_{2} \mathrm{H}_{4}+\mathrm{M}$ & 2.40 & $\begin{array}{l}k_{0}=8.54 \times 10^{-27} \\
k_{\infty}=1.76 \times 10^{-10}\end{array}$ & $1.51 \times 10^{12}$ & $7.08 \times 10^{-12}$ & 47 \\
\hline $\mathrm{R}_{k} 2$ & $\mathrm{C}+\mathrm{CH}_{4}+\mathrm{M} \rightarrow \mathrm{C}_{2} \mathrm{H}_{4}+\mathrm{M}$ & 3.06 & $2.00 \times 10^{-15}$ & $4.37 \times 10^{19}$ & $2.04 \times 10^{-4}$ & 67 \\
\hline $\mathrm{R}_{k} 3 / \mathrm{R}_{d} 3$ & $\mathrm{CH}+\mathrm{C}_{2} \mathrm{H}_{6} \rightarrow \mathrm{C}_{2} \mathrm{H}_{4}+\mathrm{CH}_{3}$ & 1.23 & $3.09 \times 10^{-10}$ & $4.13 \times 10^{20}$ & $1.93 \times 10^{-3}$ & 31,68 \\
\hline $\mathrm{R}_{k} 4 / \mathrm{R}_{d} 7$ & ${ }^{1} \mathrm{CH}_{2}+\mathrm{C}_{2} \mathrm{H}_{5} \rightarrow \mathrm{C}_{2} \mathrm{H}_{4}+\mathrm{CH}_{3}$ & 1.37 & $1.50 \times 10^{-11}$ & $2.41 \times 10^{19}$ & $1.13 \times 10^{-4}$ & 37 \\
\hline $\mathrm{R}_{k} 5 / \mathrm{R}_{i} 2$ & ${ }^{1} \mathrm{CH}_{2}+\mathrm{C}_{3} \mathrm{H}_{5} \rightarrow \mathrm{C}_{2} \mathrm{H}_{4}+\mathrm{C}_{2} \mathrm{H}_{3}$ & 1.21 & $6.67 \times 10^{-11}$ & $1.30 \times 10^{19}$ & $6.26 \times 10^{-5}$ & 39 \\
\hline $\mathrm{R}_{k} 6 / \mathrm{R}_{l} 2$ & ${ }^{1} \mathrm{CH}_{2}+\mathrm{C}_{3} \mathrm{H}_{7} \rightarrow \mathrm{C}_{2} \mathrm{H}_{4}+\mathrm{C}_{2} \mathrm{H}_{5}$ & 1.82 & $4.29 \times 10^{-11}$ & $4.26 \times 10^{14}$ & $1.99 \times 10^{-9}$ & 38 \\
\hline $\mathrm{R}_{k} 7 / \mathrm{R}_{d} 11$ & ${ }^{3} \mathrm{CH}_{2}+\mathrm{C}_{2} \mathrm{H}_{5} \rightarrow \mathrm{C}_{2} \mathrm{H}_{4}+\mathrm{CH}_{3}$ & 1.22 & $3.00 \times 10^{-11}$ & $5.99 \times 10^{20}$ & $2.79 \times 10^{-3}$ & 37 \\
\hline $\mathrm{R}_{k} 8 / \mathrm{R}_{l} 3$ & ${ }^{3} \mathrm{CH}_{2}+\mathrm{C}_{3} \mathrm{H}_{7} \rightarrow \mathrm{C}_{2} \mathrm{H}_{4}+\mathrm{C}_{2} \mathrm{H}_{5}$ & 1.62 & $3.00 \times 10^{-12}$ & $3.48 \times 10^{14}$ & $1.62 \times 10^{-9}$ & 38 \\
\hline $\mathrm{R}_{k} 9 / \mathrm{R}_{e} 3$ & $\mathrm{CH}_{3}+\mathrm{C}_{2} \mathrm{H}_{5} \rightarrow \mathrm{C}_{2} \mathrm{H}_{4}+\mathrm{CH}_{4}$ & 1.10 & $6.87 \times 10^{-12}$ & $2.27 \times 10^{21}$ & 0.011 & 15,26 \\
\hline $\mathrm{R}_{k} 10 / \mathrm{R}_{g} 9$ & $\mathrm{C}_{2} \mathrm{H}+\mathrm{C}_{2} \mathrm{H}_{5} \rightarrow \mathrm{C}_{2} \mathrm{H}_{4}+\mathrm{C}_{2} \mathrm{H}_{2}$ & 2.03 & $3.00 \times 10^{-12}$ & $2.09 \times 10^{18}$ & $9.74 \times 10^{-6}$ & 37 \\
\hline $\mathrm{R}_{k} 11 / \mathrm{R}_{g} 16$ & $\mathrm{C}_{2} \mathrm{H}_{3}+\mathrm{C}_{2} \mathrm{H}_{3} \rightarrow \mathrm{C}_{2} \mathrm{H}_{4}+\mathrm{C}_{2} \mathrm{H}_{2}$ & 1.60 & $3.50 \times 10^{-11}$ & $1.27 \times 10^{17}$ & $5.91 \times 10^{-7}$ & 66 \\
\hline $\mathrm{R}_{k} 12$ & $\mathrm{C}_{2} \mathrm{H}_{3}+\mathrm{C}_{2} \mathrm{H}_{5} \rightarrow 2 \mathrm{C}_{2} \mathrm{H}_{4}$ & 1.64 & $1.50 \times 10^{-11}$ & $2.40 \times 10^{17}$ & $2.10 \times 10^{-5}$ & 66 \\
\hline $\mathrm{R}_{k} 13$ & $\mathrm{C}_{2} \mathrm{H}_{3}+\mathrm{C}_{3} \mathrm{H}_{5} \rightarrow \mathrm{C}_{2} \mathrm{H}_{4}+\mathrm{CH}_{2} \mathrm{CCH}_{2}$ & 1.39 & $4.00 \times 10^{-12}$ & $8.05 \times 10^{16}$ & $3.76 \times 10^{-7}$ & 39 \\
\hline $\mathrm{R}_{k} 14$ & $\mathrm{C}_{2} \mathrm{H}_{3}+\mathrm{C}_{3} \mathrm{H}_{7} \rightarrow \mathrm{C}_{2} \mathrm{H}_{4}+\mathrm{C}_{3} \mathrm{H}_{6}$ & 1.97 & $2.00 \times 10^{-12}$ & $2.31 \times 10^{12}$ & $1.08 \times 10^{-11}$ & 38 \\
\hline $\mathrm{R}_{k} 15$ & $\mathrm{C}_{2} \mathrm{H}_{3}+\mathrm{C}_{4} \mathrm{H}_{3} \rightarrow \mathrm{C}_{2} \mathrm{H}_{4}+\mathrm{C}_{4} \mathrm{H}_{2}$ & 2.07 & $1.75 \times 10^{-12}$ & $1.15 \times 10^{15}$ & $5.38 \times 10^{-9}$ & 27 \\
\hline $\mathrm{R}_{k} 16 / \mathrm{R}_{m} 4$ & $2 \mathrm{C}_{2} \mathrm{H}_{5} \rightarrow \mathrm{C}_{2} \mathrm{H}_{4}+\mathrm{C}_{2} \mathrm{H}_{6}$ & 1.44 & $2.40 \times 10^{-12}$ & $1.24 \times 10^{19}$ & $5.81 \times 10^{-5}$ & 33 \\
\hline $\mathrm{R}_{k} 17$ & $\mathrm{C}_{2} \mathrm{H}_{5}+\mathrm{C}_{3} \mathrm{H}_{3} \rightarrow \mathrm{C}_{2} \mathrm{H}_{4}+\mathrm{CH}_{3} \mathrm{CCH}$ & 1.37 & $6.68 \times 10^{-12}$ & $1.39 \times 10^{18}$ & $6.48 \times 10^{-6}$ & 37,44 \\
\hline
\end{tabular}

A8, page 16 of 20 
Table A.1. continued.

\begin{tabular}{|c|c|c|c|c|c|c|}
\hline No. & Reaction & $\begin{array}{c}\Delta E \\
(\mathrm{eV})\end{array}$ & $\begin{array}{c}k \\
\left(\mathrm{~cm}^{3} \mathrm{~s}^{-1}\right) \\
\end{array}$ & $\begin{array}{l}\Phi_{\mathrm{esc}} \\
\left(\mathrm{s}^{-1}\right) \\
\end{array}$ & $\Phi_{\mathrm{esc}} / \Phi_{\mathrm{esc}}^{(\mathrm{tot})}$ & Reference \\
\hline $\mathrm{R}_{k} 18$ & $\mathrm{C}_{2} \mathrm{H}_{5}+\mathrm{C}_{3} \mathrm{H}_{5} \rightarrow \mathrm{C}_{2} \mathrm{H}_{4}+\mathrm{C}_{3} \mathrm{H}_{6}$ & 1.36 & $6.68 \times 10^{-12}$ & $5.27 \times 10^{18}$ & $2.46 \times 10^{-5}$ & 34 \\
\hline $\mathrm{R}_{k} 19$ & $\mathrm{C}_{2} \mathrm{H}_{5}+\mathrm{C}_{3} \mathrm{H}_{7} \rightarrow \mathrm{C}_{2} \mathrm{H}_{4}+\mathrm{C}_{3} \mathrm{H}_{8}$ & 1.67 & $5.00 \times 10^{-11}$ & $6.37 \times 10^{13}$ & $7.82 \times 10^{-9}$ & 15,38 \\
\hline $\mathrm{R}_{k} 20$ & $\mathrm{C}_{2} \mathrm{H}_{5}+\mathrm{C}_{4} \mathrm{H}_{3} \rightarrow \mathrm{C}_{2} \mathrm{H}_{4}+\mathrm{C}_{4} \mathrm{H}_{4}$ & 2.13 & $8.00 \times 10^{-13}$ & $4.50 \times 10^{8}$ & $2.10 \times 10^{-15}$ & 27 \\
\hline $\mathrm{R}_{k} 21 / \mathrm{R}_{c} 3$ & $\mathrm{~N}\left({ }^{4} \mathrm{~S}\right)+\mathrm{C}_{2} \mathrm{H}_{5} \rightarrow \mathrm{C}_{2} \mathrm{H}_{4}+\mathrm{NH}$ & 0.67 & $7.10 \times 10^{-11}$ & $1.87 \times 10^{15}$ & $8.73 \times 10^{-9}$ & 22 \\
\hline $\mathrm{R}_{k} 22$ & $\mathrm{C}_{2} \mathrm{H}_{5}^{+}+\mathrm{NH}_{3} \rightarrow \mathrm{C}_{2} \mathrm{H}_{4}+\mathrm{NH}_{4}^{+}$ & 0.89 & $2.09 \times 10^{-9}$ & $4.22 \times 10^{19}$ & $1.97 \times 10^{-4}$ & 43 \\
\hline $\mathrm{R}_{k} 23$ & $\mathrm{C}_{2} \mathrm{H}_{5}^{+}+\mathrm{CH}_{2} \mathrm{NH} \rightarrow \mathrm{C}_{2} \mathrm{H}_{4}+\mathrm{CH}_{2} \mathrm{NH}_{2}^{+}$ & 1.03 & $2.57 \times 10^{-9}$ & $5.40 \times 10^{20}$ & $2.52 \times 10^{-3}$ & 61 \\
\hline $\mathrm{R}_{k} 24$ & $\mathrm{C}_{2} \mathrm{H}_{5}^{+}+\mathrm{CH}_{3} \mathrm{CN} \rightarrow \mathrm{C}_{2} \mathrm{H}_{4}+\mathrm{CH}_{4} \mathrm{CN}^{+}$ & 1.58 & $3.80 \times 10^{-9}$ & $3.64 \times 10^{20}$ & $1.70 \times 10^{-3}$ & 3 \\
\hline $\mathrm{R}_{k} 25$ & $\mathrm{C}_{2} \mathrm{H}_{5}^{+}+\mathrm{HC}_{3} \mathrm{~N} \rightarrow \mathrm{C}_{2} \mathrm{H}_{4}+\mathrm{HC}_{3} \mathrm{NH}^{+}$ & 0.75 & $3.55 \times 10^{-9}$ & $7.39 \times 10^{18}$ & $3.45 \times 10^{-5}$ & 3 \\
\hline $\mathrm{R}_{k} 26$ & $\mathrm{C}_{2} \mathrm{H}_{5}^{+}+\mathrm{C}_{3} \mathrm{H}_{3} \mathrm{~N} \rightarrow \mathrm{C}_{2} \mathrm{H}_{4}+\mathrm{C}_{3} \mathrm{H}_{3} \mathrm{NH}^{+}$ & 1.51 & $5.80 \times 10^{-9}$ & $2.35 \times 10^{19}$ & $1.10 \times 10^{-4}$ & 15 \\
\hline $\mathrm{R}_{k} 27$ & $\mathrm{C}_{2} \mathrm{H}_{5}^{+}+\mathrm{C}_{3} \mathrm{H}_{5} \mathrm{~N} \rightarrow \mathrm{C}_{2} \mathrm{H}_{4}+\mathrm{C}_{3} \mathrm{H}_{5} \mathrm{NH}^{+}$ & 1.10 & $6.00 \times 10^{-9}$ & $2.10 \times 10^{16}$ & $9.81 \times 10^{-8}$ & 15 \\
\hline $\mathrm{R}_{k} 28 / \mathrm{R}_{b} 9$ & $\mathrm{C}_{3} \mathrm{H}_{6}^{+}+\mathrm{e} \rightarrow \mathrm{C}_{2} \mathrm{H}_{4}+{ }^{3} \mathrm{CH}_{2}$ & 1.82 & $1.20 \times 10^{-7}\left(300 / T_{\mathrm{e}}\right)^{0.70}$ & $3.81 \times 10^{15}$ & $1.78 \times 10^{-8}$ & 18 \\
\hline $\mathrm{R}_{k} 29 / \mathrm{R}_{d} 34$ & $\mathrm{C}_{3} \mathrm{H}_{7}^{+}+\mathrm{e} \rightarrow \mathrm{C}_{2} \mathrm{H}_{4}+\mathrm{CH}_{3}$ & 2.90 & $3.80 \times 10^{-8}\left(300 / T_{\mathrm{e}}\right)^{0.68}$ & $1.56 \times 10^{20}$ & $7.27 \times 10^{-4}$ & 12 \\
\hline \multicolumn{7}{|c|}{$\mathrm{C}_{2} \mathrm{H}_{5}$} \\
\hline $\mathrm{R}_{l} 1$ & $\mathrm{H}+\mathrm{C}_{2} \mathrm{H}_{4}+\mathrm{M} \rightarrow \mathrm{C}_{2} \mathrm{H}_{5}+\mathrm{M}$ & 0.77 & $\begin{array}{c}k_{0}=1.64 \times 10^{-28} \\
k_{\infty}=4.85 \times 10^{-14} \\
k_{\mathrm{R}}=5.62 \times 10^{-17} \\
F_{c}=0.20\end{array}$ & $2.85 \times 10^{16}$ & $1.33 \times 10^{-7}$ & 34,77 \\
\hline $\mathrm{R}_{l} 2 / \mathrm{R}_{k} 6$ & ${ }^{1} \mathrm{CH}_{2}+\mathrm{C}_{3} \mathrm{H}_{7} \rightarrow \mathrm{C}_{2} \mathrm{H}_{5}+\mathrm{C}_{2} \mathrm{H}_{4}$ & 1.76 & $4.29 \times 10^{-11}$ & $2.40 \times 10^{14}$ & $1.12 \times 10^{-9}$ & 38 \\
\hline $\mathrm{R}_{l} 3 / \mathrm{R}_{k} 8$ & ${ }^{3} \mathrm{CH}_{2}+\mathrm{C}_{3} \mathrm{H}_{7} \rightarrow \mathrm{C}_{2} \mathrm{H}_{5}+\mathrm{C}_{2} \mathrm{H}_{4}$ & 1.56 & $3.00 \times 10^{-12}$ & $2.00 \times 10^{14}$ & $9.33 \times 10^{-10}$ & 38 \\
\hline $\mathrm{R}_{l} 4 / \mathrm{R}_{g} 11$ & $\mathrm{C}_{2} \mathrm{H}+\mathrm{C}_{2} \mathrm{H}_{6} \rightarrow \mathrm{C}_{2} \mathrm{H}_{2}+\mathrm{C}_{2} \mathrm{H}_{5}$ & 0.65 & $4.15 \times 10^{-11}$ & $1.68 \times 10^{19}$ & $1.51 \times 10^{-6}$ & 52 \\
\hline $\mathrm{R}_{l} 5$ & $\mathrm{C}_{2} \mathrm{H}+\mathrm{C}_{3} \mathrm{H}_{7} \rightarrow \mathrm{C}_{2} \mathrm{H}_{5}+\mathrm{C}_{3} \mathrm{H}_{3}$ & 1.22 & $2.00 \times 10^{-11}$ & $2.00 \times 10^{13}$ & $9.32 \times 10^{-11}$ & 38 \\
\hline $\mathrm{R}_{l} 6$ & $\mathrm{C}_{3} \mathrm{H}_{6}^{+}+\mathrm{e} \rightarrow \mathrm{C}_{2} \mathrm{H}_{5}+\mathrm{CH}$ & 0.91 & $8.00 \times 10^{-8}\left(300 / T_{\mathrm{e}}\right)^{0.70}$ & $3.34 \times 10^{18}$ & $1.56 \times 10^{-5}$ & 18 \\
\hline $\mathrm{R}_{l} 7 / \mathrm{R}_{d} 35$ & $\mathrm{C}_{3} \mathrm{H}_{8}^{+}+\mathrm{e} \rightarrow \mathrm{C}_{2} \mathrm{H}_{5}+\mathrm{CH}_{3}$ & 2.75 & $1.60 \times 10^{-7}\left(300 / T_{\mathrm{e}}\right)^{0.70}$ & $1.58 \times 10^{19}$ & $7.38 \times 10^{-5}$ & 18 \\
\hline \multicolumn{7}{|c|}{$\mathrm{C}_{2} \mathrm{H}_{6}$} \\
\hline $\mathrm{R}_{m} 1$ & $\mathrm{H}+\mathrm{C}_{2} \mathrm{H}_{5}+\mathrm{M} \rightarrow \mathrm{C}_{2} \mathrm{H}_{6}+\mathrm{M}$ & 2.09 & $\begin{array}{l}k_{0}=2.38 \times 10^{-30} \\
k_{\infty}=1.66 \times 10^{-10}\end{array}$ & $4.57 \times 10^{9}$ & $2.13 \times 10^{-14}$ & 62,63 \\
\hline $\mathrm{R}_{m} 2$ & $2 \mathrm{CH}_{3}+\mathrm{M} \rightarrow \mathrm{C}_{2} \mathrm{H}_{6}+\mathrm{M}$ & 1.85 & $\begin{array}{c}k_{0}=2.04 \times 10^{-25} \\
k_{\infty}=7.45 \times 10^{-11} \\
k_{\mathrm{R}}=1.65 \times 10^{-13} \\
F_{c}=0.37\end{array}$ & $6.18 \times 10^{21}$ & 0.029 & 15 \\
\hline $\mathrm{R}_{m} 3 / \mathrm{R}_{g} 17$ & $\mathrm{C}_{2} \mathrm{H}_{3}+\mathrm{C}_{2} \mathrm{H}_{5} \rightarrow \mathrm{C}_{2} \mathrm{H}_{6}+\mathrm{C}_{2} \mathrm{H}_{2}$ & 1.53 & $8.00 \times 10^{-13}$ & $6.76 \times 10^{16}$ & $3.16 \times 10^{-7}$ & 37 \\
\hline $\mathrm{R}_{m} 4 / \mathrm{R}_{k} 16$ & $2 \mathrm{C}_{2} \mathrm{H}_{5} \rightarrow \mathrm{C}_{2} \mathrm{H}_{6}+\mathrm{C}_{2} \mathrm{H}_{4}$ & 1.34 & $2.40 \times 10^{-12}$ & $7.08 \times 10^{18}$ & $3.30 \times 10^{-5}$ & 33 \\
\hline $\mathrm{R}_{m} 5$ & $\mathrm{C}_{2} \mathrm{H}_{5}+\mathrm{C}_{3} \mathrm{H}_{7} \rightarrow \mathrm{C}_{2} \mathrm{H}_{6}+\mathrm{C}_{3} \mathrm{H}_{6}$ & 1.72 & $5.00 \times 10^{-11}$ & $4.51 \times 10^{13}$ & $2.10 \times 10^{-10}$ & 15,38 \\
\hline $\mathrm{R}_{m} 6$ & $\mathrm{C}_{2} \mathrm{H}_{5}+\mathrm{C}_{4} \mathrm{H}_{3} \rightarrow \mathrm{C}_{2} \mathrm{H}_{6}+\mathrm{C}_{4} \mathrm{H}_{2}$ & 1.74 & $8.00 \times 10^{-13}$ & $7.07 \times 10^{15}$ & $3.30 \times 10^{-8}$ & 27 \\
\hline $\mathrm{R}_{m} 7$ & $\mathrm{C}_{2} \mathrm{H}_{3}^{+}+\mathrm{C}_{3} \mathrm{H}_{8} \rightarrow \mathrm{C}_{2} \mathrm{H}_{6}+\mathrm{C}_{3} \mathrm{H}_{5}^{+}$ & 0.82 & $5.00 \times 10^{-11}$ & $3.02 \times 10^{15}$ & $1.41 \times 10^{-8}$ & 26 \\
\hline $\mathrm{R}_{m} 8$ & $\mathrm{C}_{3} \mathrm{H}_{7}^{+}+\mathrm{e} \rightarrow \mathrm{C}_{2} \mathrm{H}_{6}+\mathrm{CH}$ & 1.17 & $3.80 \times 10^{-7}\left(300 / T_{\mathrm{e}}\right)^{0.68}$ & $2.25 \times 10^{20}$ & $1.05 \times 10^{-3}$ & 20 \\
\hline $\mathrm{R}_{m} 9 / \mathrm{R}_{b} 10$ & $\mathrm{C}_{3} \mathrm{H}_{8}^{+}+\mathrm{e} \rightarrow \mathrm{C}_{2} \mathrm{H}_{6}+{ }^{3} \mathrm{CH}_{2}$ & 2.55 & $1.60 \times 10^{-7}\left(300 / T_{\mathrm{e}}\right)^{0.70}$ & $6.65 \times 10^{18}$ & $3.10 \times 10^{-5}$ & 15 \\
\hline $\mathrm{R}_{m} 10 / \mathrm{R}_{d} 36$ & $\mathrm{C}_{3} \mathrm{H}_{9}^{+}+\mathrm{e} \rightarrow \mathrm{C}_{2} \mathrm{H}_{6}+\mathrm{CH}_{3}$ & 2.67 & $5.00 \times 10^{-7}\left(300 / T_{\mathrm{e}}\right)^{0.70}$ & $8.19 \times 10^{18}$ & $3.82 \times 10^{-5}$ & 15 \\
\hline $\mathrm{R}_{m} 11 / \mathrm{R}_{i} 7$ & $\mathrm{C}_{4} \mathrm{H}_{9}^{+}+\mathrm{e} \rightarrow \mathrm{C}_{2} \mathrm{H}_{6}+\mathrm{C}_{2} \mathrm{H}_{3}$ & 3.32 & $8.70 \times 10^{-9}\left(300 / T_{\mathrm{e}}\right)^{0.59}$ & $2.20 \times 10^{18}$ & $1.03 \times 10^{-5}$ & 18,48 \\
\hline
\end{tabular}




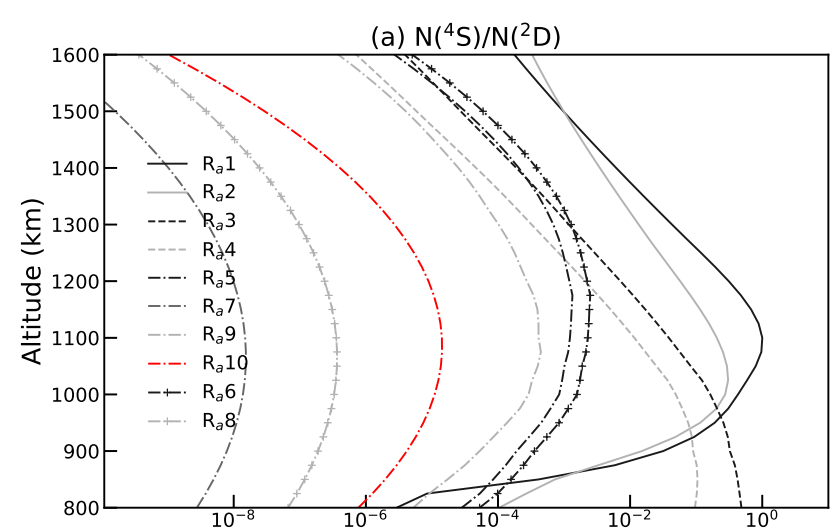

(c) $\mathrm{HCN}$

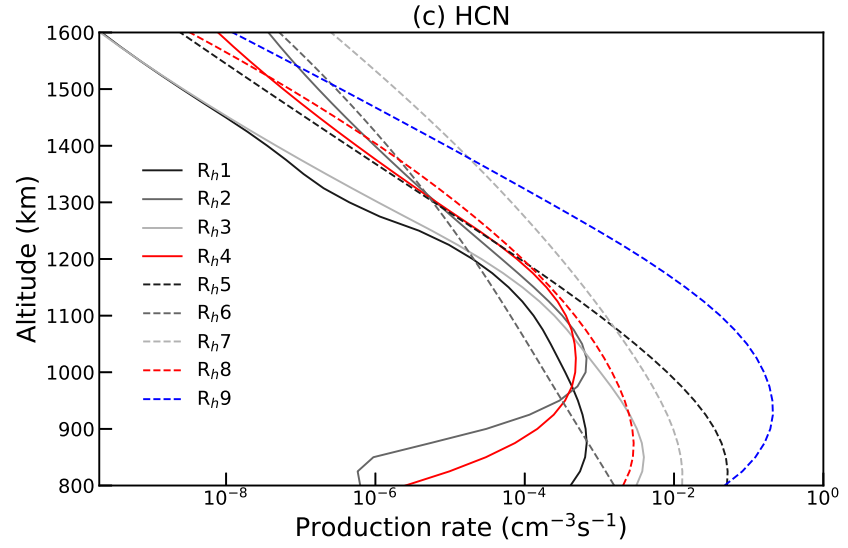

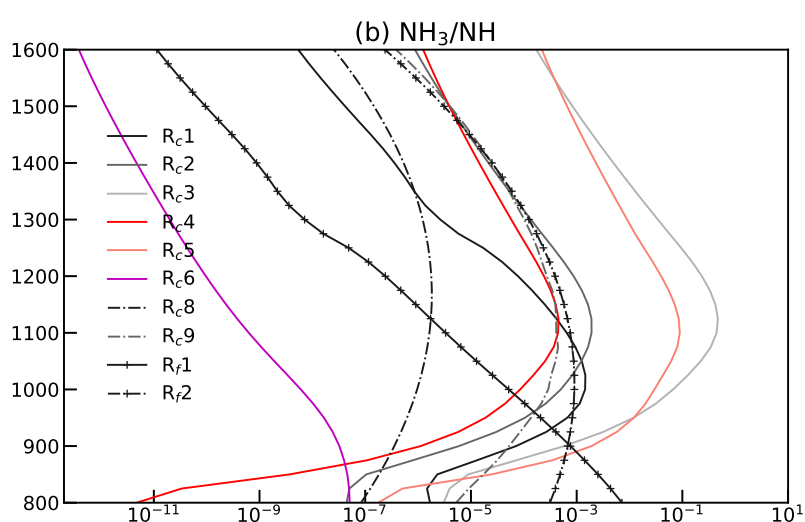

(d) $\mathrm{N}_{2}$

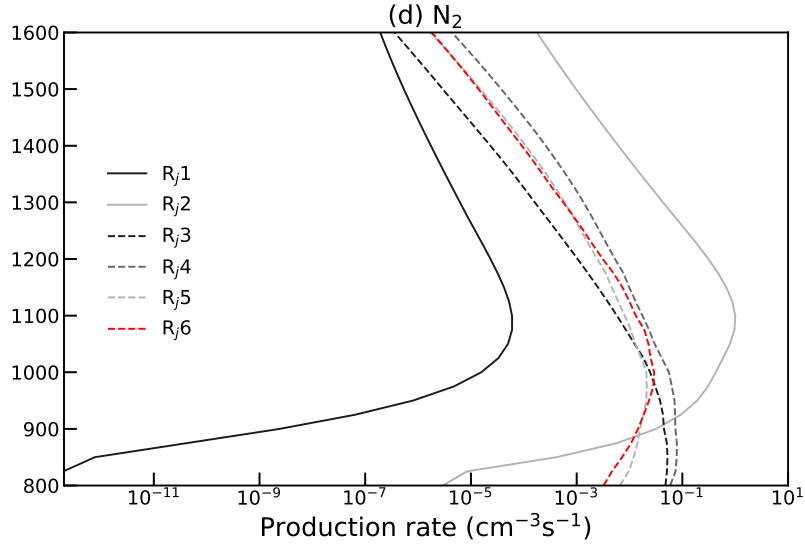

Fig. A.1. Hot neutral production rates calculated via the neutral, ion, and electron density profiles in Figs. $1-4$, for $\mathrm{N}\left({ }^{4} \mathrm{~S}\right)$ and $\mathrm{N}\left({ }^{2} \mathrm{D}\right)$ in panel a, $\mathrm{NH}_{3}$ and $\mathrm{NH}$ in panel $b, \mathrm{HCN}$ in panel $c$, as well as $\mathrm{N}_{2}$ in panel $d$, respectively, with the contributions from different chemical channels shown separately. For clarification, the neutral-neutral, ion-neutral, and DR reactions are indicated by the solid, dashed, and dash-dotted lines, respectively.

Table A.2. Best-fit parameters $\left(a_{1}, a_{2}\right.$, and $\left.a_{3}\right)$ to describe the altitude dependence of escape probability for a given species at a given nascent energy (see Eq. (34) for details).

\begin{tabular}{|c|c|c|c|c|c|c|c|c|c|}
\hline \multirow{2}{*}{ Species } & \multicolumn{8}{|c|}{ Energy $(\mathrm{eV})$} & \multirow[b]{2}{*}{$a_{2}$} \\
\hline & & 0.5 & 1.0 & 1.5 & 2.5 & 3.5 & 5.0 & 6.5 & \\
\hline \multirow{2}{*}{$\mathrm{N}\left({ }^{4} \mathrm{~S}\right) / \mathrm{N}\left({ }^{2} \mathrm{D}\right)$} & $a_{1}$ & 0.272 & 0.274 & 0.275 & 0.276 & 0.276 & 0.277 & 0.277 & \multirow{2}{*}{1450} \\
\hline & $a_{3}$ & 0.180 & 0.234 & 0.267 & 0.303 & 0.326 & 0.347 & 0.361 & \\
\hline \multirow{2}{*}{${ }^{3} \mathrm{CH}_{2} / \mathrm{CH}_{3} / \mathrm{CH}_{4}$} & $a_{1}$ & 0.236 & 0.268 & 0.281 & 0.297 & 0.306 & 0.316 & 0.319 & \multirow{2}{*}{1500} \\
\hline & $a_{3}$ & 0.135 & 0.181 & 0.206 & 0.235 & 0.254 & 0.271 & 0.283 & \\
\hline \multirow{4}{*}{$\mathrm{NH} / \mathrm{NH}_{3}$} & $a_{1}$ & 0.233 & 0.265 & 0.280 & 0.297 & 0.307 & 0.315 & 0.318 & \multirow{2}{*}{1500} \\
\hline & $a_{3}$ & 0.130 & 0.177 & 0.202 & 0.231 & 0.250 & 0.268 & 0.279 & \\
\hline & \multicolumn{8}{|c|}{ Energy $(\mathrm{eV})$} & \\
\hline & & 1 & 1.5 & 2.0 & 3.0 & 4.0 & 5.0 & - & \\
\hline \multirow{2}{*}{$\mathrm{C}_{2} \mathrm{H}_{2}$} & $a_{1}$ & 0.235 & 0.252 & 0.263 & 0.279 & 0.289 & 0.296 & - & \multirow{2}{*}{1530} \\
\hline & $a_{3}$ & 0.157 & 0.182 & 0.199 & 0.224 & 0.239 & 0.251 & - & \\
\hline \multirow{2}{*}{$\mathrm{HCN}$} & $a_{1}$ & 0.197 & 0.221 & 0.237 & 0.257 & 0.269 & 0.279 & - & \multirow{2}{*}{1600} \\
\hline & $a_{3}$ & 0.151 & 0.178 & 0.196 & 0.221 & 0.236 & 0.249 & - & \\
\hline \multirow{2}{*}{$\mathrm{N}_{2}$} & $a_{1}$ & 0.244 & 0.256 & 0.263 & 0.274 & 0.282 & 0.285 & - & \multirow{2}{*}{1520} \\
\hline & $a_{3}$ & 0.178 & 0.206 & 0.226 & 0.253 & 0.270 & 0.283 & - & \\
\hline \multirow{2}{*}{$\mathrm{C}_{2} \mathrm{H}_{3} / \mathrm{C}_{2} \mathrm{H}_{4}$} & $a_{1}$ & 0.230 & 0.247 & 0.258 & 0.273 & 0.282 & 0.290 & - & \multirow{2}{*}{1540} \\
\hline & $a_{3}$ & 0.164 & 0.191 & 0.208 & 0.234 & 0.251 & 0.263 & - & \\
\hline \multirow{2}{*}{$\mathrm{C}_{2} \mathrm{H}_{5} / \mathrm{C}_{2} \mathrm{H}_{6}$} & $a_{1}$ & 0.219 & 0.240 & 0.252 & 0.266 & 0.277 & 0.285 & - & \multirow{2}{*}{1560} \\
\hline & $a_{3}$ & 0.151 & 0.178 & 0.196 & 0.221 & 0.236 & 0.249 & - & \\
\hline
\end{tabular}



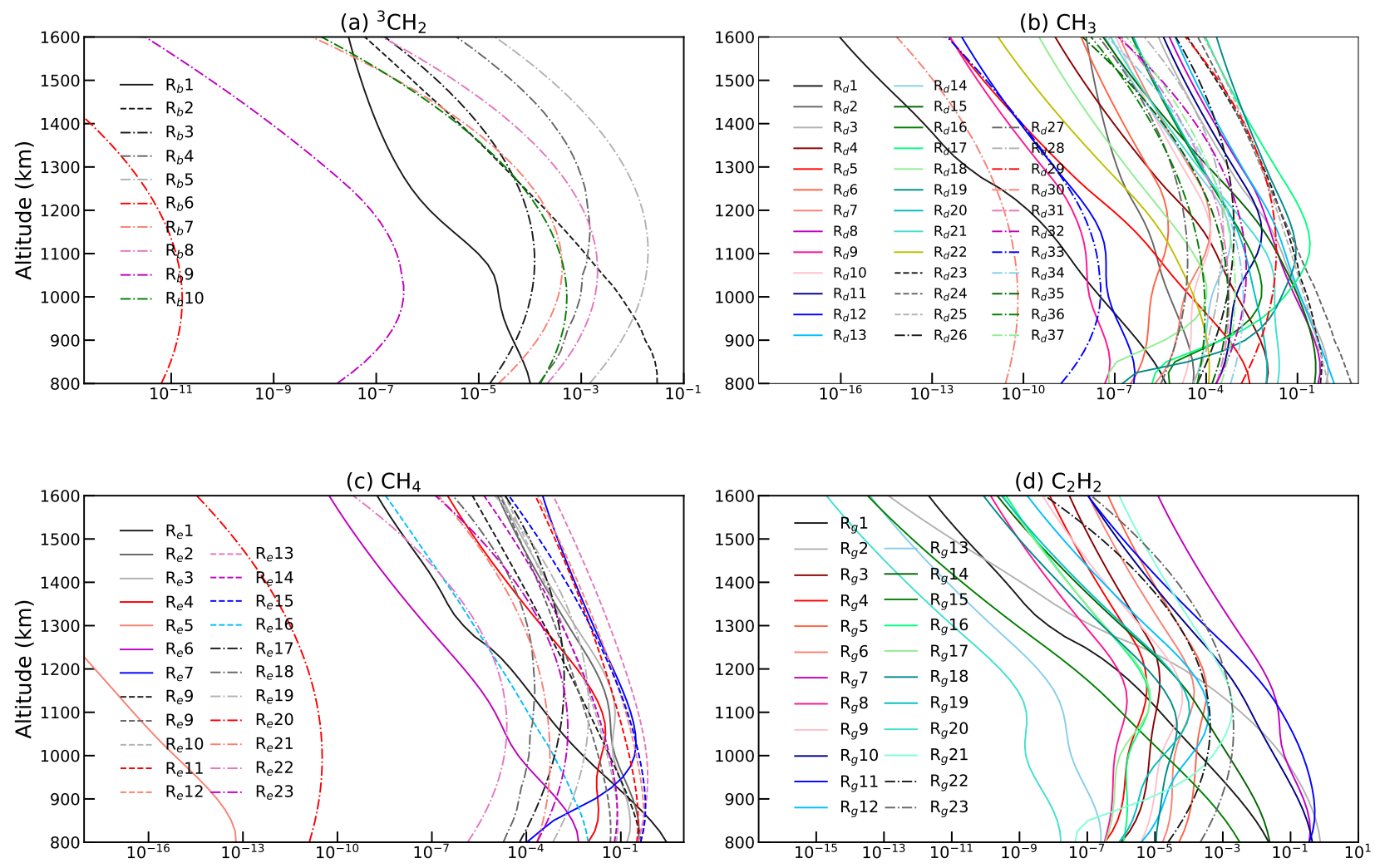

(e) $\mathrm{C}_{2} \mathrm{H}_{3}$
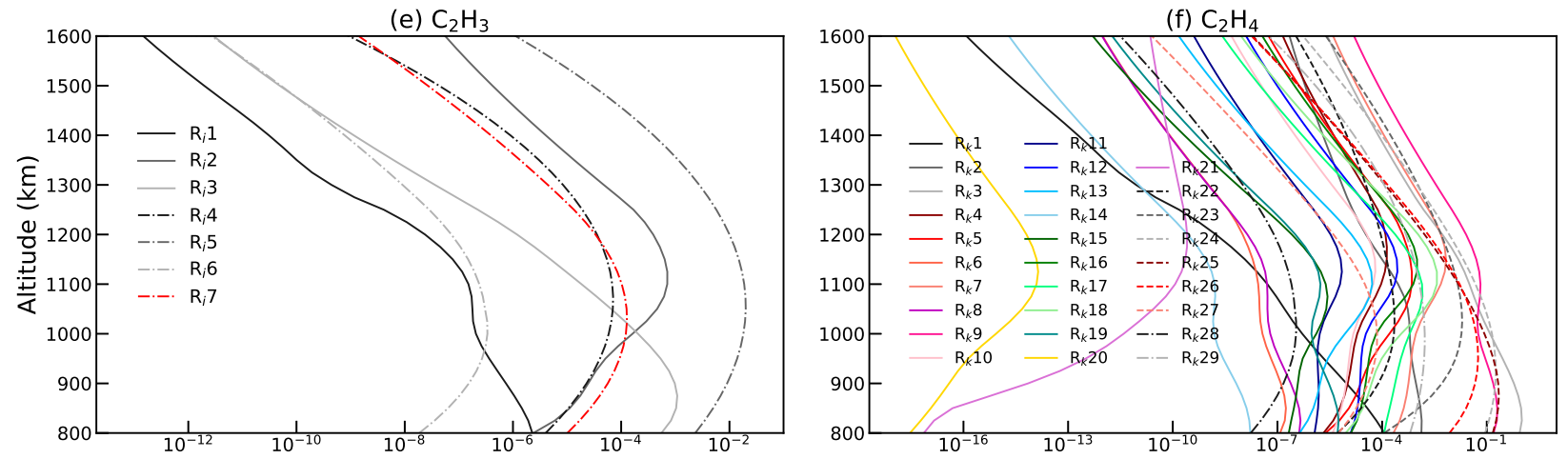

(g) $\mathrm{C}_{2} \mathrm{H}_{5}$
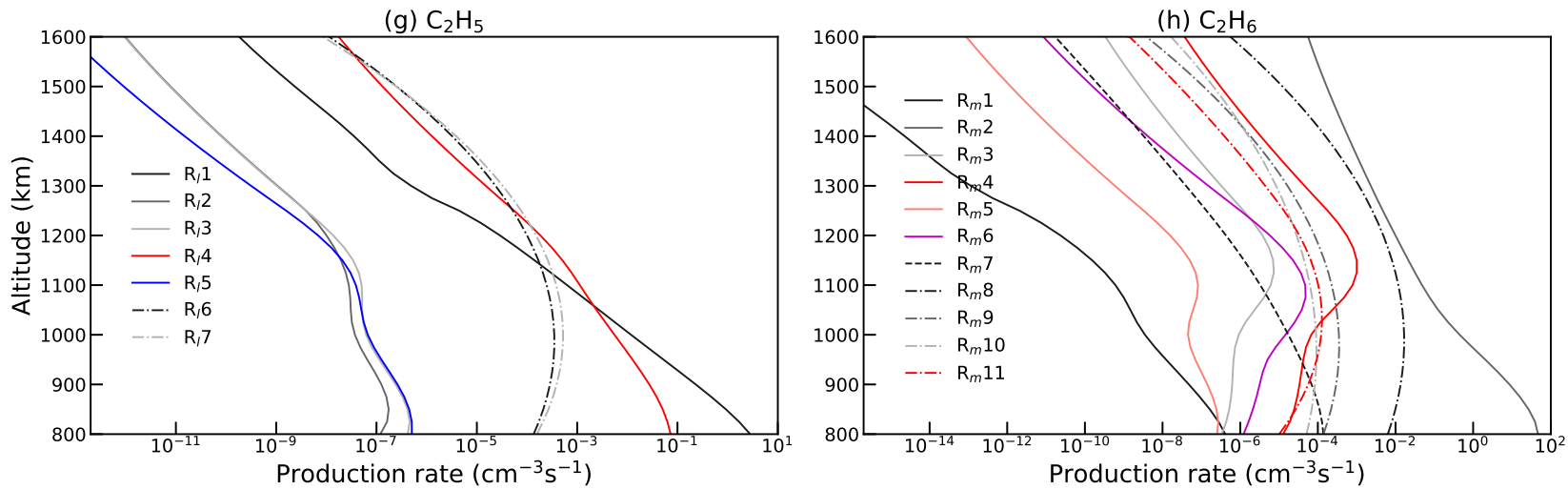

Fig. A.2. Similar to Fig. A.1 but for ${ }^{3} \mathrm{CH}_{2}$ in panel a, $\mathrm{CH}_{3}$ in panel $b, \mathrm{CH}_{4}$ in panel $c, \mathrm{C}_{2} \mathrm{H}_{2}$ in panel $d, \mathrm{C}_{2} \mathrm{H}_{3}$ in panel e, $\mathrm{C}_{2} \mathrm{H}_{4}$ in panel $f, \mathrm{C}_{2} \mathrm{H}_{5}$ in panel $g$, and $\mathrm{C}_{2} \mathrm{H}_{6}$ in panel $h$, respectively. 
Table A.3. Best-fit parameters $\left(b_{1}, b_{2}, b_{3}\right.$, and $\left.b_{4}\right)$ to describe the energy dependences of the parameters listed in Table A.2 $\left(a_{1}, a_{2}\right.$, and $\left.a_{3}\right)$ (see Eq. (35) for details).

\begin{tabular}{ccccc}
\hline \hline Species & $b_{1}$ & $b_{2}$ & $b_{3}$ & $b_{4}$ \\
\hline $\mathrm{N}\left({ }^{4} \mathrm{~S}\right) / \mathrm{N}\left({ }^{2} \mathrm{D}\right)$ & -0.0073 & 0.277 & 0.0709 & 0.234 \\
${ }^{3} \mathrm{CH}_{2} / \mathrm{CH}_{3} / \mathrm{CH}_{4}$ & -0.129 & 0.313 & 0.0575 & 0.179 \\
$\mathrm{NH}^{\mathrm{N} H} \mathrm{~N}_{3}$ & -0.134 & 0.313 & 0.0579 & 0.175 \\
$\mathrm{C}_{2} \mathrm{H}_{2}$ & 0.0383 & 0.236 & 0.0587 & 0.158 \\
$\mathrm{HCN}$ & 0.0506 & 0.199 & 0.0608 & 0.153 \\
$\mathrm{~N}_{2}$ & 0.0368 & 0.232 & 0.0619 & 0.165 \\
$\mathrm{C}_{2} \mathrm{H}_{3} / \mathrm{C}_{2} \mathrm{H}_{4}$ & 0.0259 & 0.245 & 0.0657 & 0.179 \\
$\mathrm{C}_{2} \mathrm{H}_{5} / \mathrm{C}_{2} \mathrm{H}_{6}$ & 0.0399 & 0.222 & 0.0646 & 0.167 \\
\hline
\end{tabular}

